\title{
Ecology of the possum (Trichosurus vulpecula Kerr) in the Karori Water Supply Reserve, Wellington, Sounds Ecological District
}

\author{
By
}

Hans Stoffregen

Wellington, New Zealand, 1997

A thesis presented to Victoria University of Wellington in partial fulfilment of the requirements for the degree of Master of Conservation Science 


\section{Abstract}

The abundance and condition of possums in various areas of the Karori Reserve, Wellington - Sounds Ecological District was assessed. Possums were most abundant in the upper part of the reserve in an area dominated by bishop and radiata pines with an undergrowth of native species and in an area dominated by gorse and flax shrublands. In the lower part of the reserve, possums were less abundant and there a number of characteristics were observed: possums had a higher body weight for age, their reproductive output was higher and the population was marked by a higher proportion of females and juveniles. This was interpreted as a "compensatory response" characteristic of possum populations maintained at low densities.

Possum stomachs were sampled in spring and their contents analysed in order to investigate the importance of Fuchsia excorticata and other plant species to possum diet. In the lower part of the reserve the leaves of Fuchsia excorticata and the flowers of Cytisus scoparius made up more than 50 percent of the possums' forage. In the upper part of the reserve exotic species such as the flowers of Cytisus scoparius and Ulex europeans as well as the leaves of native species such as Aristotelia serrata, Pseudopanax arboreus and Coprosma robusta made up the bulk of possum forage. Exotic plants accounted for a significant proportion of the spring possum diet in the reserve. Whereas most leaves originated from native plants, the exotic species contributed mainly carbohydrate-rich flowers and pollen.

The canopy condition of two possum-susceptible tree species Fuchsia excorticata and Pseudopanax arboreus was assessed early in autumn over the years 1993, 1995 and 1996. Over these years, 47 percent of marked fuchsia trees were completely defoliated and most trees are unlikely to recover even if possums are eradicated from the reserve. All defoliated fuchsia trees were located in the upper part of the reserve. On the other hand, 37 percent of marked fuchsia trees exhibited only a little possum damage. Most of these trees were located in the lower part of the reserve where possum density was lower. Increasing possum densities could therefore be correlated with an increasing level of possum damage to fuchsia canopies. Even though Pseudopanax arboreus leaves and petioles were encountered in 10 percent of possum stomachs, the canopies 
leaves and petioles were encountered in 10 percent of possum stomachs, the canopies of assessed trees did not seem to be greatly affected. It appeared that due to the high abundance of this plant species in the reserve the effects of possum browse were spread over the whole reserve to levels which could be tolerated by an individual Pseudopanax arboreus tree. 


\section{Acknowledgements}

I would like to thank Neill Mc Dergill from Wellington Regional Council and Garth Nixon from Wellington City Council for allowing me to carry out the field work in the Lower and Upper Reserve areas. I am especially indebted to Dr. Shirley Pledger, who initiated me to the mysteries of statistics, Dr. Ben Bell, who kept me on track and gave me the necessary advice and support and Dr. Kath Dickinson who never failed to encourage me to get this thesis finished. Dr. Barry Sneddon was always helpful in identifying plants which were unfamiliar to me.

My special appreciation is extended to those people who helped me with parts of this study which I could not have done by myself. In particular: Sean Husheer for giving me a start in an unexpected direction, John Campbell and Dr. Bob Brockie, who helped me sorting and identifying all these bits and pieces of chewed up leaf fragments, and Case Pekelharing, who generously made the data of his 1993 survey available to me.

I am also grateful to those people assisting me with fieldwork. In particular: Ken Wright and Steve Farrell for collecting numerous poisoned possums from the Lower Reserve area and René Duindam, Randall Milne, Phil James, the late Alison Morton, Norbert Hausberg and Stephen Fuller who all helped me collecting possum pellets and assessing the canopy condition of trees.

Thanks also go to Phil Brady for discussing the theme of this thesis, to Dr. Dave Morgan and Dr. Colin Miskelly for giving valuable comments, to Justin from VUW references for finding relevant literature in the jungle of publications, and to Philippa Spackman who supplied the necessary equipment.

I am particularly grateful to Dom Wilson and Caren Schroeder for proof-reading the manuscript and for making most useful comments and suggestions.

Lastly, I must thank my partner Ina who supported me throughout this work and my two little soys Timo and Fabian who never failed encouraging me to do other things than puzzling over a hesis. 


\section{TABLE OF CONTENTS}

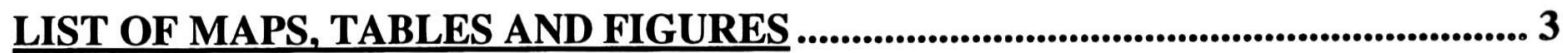

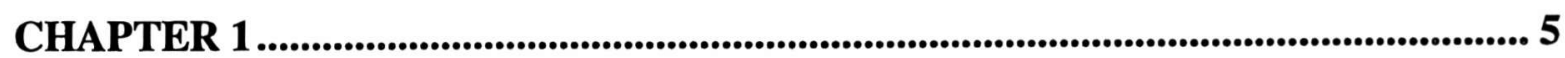

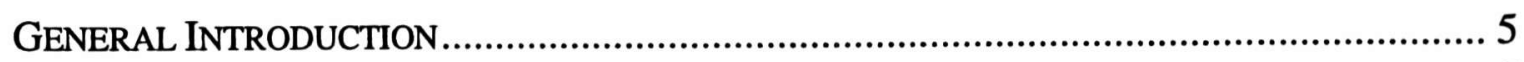

1.1. The Karori Sanctuary proposal......................................................................... 5

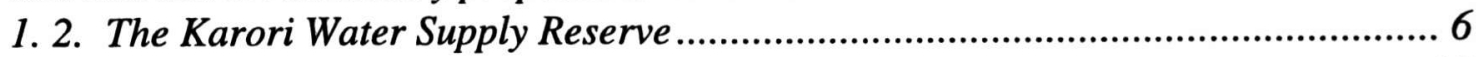

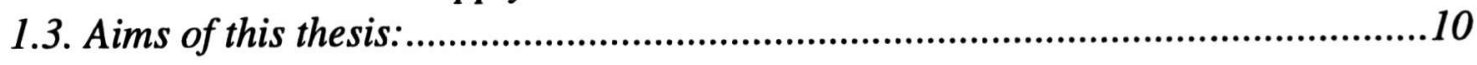

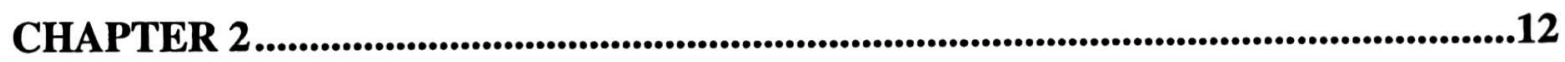

POSSUM DENSITIES IN THE KARORI RESERVE IN SUMMER .........................................12

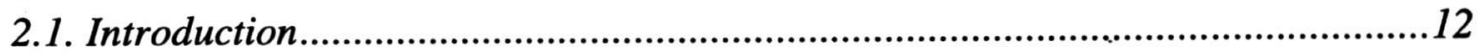

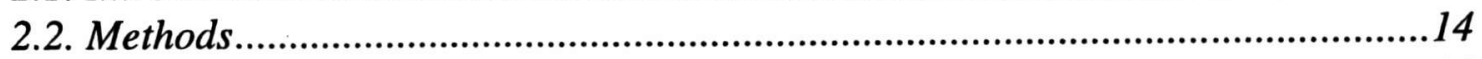

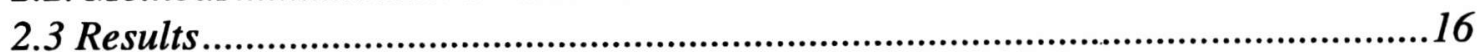

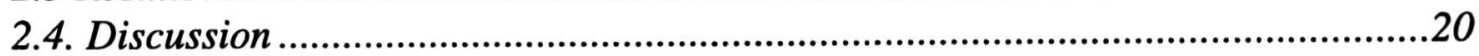

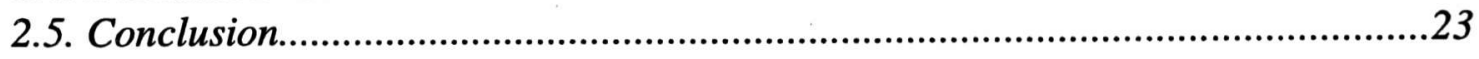

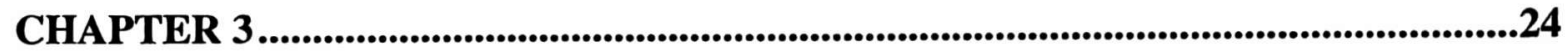

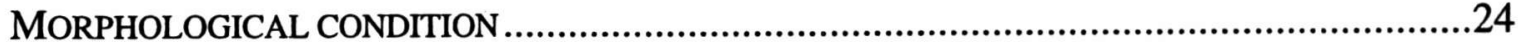

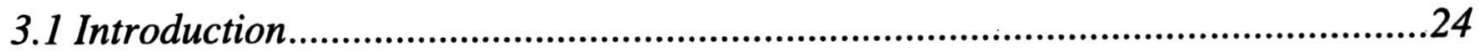

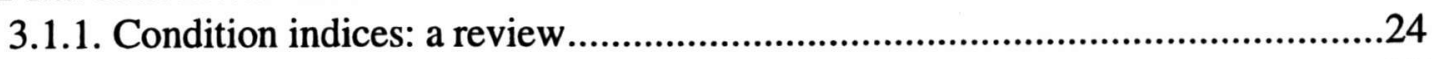

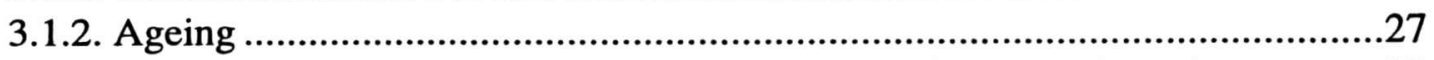

3.1.3. Morphological condition of possums in the Karori Reserve in spring ............28

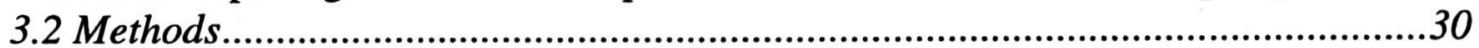

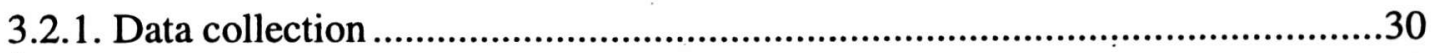

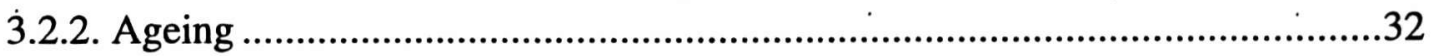

3.2.3. Calculating a morphological condition index (MCI) ..................................33

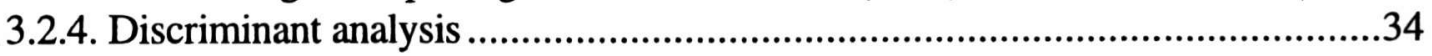

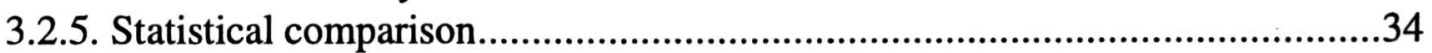

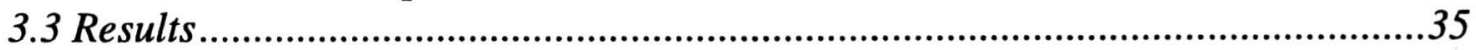

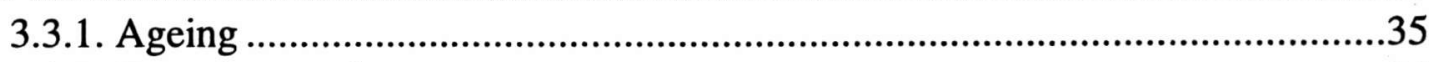

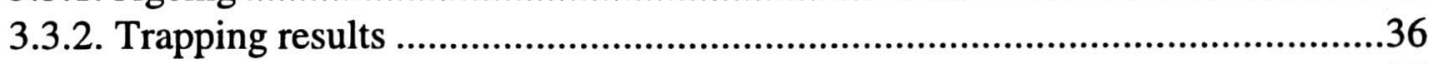

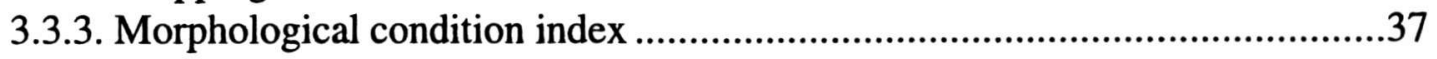

3.3.4 Discriminating possums into age classes ..................................................41

3.3.5 Comparing male and female possums in four areas of the

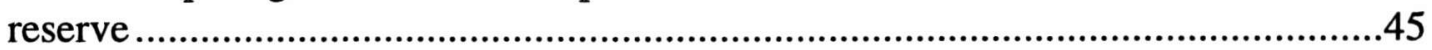

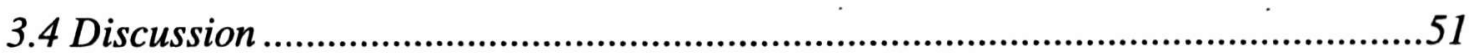

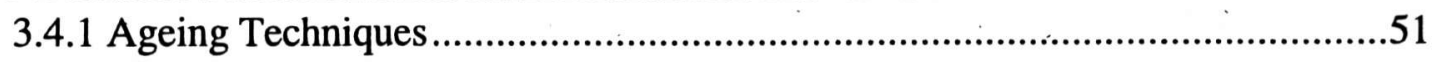

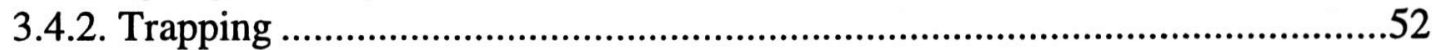

3.4.3. Comparing the condition and morphometrics of possums in four areas of the reserve ................................................................55

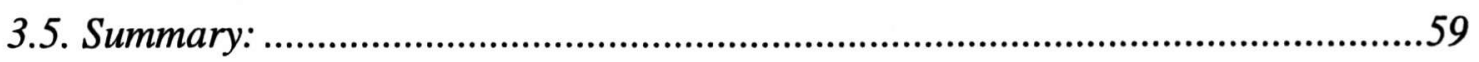




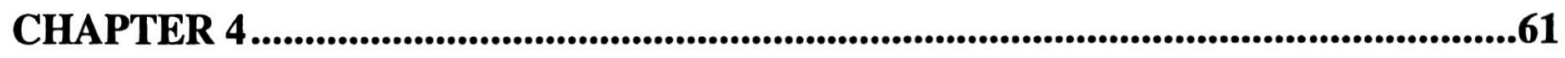

SPRING FOOD OF POSSUMS IN THE KARORI RESERVE ................................................61

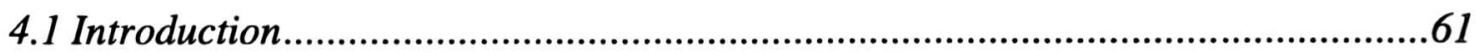

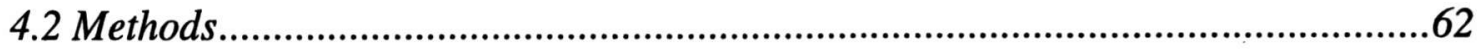

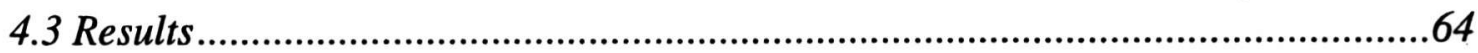

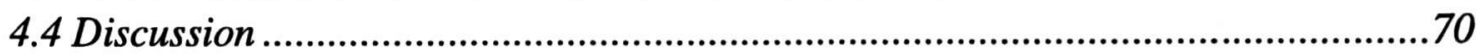

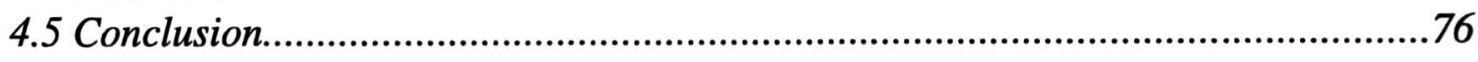

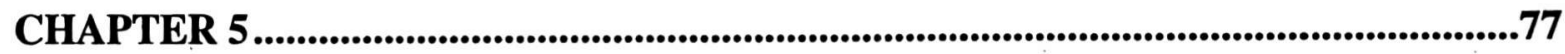

ASSESSING THE TREE CONDITION OF THE SUSCEPTIBLE CANOPY SPECIES

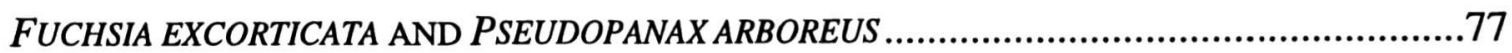

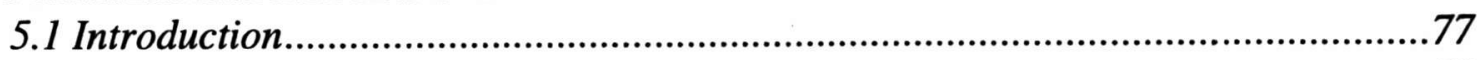

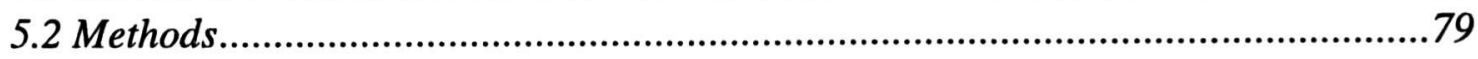

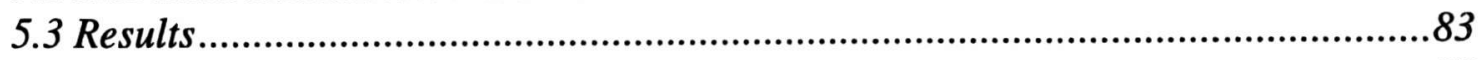

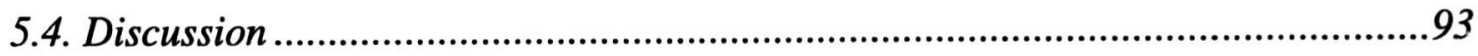

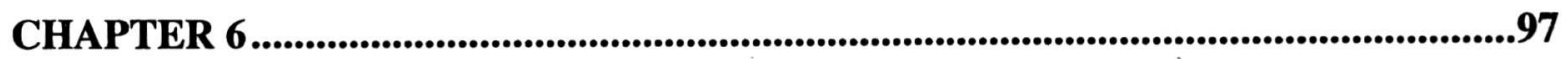

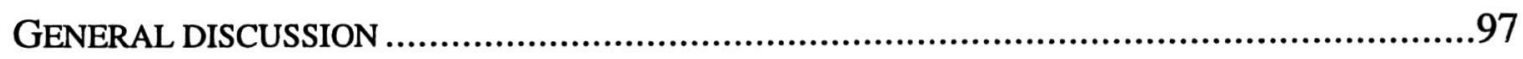

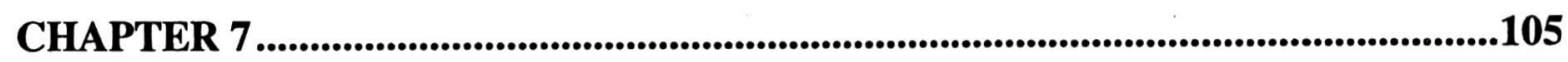

ERADICATING POSSUMS FROM THE KARORI RESERVE............................................... 105

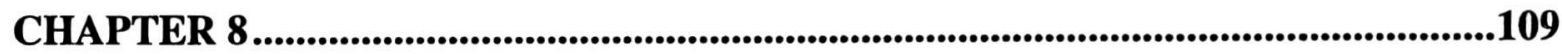

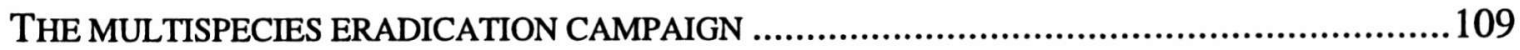

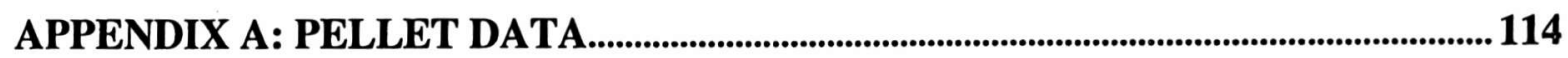

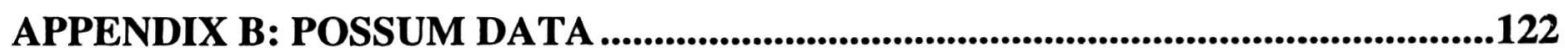

1.MORPHOMETRIC MEASUREMENTS AND COLLECTION DATA ...................................122

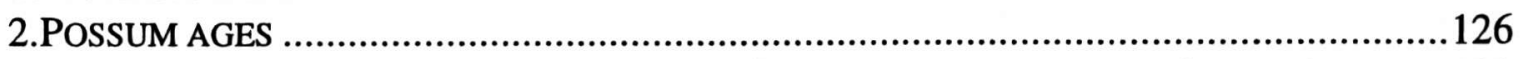

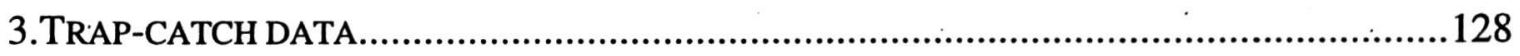

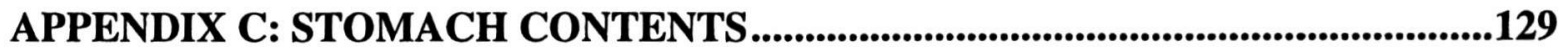

APPENDIX D: CANOPY ASSESSMENT SURVEYS 1993, 1995, AND 1996..........136

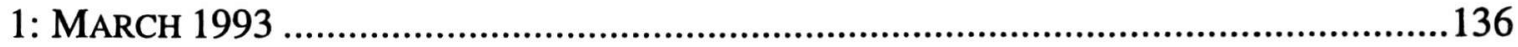

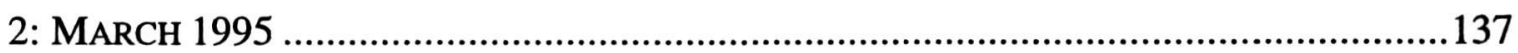

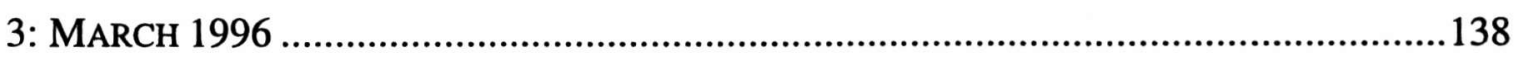

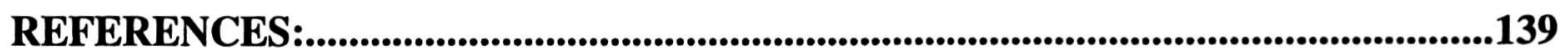




\section{LIST OF MAPS, TABLES AND FIGURES}

Map 1 and Map 2: The location of the Karori Reserve in Wellington..................................... 7 Map 3: The Karori Reserve, its vegetation types and system of tracks....................................8 8

Map 4: Location of pellet transects in the Karori Reserve. ...................................................... 15

Table 1: Kruskal-Wallis one-way analysis of variance for the parameters "vegetation type" and "aspect" .......................................................................................................................... 16

Figure 1: Lattice diagram comparing the relative importance of vegetation type and aspect.................................................................................................................................... 17

Table 2: The standing crop of pellets per hectare and the pellet frequency within pine forest and native forest in the Lower and Upper Reserve areas................................................... 18

Figure 2: The linear relationship of mean pellet count and presence of pellets in the six main vegetation types......................................................................................................................... 19

Table 3: Results from chi-square contingency tables using pellet frequency data.................. 19

Map 5: Karori Reserve traplines and study areas October - November 1995......................... 31

Table 4: Trap-catch data........................................................................................................... 36

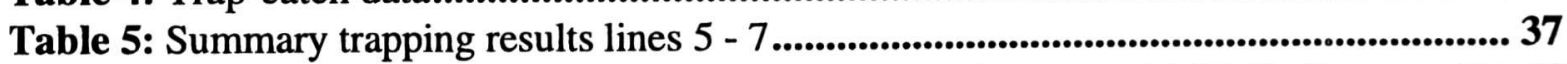

Figure 3: Weight of male and female possums plotted against age with Weibull curves fitted38

Figure 4: Condition index plotted against age. ........................................................................... 39

Table 6: Testing differences in mean condition indices line 4 against lines $5+6+7$............... 39

Table 7: The differences in mean condition indices......................................................................... 40

Figure 5: Discriminating female possums into two age classes.................................................... 41

Figure 6: Discriminating male possums into two age classes ...................................................... 42

Figure 7: Discriminating male possums into three age classes................................................... 43

Table 8: Results from univariate tests of effects ............................................................................ 44

Table 9: Results from Wilks Lambda multivariate analyses..................................................... 44

Table 10: Means and standard errors of the three morphometric variables weight, body length and total length in areas 1 to 4

Figure 8: The fitted means of male and female weight, body length and total length in the four areas in relation to their actual means.

Table 11: Differences of the morphometric variables weight, body length and total length between male and female possums in the four areas................................................................. 48

Table 12: Summary of adult to juvenile ratios in areas $1-4 \ldots \ldots$

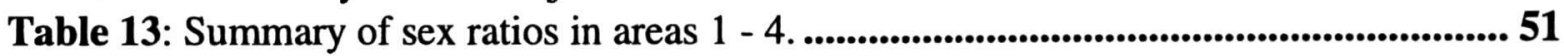

Figure 9: Rear view of the leaf fragment sampling device................................................ 62

Figure 10: Laboratory tray with 20 graduations for locating the positions of the sampling device 
Map 6: Main food items found in stomachs of areas 1 to 4 . 66

Table 14: List of species encountered in stomachs of Karori Reserve possums caught in November 1995.

Table 15: Summary of major plant species identified from possum stomachs ....................... 69

Table 16: Means and standard deviations of ranks for assessed fuchsia trees........................ 83

Table 17: Means and standard deviations of ranks for assessed five-finger trees ................. 83

Table 18: Wilcoxon signed ranks test results ......................................................................... 84

Table 19: Friedman paired analysis of variance test results .............................................. 84

Figure 11: Changes in FDI from 1993 to 1996.................................................................. 85

Figures 12 a-c: Photographs of fuchsia canopies taken in March 1995................................. 87

Figure 13: Changes in dieback in the upper canopy from 1993 to 1996 ............................... 88

Figure 14: Changes in the degree of trunk use from 1993 to 1996 ...................................... 89

Map 7: Approximate location of variable area plots in the Karori Reserve.......................... 91

Table 20: Summary of information and references relevant for the eradication of mammalian

pests in the Karori Reserve. ......................................................................................111 


\section{Chapter 1}

\section{General Introduction}

\subsection{The Karori Sanctuary proposal}

Being a Wellington City water supply catchment with two water storage dams, the Karori Reserve was closed to public access from the 1870s. After the upper dam was declared an earthquake risk in 1991, the reservoir was emptied and the management of the Upper Karori Reserve was handed over from the Regional to the City Council. While the Upper Karori. Reserve was opened for public access in 1992, the area around the lower dam, the Lower Karori Reserve, remained with the Regional Council and is now designated for emergency water supply.

In 1992, a consortium of Wellington conservation and natural science organisations made a proposal to use the whole reserve for the establishment of an enclosed sanctuary for native flora and fauna. Initial funding of $\$ 55,000$ was provided by the Wellington City Council in March 1993 towards a feasibility study, which was completed in March 1994. This study concluded that the area was suitable for the establishment of a sanctuary and that pest eradication and prevention of mammal re-invasion was possible, subject to the erection of a pest-proof fence around the area. The long-term goal is the establishment of an enclosed urban "mainland island" for the conservation of threatened or rare species which were once abundant in the Wellington ecological district (Fuller 1996).

The idea of restoring the 252 hectares of mixed native shrub/hardwood forest and introduced exotic flora to as close as possible to a pre-human condition grew out of the "Natural Wellington" plan (Kitchin 1991). This plan proposed connecting scattered remnants of native bush through green corridors in order to enable native flora and fauna to re-establish in the region. The Karori catchment, being a connecting part of these green corridors was seen as the "hub" or a possible source of locally extinct or rare endemic species needed to enhance biodiversity in the wider Wellington region. 
The Karori Wildlife Sanctuary will be the first attempt to completely exclude all exotic species in order to restore a habitat for native flora and fauna on mainland New Zealand. Information about density, distribution and feeding ecology of all mammalian pest species in the reserve and their impact on the vegetation will not only increase the chances of a successful eradication programme, but will be useful in further investigating the role of the various mammalian pest species in New Zealand's forest ecology.

Information from an established baseline will also be essential for assessing the chances of success, and causes in the event of failures, in the implementation of this mainland nature sanctuary. The process of mammalian exclusion and habitat restoration needs to be carefully monitored and documented as this may provide a foundation for further mainland sanctuary proposals.

\section{2. The Karori Water Supply Reserve}

The Karori Reserve (NZMS 260LR27 560880) is located approximately 5 kilometres southwest of the central Wellington city and comprises a 252 hectare forested valley located in the headwaters of the Kaiwharawhara Stream (Maps 1, 2 and 3). The stream follows the Wellington faultline. Continuing movements along this major faultline result in intensive folding and fracturing of rocks which mainly consist of Torlesse greywacke (Fuller 1996).

The whole valley landscape is a geologically young uplift which has risen rapidly in recent geological times ( 500,000 to 200,000 years ago). However, the discovery of fossilised remains of seashells that are known to have become extinct some 200 million years ago suggests that the rocks that compose these hills must be much older (Stevens 1974). 
Map 1 and Map 2: The location of the Karori Reserve in Wellington.

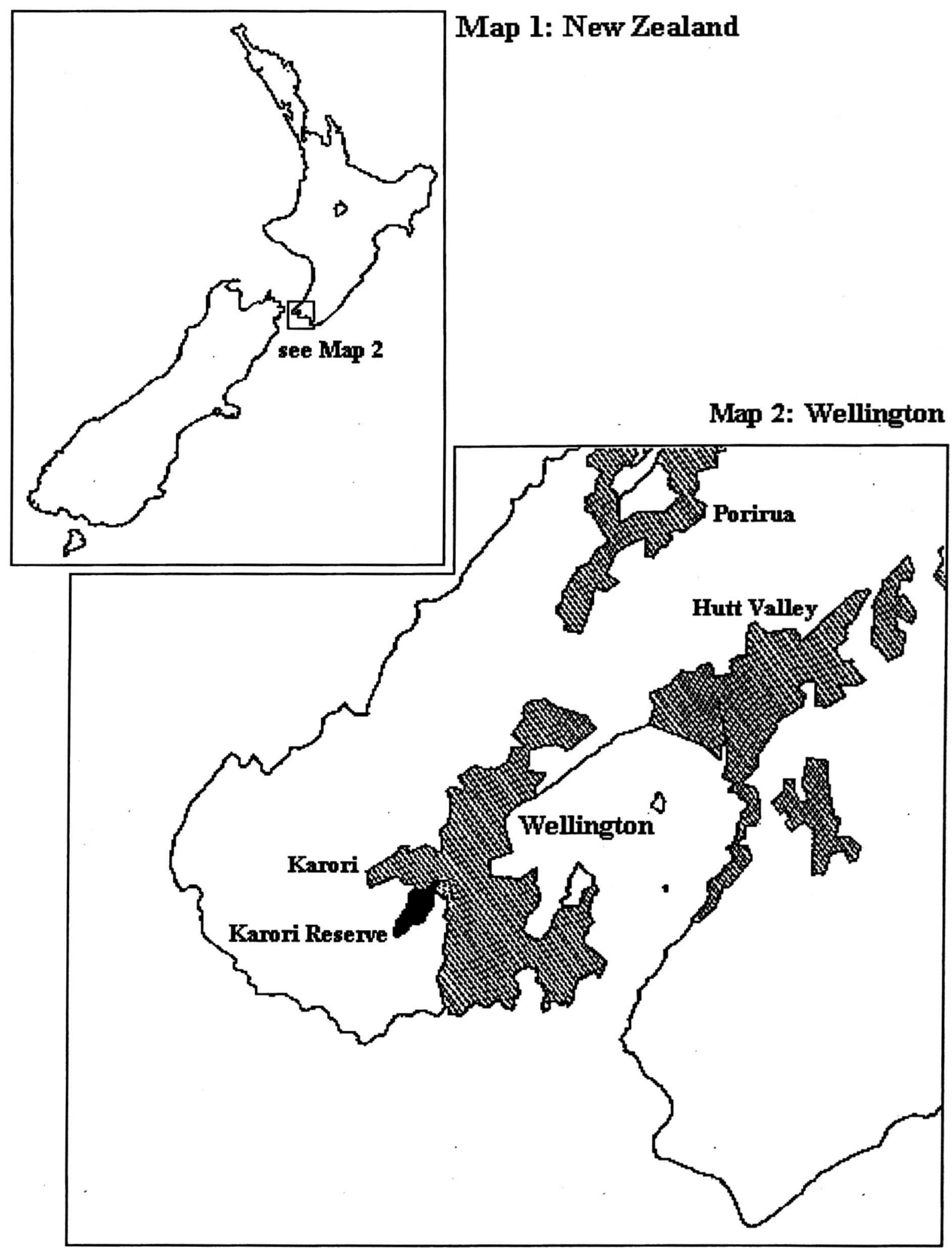


Map 3: The Karori Reserve, its vegetation types and system of tracks.

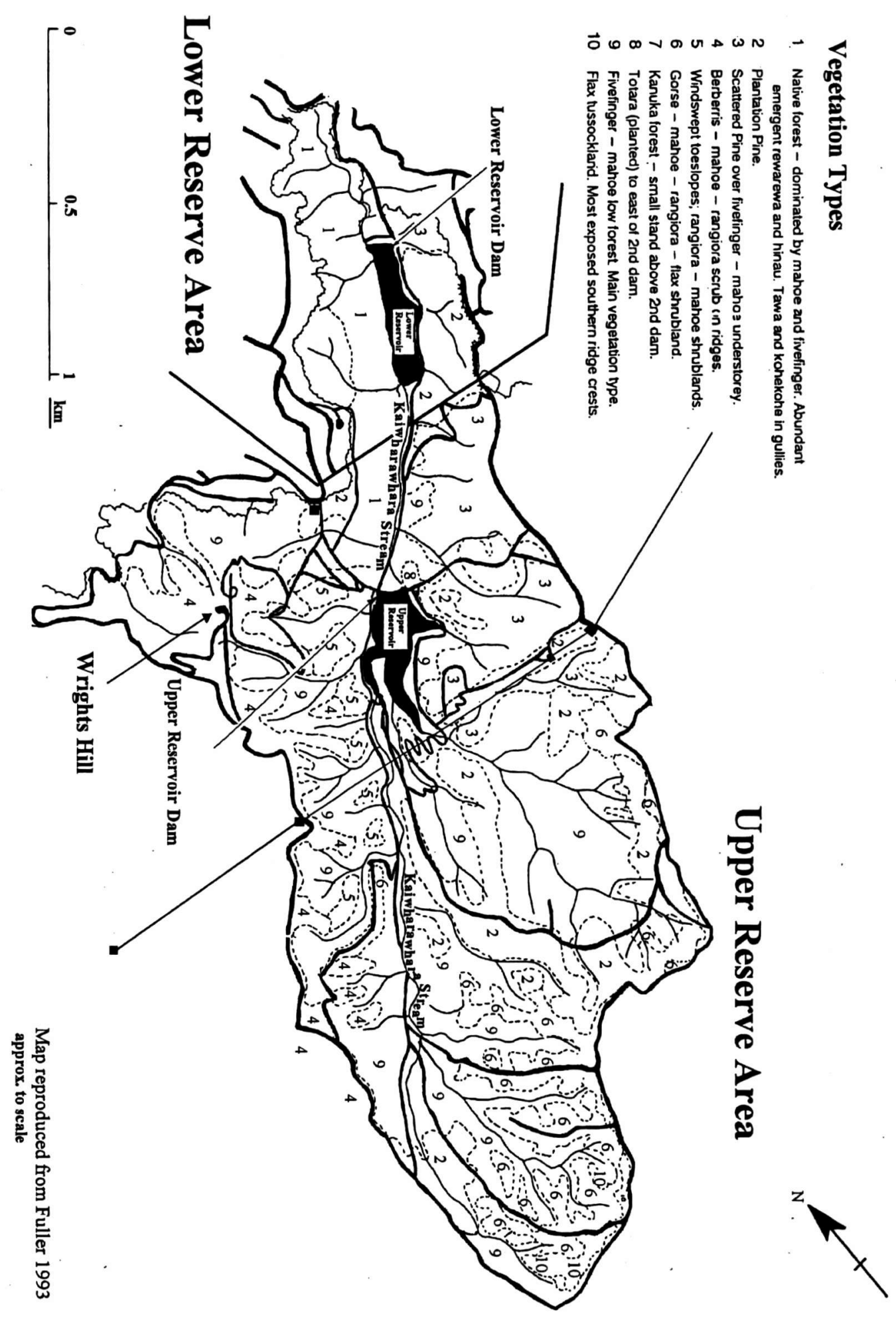


The soils are predominantly loess-derived Ngaio and Belmont yellow brown silt loams. These loams are typically fertile but are also subject to high seasonal water stress which leads to summer droughts on the upper slopes of the valley. On the steep western slopes of the valley, the soils consist of Makara steepland and hill soils which have developed in situ from basement rock and which are typically fertile, moist and stony (Fuller 1996). The topography of the catchment is steep exceeding 25 degrees in many places. Structurally weak, the greywacke base rock forms unstable slopes and without the vegetation cover soil loss through erosion would be significant. Due to its proximity to Cook Strait, the relatively exposed Karori Reserve faces strong winds from predominantly southern and northern directions. Salt sprays, carried into the reserve by strong north-westerly winds, have an impact on the vegetation as they can cause localised defoliation and death of trees and shrubs (Fuller 1996). Rainfall is moderate with a yearly average of $1268 \mathrm{~mm}$ of precipitation measured at the nearby Kelburn weather station. Frosts are not very common.

Much of the original forest in the reserve was probably dominated by kohekohe (Dysoxylum spectabile $^{l}$ ) tawa (Beilschmiedia tawa) and rewarewa (Knightia excelsa) with interspersed emergent northern rata (Metrosideros robusta) and rimu (Dacrydium cupressinum). Other common tree species in this forest would have been pukatea (Laurelia novae-zelandiae), hinau (Eleocarpus dentatus), kamahi (Weinmannia racemosa), fivefinger (Pseudopanax) species and mahoe (Melicytus ramiflorus). The deep root systems of particularly tawa and mahoe would have helped to perpetuate the fertility of the soils (Gabites 1993). On the exposed ridges, a more stunted coastal vegetation consisting of ngaio (Myoporum laetum), hebe (Hebe spp.), kohekohe, flax (Phormium tenax) and coprosma (Coprosma spp.) are likely to have been present. Much of this original vegetation cover was cleared for farming in the last century (Brodie 1986), and only a small remnant of the tall forest type has remained on the western slope of the Lower Reservoir area. At present, the valley contains a mixture of pine (Pinus radiata and Pinus muricata) plantations with native regenerating vegetation in the understory and regenerating secondary mixed hardwood forest which is dominated by seral species such as mahoe, five finger (Pseudopanax arboreus), hangehange (Geniostema rupestre), rangiora (Brachyglottis repanda), wineberry (Aristotelia serrata) and kawakawa (Macropiper excelsum).

\footnotetext{
${ }^{1}$ Nomenclature of plants follows Allen (1982) and references contained therein.
} 
Possums were liberated in the Wellington region on two occasions in 1898 (Pracy 1974). The second-growth forest, which now covers the reserve, has therefore evolved under the impact of possums and also of feral goats producing a forest which is comparatively species poor.

Parrish (1984) rated the Karori Reserve as a forested site of moderate to high conservation value. The reserve is habitat for common indigenous birds like fantail, silvereye and grey warbler. Tui are thought to be more common here than anywhere else in the Wellington City District. Furthermore, kereru (wood pigeons) and a remnant population of green geckoes have been sighted (Parrish 1984).

Probably the largest remaining population of native tree fuchsia (Fuchsia excorticata) in the Wellington City District is established along the Kaiwharawhara Stream above the upper and between upper and lower dam, in the Wrights Hill gullies and on the western face of the Lower Reserve area. Fuchsia is an important seasonal food source for tui and kereru but is also well recognised as a food sought after by possums.

Possum numbers seem to be at very high population levels in the reserve (pers. obs.) and many fuchsia trees appear significantly affected by possum browse. This impact has not only the potential to significantly alter the forest composition of the catchment, but may have. a negative affect on the likely success of reintroducing endemic fauna to the sanctuary at least in the short term.

\subsection{Aims of this thesis:}

The overall aim of this thesis is to contribute to the design of the most appropriate possum eradication strategy for the Karori Reserve. To develop such a strategy, aspects of the ecology of the resident possum population need to be known. Priority elements were the abundance, condition and diet of this possum population. As part of this assessment, Fuchsia excorticata, a plant species favoured by possums was monitored as an indicator of possum damage and dietary preference. Together with Pseudopanax arboreus, another susceptible 
tree species, this provided a baseline from which the effects of possum exclusion can be measured once the wildlife reserve has been established.

Chapter 2 of this thesis assesses the relative abundance of possums within different areas of the reserve. Relative possum abundances may reveal which vegetation and habitat types are most utilised by possums. Such information is critical for designing the most effective eradication strategy.

Chapter 3 assesses the condition of possums from various areas within the reserve. If possums are healthier and more fecund in particular areas of the reserve, then they may respond less to control there and alternative strategies or control intensities may be necessary for their eradication.

Chapter 4 and Chapter 5 focus on possum diet and the condition of possum food plants in the reserve. Information about the seasonal importance of possum food plants is important in identifying areas of last possum survivors. Studying the diet of possums in spring also shows the degree in which possums utilise Fuchsia excorticata trees in the reserve and how much defoliation and associated fuchsia mortality can be attributed to possum browse.

In Chapter 5, the condition of tree fuchsia is assessed in order to study the tolerance of this food plant to possum browse. The recovery potential of fuchsia can be further studied once possums are excluded from the reserve. 


\section{Chapter 2}

\section{Possum densities in the Karori Reserve in summer}

\subsection{Introduction}

Because possums are nocturnal, arboreal and inconspicuous animals it is difficult to directly observe their abundance. For species such as rabbit, thar, wallaby and hare the most widely employed direct method to obtain population indices, trends or even absolute density estimates, is spot-light counting (Baddeley 1985). However, monitoring results can be unreliable as they depend on the skill of the observer and the visibility within differing vegetation types.

For estimating possum densities, spot-light counts have little value because possum behaviour and the subsequent number of possum sightings is influenced by the night climate. Furthermore, the method is only useful in open and accessible terrain where the observer can move safely at night without being noticed by the animals.

A more accurate direct population estimate can be derived from the Jolly Seber multiple recapture technique which delivers absolute abundance results. However, this technique is laborious and time consuming and was considered impractical given the time constraints of a MConSc project.

The systematic counting of faecal pellets has been widely used for estimating distributions and abundances of possums in New Zealand (e.g. Riney 1957, Pekelharing 1979, Coleman et al. 1980). This method is a fast indirect alternative to direct abundance assessment techniques, especially when larger survey areas are assessed. Assuming a constant rate of defecation, counting pellet recruitment on cleared plots and dividing the result by the estimated number of pellets voided per animal per day potentially delivers absolute animal densities. However, for possums, the decomposition rate of faecal pellet and the daily defecation rate vary widely (D. Morgan pers. comm.1995). 
The faecal decomposition rate is determined by observing the fate of pellet groups from a subsample of recorded pellet plots. The decomposition of pellets is determined by solar radiation, rainfall, temperature and by the substrate on which the pellets are deposited (Riney 1957, Pekelharing and Reynolds 1983). All these variables may vary significantly spatially and also temporally. A way in which to omit the need to account for the decomposition rate is to clear fixed-area plots and to measure pellet recruitment as pellets per hectare per day. However, this involves visiting each pellet plot twice, thus doubling the survey effort. Additionally, the risk of accidentally introducing pellets into the cleared plot by observers moving between plots or by wind or animals in the time between surveys may lead to an overestimation of the pellet recruitment rate (D. Morgan pers. comm. 1995).

The daily defecation rate has been repeatedly studied for possums in captivity (Honigmann 1941, Riney 1957, Fitzgerald 1977). Fitzgerald (1977) estimated the mean numbers and weights of faecal pellets voided by studying seven adult possums on a diet of single and mixed native leaves and on commercial herbivore food. Both mean defecation rate (24.4 to 105.1 pellets per day) and mean pellet dry weight $(0.117$ to $0.288 \mathrm{~g}$ d.w. $)$ varied markedly and appeared to be influenced by the nutritive value as well as the mix of foods eaten. Both Honigmann (1941) and Riney (1957) fed captive possums an unnatural diet of bread, fruit and vegetables and also recorded marked variations in the number and weight of faeces passed in any one day. Comparing the number of defecations per day with those of red deer, fallow deer and goat, Riney (1957) noted that none of the ungulates showed such marked daily variations.

D.Morgan (pers. comm. 1995) measured the pellet recruitment rate over 7 day intervals on cleared fixed area plots. He found significant changes in mean recruitment rates and suggested seasonal changes in possum diet as the reason. He concluded that if seasonal and spatial variations of possum diet influenced the rate of defecations, then pellet counts would not reliably convert recruitment rate into absolute animal density. The counting of pellets therefore only gives a relative indication of possum abundance. 


\subsection{Methods}

For this study, the standing crop of pellets was counted and used to assess relative possum abundances in various possum habitats within the Karori Reserve. To achieve an unbiased coverage, the study area was stratified following Baddeley (1985). An imaginary baseline was placed along the valley floor of the Kaiwharawhara Stream. This baseline started on the north-west corner of the Lower Reservoir dam and followed a magnetic bearing of 195 degrees along the main valley floor with a change in direction to 167 degrees magnetic to cover the upper reaches of the stream (Map 4). The total length of this baseline was divided into 10 equal units, which were then subdivided into 10 subunits. Single digit random numbers (0-9) were generated to select one subunit per unit as a transect origin. One side of the catchment was randomly chosen to be sampled by the first transect which originated in a 90 degree angle from the 195 degree baseline and which ran on this bearing from valley floor to the upper ridges of the catchment ${ }^{2}$. The following transect sampled the opposite side of the catchment, thus alternating the choice. Eight transects originated from the 195 degree baseline, and a further two transects originated from the 167 degree baseline. In total, 350 pellet plots were sampled throughout the survey area. The transects were sampled in the period from February to May 1995, the overall transect layout is shown on Map 4.

Along each transect, plots were located at 10 metre intervals. The distance between sample points was measured using a 10 metre nylon cord with a peg attached. The peg was used to fix the cord to the last sample point and was pulled out of the ground when the location for the next sample point was reached. For each sample point, all clearly identifiable possum pellets were counted within a $80 \mathrm{~cm}$ radius $\left(=2 \mathrm{~m}^{2}\right)$ and the aspect and vegetation type, as shown on the maps, recorded.

\footnotetext{
${ }^{2}$ Transect 4 was first sampled. By (purely random) mistake the transect followed a true instead of a magnetic bearing. (ie. 105 degrees magnetic equals 128 degrees true which was followed as the magnetic bearing for this transect)
} 
Map 4: Location of pellet transects in the Karori Reserve. The standing crop of pellets was counted between February and May 1995.

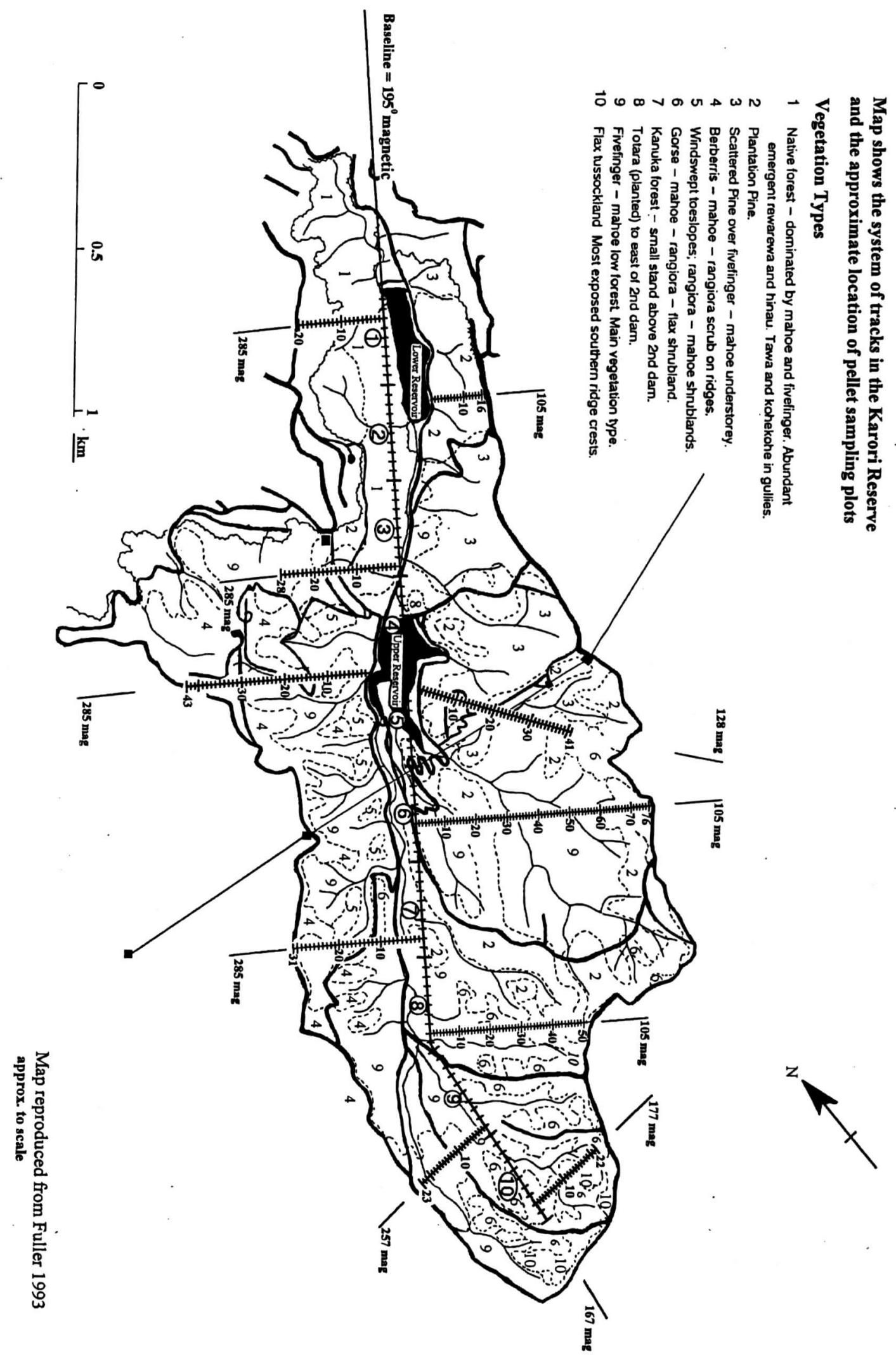




\subsection{Results}

In total, 350 pellet plots $\left(700 \mathrm{~m}^{2}\right)$ were sampled of which 145 plots $(41.43 \%)$ contained possum pellets. On average 2.59 possum pellets were counted per plot which equates to a standing crop of 12,957 possum pellets per hectare for the whole reserve. However, pellets were not evenly distributed and both the vegetation type and the topographical aspect had a highly significant impact on the mean number of pellets per plot (Table 1).

Table 1: Kruskal-Wallis one-way analysis of variance for the parameters "vegetation type" and "aspect". Groupings for "aspect" are: North = pellets found on plots with aspect $315^{\circ}$ to $44^{\circ}$, East $=45^{\circ}$ to $134^{\circ}$, South $=135^{\circ}$ to $224^{\circ}$, and West $=225^{\circ}$ to $314^{\circ}$. All bearings are magnetic.

\begin{tabular}{lccc}
\hline & Test Statistics & p & d.o.f. \\
\hline Vegetation Type & 36.613 & $<\mathbf{0 . 0 0 1}$ & 7 \\
Aspect & 20.32 & $<\mathbf{0 . 0 0 1}$ & 4 \\
\hline
\end{tabular}

The relative importance of vegetation type and aspect was assessed by a two way analysis of variance using the means of the square roots of the pellet counts. Taking the square root of counts assimilates the variances while preserving any differences in means, and the transformed data can then be tested using more elaborate parametric models. The two way analysis of variance showed that vegetation types affected the means of the square roots of the counts even when aspect was allowed for. Conversely, when vegetation type was taken into account, aspect was only a useful extra predictor at the $5 \%$ level of significance but not at the $1 \%$ level of significance. Figure 1 illustrates this relationship of vegetation type and aspect. 


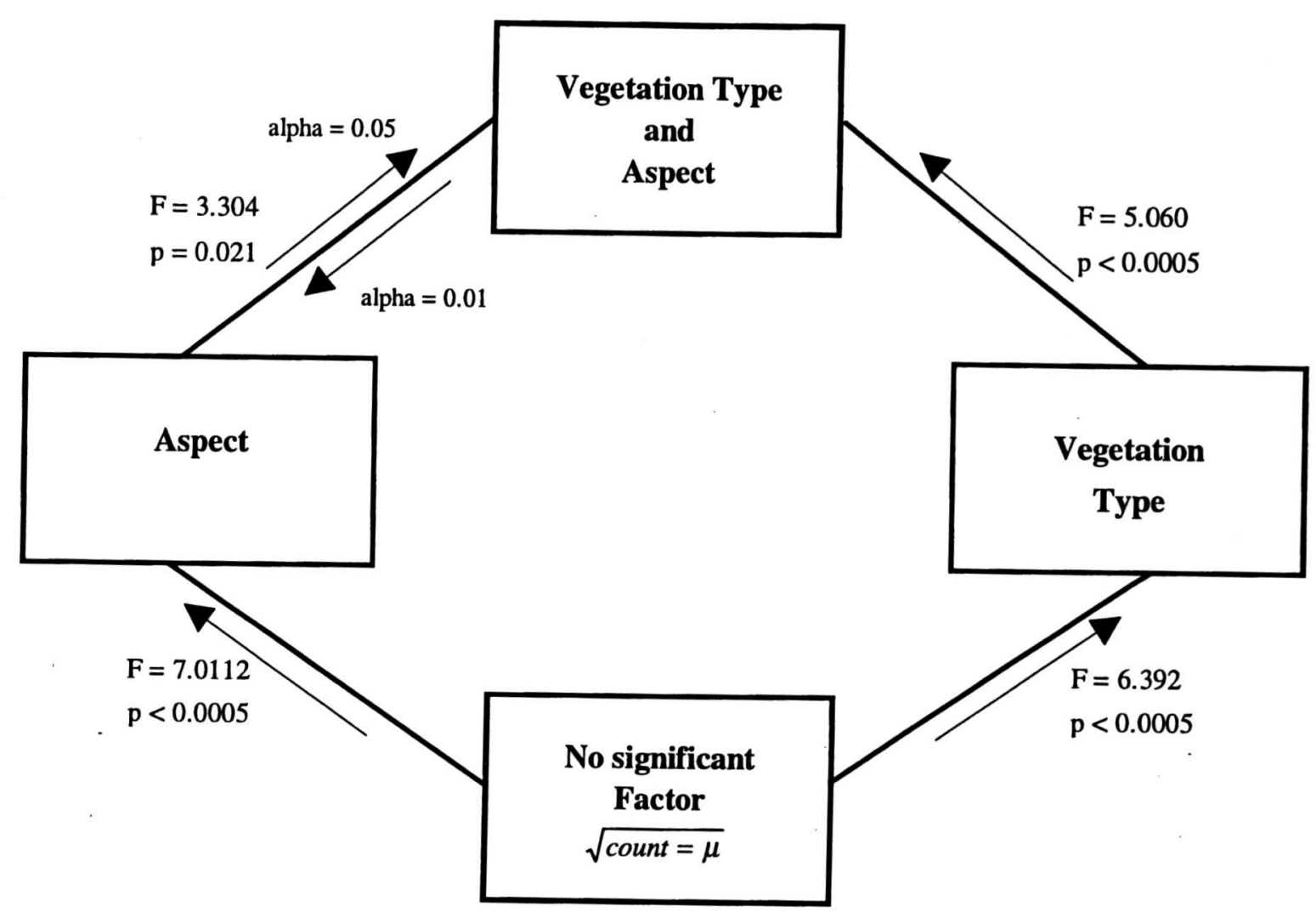

Figure 1: Lattice diagram comparing the relative importance of vegetation type and aspect. Vegetation type is the better predictor for the expected number of pellets in a plot.

Highly variable averages between the 10 transects showed that the sampling area, which is to some extend a combination of vegetation type and aspect, also significantly determined the average number of pellets (Kruskal-Wallis test statistics $=36.882, \mathrm{p}<0.001,9$ d.o.f.)

In order to contrast the main vegetation types and the areas of the Lower and Upper Reserve, pellet frequencies were calculated as a percentage of plots containing one or more pellets. The correlation of pellet frequencies and the average number of pellets in the six major vegetation types was highly significant $(R=0.82$, Figure 2 ) suggesting that the recording of presence or absence data yields similar results to counting the standing crop of pellets.

Chi-square contingency tables suggested that pellet frequencies were significantly higher in the Upper than in the Lower Reserve (Table 3). The most significant discrepancy was observed between the pine forests of these two areas. On average, pine forests yielded by far 
the highest standing crop of pellets. However, this crop was highly variable with the pine forest of the Lower Reserve yielding the lowest count of pellets anywhere in the study area and only the very high standing crop of pellets in the pine forests of the Upper Reserve balanced this low count.

Table 2: The standing crop of pellets per hectare and the pellet frequency within pine forest and native forest in the Lower and Upper Reserve areas.

\begin{tabular}{l|ccccc} 
& $\begin{array}{c}\text { Pellets/ } \\
\text { hectare }\end{array}$ & $\begin{array}{c}\text { Mean count/ } \\
\text { plot }\end{array}$ & $\begin{array}{c}\text { Std. } \\
\text { error }\end{array}$ & n frequency \\
\hline Total & 12957 & 2.59 & 0.29 & 350 & 41.43 \\
Lower Reserve (transect 1 -3) & 4844 & 0.97 & 0.27 & 64 & 25.00 \\
Upper Reserve (transect 4 - 10) & 14773 & 2.95 & 0.34 & 286 & 45.10 \\
\hline Pine forest (vegetation type 2+3) & 25156 & 5.03 & 0.03 & 64 & 59.37 \\
Native forest (vegetation type 1+9) & 8774 & 1.75 & 0.22 & 257 & 36.18 \\
\hline Pine forest (Lower Reserve) & 3333 & 0.66 & 0.52 & 12 & 16.67 \\
Native Forest (Lower Reserve) & 5192 & 1.04 & 0.27 & 52 & 26.92 \\
\hline Pine forest (Upper Reserve) & 30192 & 6.03 & 1.23 & 52 & 69.23 \\
Native forest (Upper Reserve) & 9682 & 1.93 & 0.27 & 205 & 38.54
\end{tabular}

Within native forest communities the standing crop of pellets was almost twice as high in the Upper than in the Lower Reserve. Also the percent frequency was higher in the Upper Reserve, but this difference was statistically not significant at $p=0.119$ (Table 3). 


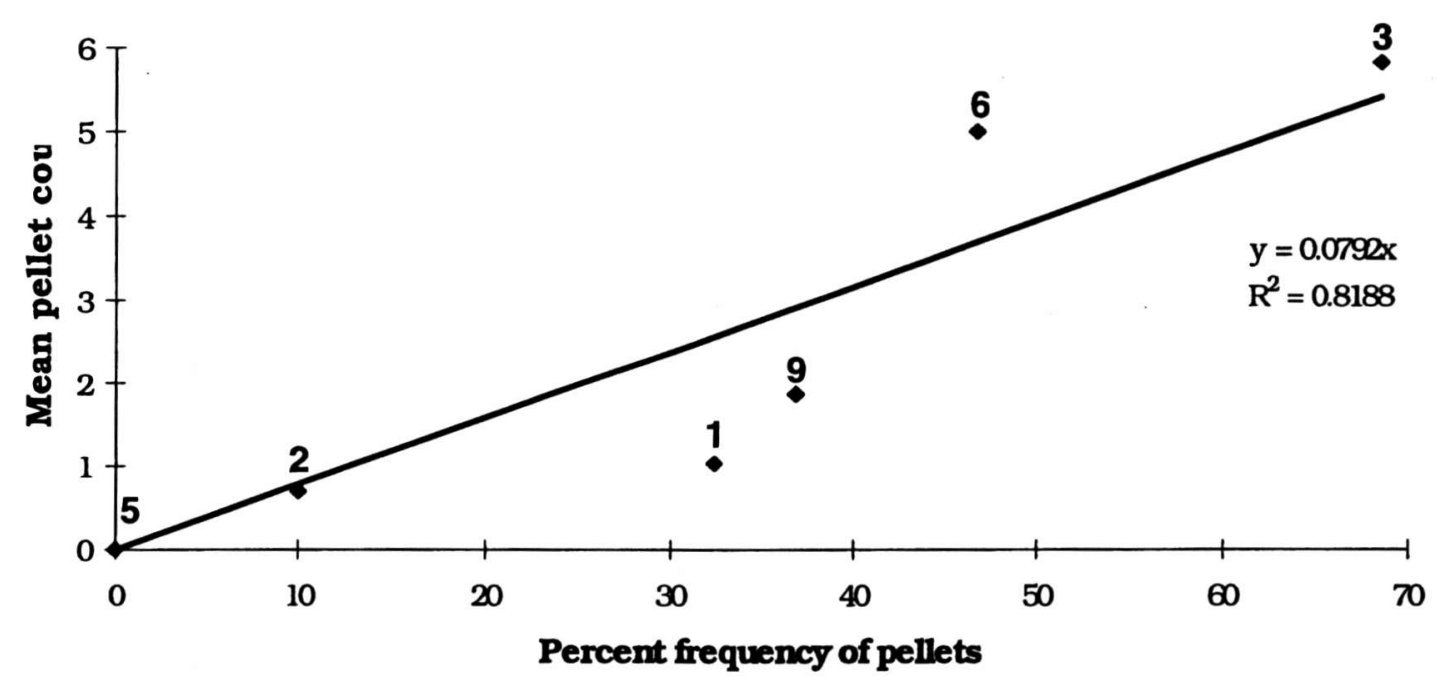

Figure 2: The linear relationship of mean pellet count and presence of pellets in the six main vegetation types (bold numbers) suggests that the frequency data can be used to estimate the standing crop of pellets in any one area. For the vegetation patterns refer to Map1. Vegetation type $1(n=34)$ is the mature native forest in the Lower Reserve, type $2(n=10)$ is

the plantation pine forest in the Lower Reserve, type $3(n=54)$ is the pine over native vegetation forest in the Upper Reserve, type $5(n=5)$ are the windswept rangiora and mahoe shrublands, type 6 are the gorse and flax dominated shrublands $(n=15)$ and type $9(n=223)$ is the regenerating native forest in the Upper Reserve.

Table 3: Results from chi-square contingency tables using pellet frequency data.

\begin{tabular}{l|ccc} 
& Chi-square & p & d.o.f. \\
\hline Upper vs Lower Reservoir & 8.705 & $\mathbf{0 . 0 0 3}$ & 1 \\
Upper vs Lower Reservoir (native forest) & 2.425 & $\mathbf{0 . 1 1 9}$ & 1 \\
Upper vs Lower Reservoir (pine forest) & 11.191 & $<\mathbf{0 . 0 0 1}$ & 1 \\
Native vs pine forest (Lower Reservoir) & 12.463 & $<\mathbf{0 . 0 0 1}$ & 1 \\
Native vs pine forest (Upper Reservoir) & 15.86 & $<\mathbf{0 . 0 0 1}$ & 1
\end{tabular}

Over the entire reserve, possum pellets were most frequently encountered in pine forests. This observation seems to be primarily founded upon the results from the Upper Reserve alone where pellets were significantly more frequent in pine than in native forest communities. Indeed, in the Lower Reserve the opposite was observed. As the pine forest of the Lower Reserve yielded fewest pellets, the difference in pellet frequency between the pine 
forest and the mature native forest remnant on the opposite side of the Lower Lake was highly significant.

\subsection{Discussion}

The technique of counting the standing crop of pellets on transects only provides an indication of relative possum density and results must be treated with caution. The survey was conducted over a period of three months from March to May 1994. During this time period, the possum diet and associated defecation rate may have changed. Also the decay rate of pellets may not have remained constant during the sampling period. Furthermore, the disappearance rate of pellets on various substrates (mainly pine needles and native forest leave litter) was not measured. All three factors, changes in diet and defecation, the rate of decomposition and the impact of substrate on the disappearance rate may have significantly influenced the standing crop of pellets during the three survey months in the reserve.

Pekelharing and Reynolds (1983) observed highly significant temporal differences in disappearance rates of faecal possum pellets but no spatial differences between sampling areas in various altitudinal locations. They suggested that climatic rather than topographical factors determined the decomposition rate of pellets. Assuming similar defecation rates in various forest types and by calculating an index of pellet decomposition they estimated relative possum densities using corrected pellet count data. R.E.Brockie (pers. comm. 1995) assessed pellet counts for estimating population densities by comparing results with more reliable mark-recapture data in the Orongorongo Valley, Wellington. He also found the decay rate of pellets to be determined by climatic conditions and the half-life of pellets highly variable over the year. Brockie noted that the daily defecation rate of possums in the Orongorongo Valley varied through the year and has suggested changes in seasonal and local food supplies as the primary causal factor.

However, not only intrinsic factors such as variable defecation, decomposition and disappearance rates influence the probability of finding pellets. The differential skills of observers in detecting pellets may add another source of variation. In this survey, however, 
this type of observer bias was eliminated because only one person was involved in the search.

A further extrinsic source of variation may be the differential likelihood of finding pellets in various substrates and vegetation types. On pine needles, pellets appeared to be embedded on a well draining and stable substrate and had a high probability of being detected. In contrast, a pellet deposited on an unstable native leaf litter substrate could easily be dislodged and once covered by leaves could remain undetected. Some plots were within shrubby and dense vegetation where movement was difficult. Other sites were covered in dense ground vegetation. In these locations the probability of finding pellets was reduced and the true standing crop of pellets may have been underestimated. When interpreting results it is therefore important to consider that differences in pellet frequencies and pellet counts may originate from a combination of factors, namely varying possum densities, decay, disappearance and defecation rates and differential probabilities of finding pellets depending on the sampling site characteristics.

Bearing these sources of variation in mind, it seemed that test statistics comparing similar vegetation types in different areas would give the most unbiased indications of possum densities. The results suggested that possum densities were significantly higher in the pine forests of the Upper Reserve than in the pine forest of the Lower Reserve. Differences between the native forests of the two areas were not as pronounced. Possums have been repeatedly controlled by the Regional Council in the Lower Reserve area. The pine. plantation on the north-western face of the Lower Reserve is particularly accessible and the task of controlling possums in this area would be less demanding than in other areas of the Karori Reserve. The proximity to the urban fringe and the lack of a palatable understorey would also have discouraged possums from utilising this forest area. In the pine forests of the Upper Reserve, possums are only irregularly controlled through illegal poisoning and trapping. In this area, prolific native undergrowth provides the staple food while the large branching Pinus muricata trees provide a seasonal food source, good denning sites and shelter. 
As the proportion of native and pine forest plots was very similar in the Upper and Lower Reserves (chi-square $=0.07, \mathrm{p}=0.79,1$ d.o.f.), it seemed reasonable to also consider the test results which compared the combined pellet plots of the two areas. As the frequency of pellets was significantly higher and the average pellet count more than three times as high in the Upper Reserve, it seems reasonable to suggest that higher possum densities can be attributed to this difference.

The high pellet frequency in vegetation type 6 suggest that the windswept gorse and flax dominated shrublands provide a much utilised habitat. The dense vegetation in the upper reaches of the Kaiwharawhara Stream offers good protection against wind and the weather, and provides an abundance of suitable den sites within a habitat which cannot be easily accessed by larger animals or humans. The shrubland acts as a nursery for possum palatable native species such as mahoe and five-finger. The heterogeneous vegetation surrounding the shrubland also provides a variety of seasonal food sources. This combination of advantageous habitat characteristics is likely to support a possum population at high density.

Tests concerning the relative importance of vegetation type and aspect suggested that the vegetation was more important than the aspect in determining the density of possums. However, contrary to the sampling bias caused by the substrates in different vegetation types, such a bias does not exist when sampling different aspects. It therefore seems reasonable to suggest that the importance of aspect has been underestimated and that both, vegetation type and aspect have a similar influence on the probability of finding pellets at any one plot. Also, aspect and vegetation type are not independent variables because the aspect partly determines the type of vegetation at any one location. 


\subsection{Conclusion}

Even though the assessment method provides only a crude estimate of possum abundances in the Karori Reserve, the results suggest that:

- Possum densities are highest in the Upper Reserve where possums have not been subjected to control. In the Lower Reserve, possums find better protection from regular possum control operations in the mature native forest, where food supplies are abundant and human access is difficult.

- North-west facing aspects support more possums than south-east facing aspects.

- Pine forest over native understorey provides the best habitat and supports highest possum densities, especially where this forest type is located on north-western aspects.

- The extensive windswept gorse and flax shrublands along the periphery of the Upper. Reserve provide excellent shelter and den sites for a large number of possums.

When eradicating possums from the Reserve, these latter habitats should be especially considered. To kill all possums within the extremely dense gorse and flax vegetation may pose the greatest challenge for the eradication campaign. 


\section{Chapter 3}

\section{Morphological condition}

\subsection{Introduction}

\subsubsection{Condition indices: a review}

The average condition or "well-being" (Fraser 1979) of an animal population influences population dynamics and may be indicative of the quality of a habitat. Condition indices allow for statistical comparison of populations from different areas, vegetation types and habitats. This type of information is most valuable in identifying abundance, rates of increase and habitat preferences, and aids in the production of the most efficient management strategy for a given pest population.

In New Zealand, condition indices for possums have been developed to contrast the quality of habitats (Husheer 1994), to calculate and compare the reproductive potential of possums (Fraser

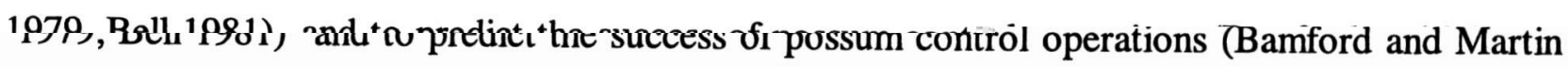
1971, Bamford 1972, Morgan 1982, Warburton 1996).

Bamford and Martin (1971) used total fat reserves as a measure of physical condition. Indices of condition were based on estimated stored fat reserves and determined separately for each male and female possum from its weight as a percentage calculated from a standard weight for length. Results showed a significant negative correlation between fat reserves and percent kill achieved in various possum control operations (correlation coefficients $(r)$ being $-0.96(p=<0.01)$ and -0.87 ( $p=<0.05$ ) for male and female possums respectively). Bamford (1972) also found the total fat reserves of individuals and condition indices closely related to the rate of increase in possum populations.

Contrary to Bamford and Martin (1971), Morgan (1982) found that possums accepted toxic and non-toxic baits more readily in winter, even though animals were in better condition than animals sampled in summer. Warburton (1996) found that possums also accepted bait when they were at medium to low densities and when natural foods were not a limiting factor. This suggests that 
condition may not be an important factor influencing bait consumption and success of possum control operations.

Fraser (1979) estimated total fat reserves of possums from three different habitats in the Copland Valley, Westland, and found large fat reserves characteristic of expanding low density populations with abundant food supplies. In contrast stable high density populations typically had diminished fat deposits. These findings correlated with highly significant differences in mean body weight $(\mathrm{p}<$ 0.001) of the high and low density populations. The differing slopes of the weight to length regressions for the high and low density populations suggested that growth differences between low and high density populations increased as animals grew older.

Bell (1981) used a weight to length index as an indication of fat reserves following Bamford (1972) and found a significant correlation $(p<0.001)$ between stored fat reserves and breeding capacity of female possums in the Orongorongo Valley, Wellington.

Husheer (1994) found female possums with pouch young in significantly better morphological condition (higher weight for age) than female possums without pouch young. He also compared physiological condition indices based on mesenteric fat weight with a morphological condition index (MCI) based on non-linear comparisons of weight and age of two disjunct possum populations in Waihaha and Hohotaka. He found fat indices susceptible to the influence of season and reproduction and recommended the use of the MCI for contrasting the relative health of possums in different habitats, as this index provided an indication of the physiological status of a population in relation to habitat.

In this study, three hypotheses were investigated which depended on premises as follows:

- that the possum population from the Lower Reserve area will be at a lower density than the Upper Reserve population, because of regular possum control by the Regional Council and possum kills by local residents;

- that in populations of lower density intraspecific competition is relaxed and the quality of habitat enhanced; 
- that there is a positive relationship between habitat quality and the morphological condition (weight, size and fecundity) of possums (Tyndale Biscoe 1973, Bell 1981).

Two hypotheses are based on these premises:

Hypothesis 1:

Possums from the Lower Reserve area will be in better morphological condition than possums from the Upper Reserve area - the Lower Reserve possums will be heavier and larger than possums of equivalent sex from the Upper Reserve area and Lower Reserve females will be more fecund than females from the Upper Reserve area.

Hypothesis 2:

The quality of habitat in the Lower Reserve area will be better than in the Upper Reserve area.

The premises for the third hypothesis are:

- that the continual removal of resident possums from the Lower Reserve area will create space for dispersing juveniles from peripheral areas.

- that the mortality rate of juvenile possums is low in low density populations.

Hypothesis 3:

There will be a higher representation of juvenile possums in the Lower Reserve population than in the Upper Reserve population. 


\subsubsection{Ageing}

In order to statistically compare the morphological condition and measurements of possums from various areas of the reserve, two independent investigations were pursued. Investigations included the:

- Construction of growth curves from non-linear regression functions using the mean increment of the Karori possum population's weight in relation to age.

- Performance of multivariate discriminant analyses based on body length and weight measurements in relation to age.

For both investigations a subset of possums had to be aged.

Various criteria for estimating the age of possums have been used in the past. Tyndale-Biscoe (1955) analysed the degree of fusion of the tibial epiphyses to divide a possum population into three age classes but did not assign absolute ages to these groups. Kingsmill (1962) examined and evaluated possums of known age to determine what criterion was best suited to determine age. She found that the growth of most structures decreased with age which made estimations increasingly inaccurate. However, Kingsmill did find that the height of the saggital crest could be used to age possums up to the age of 2.5 years, the dry weight of lenses useful for ageing up to. 3 years, and the epiphyses of limb bones useful to assign possums into three age groups. Unfortunately, Kingsmill did not determine whether the overlap between assigned age classes was insignificant enough to allow for reliable discrimination into age classes once possums had matured (older than 2 years of age) and none of the methods were reliable for assigning accurate ages to adult possums. Kingsmill also examined sections of possum incisors but found growth rings too irregular to be counted accurately.

Continuous apositional growth of teeth resulting in the development of incremental lines is found both in cementum and dentine and similar lines are also found in bone (Grue and Jensen 1979). Such incremental lines have been reported in most groups of mammals (Morris 1972). Klevezal and Kleinenberg (1967) suggested that incremental lines represent periods of arrested 
cementoblast activity coinciding with a general slowing down in growth, caused by regular seasonal changes.

Pekelharing (1970) first developed a quantitative ageing technique by sectioning and preparing possum molars and counting annual growth layers in the dental cementum. Beauchamp (1978) improved Pekelharing's method by permanently staining sectioned teeth with Ehrlich's Haematoxylin. Clout $(1977,1982)$ devised a more accurate but also more laborious method which was first described by Klevezal and Kleinenberg (1967). Clout exposed annual growth rings of molar $\mathrm{M}^{3}$ by decalcifying teeth and sectioning them into a series of 20 micron sections using a freezing microtome. The major advantage of Clout's method was that several sections from the same tooth could be compared and accessory bands, which are sometimes present between the main series of annual growth rings, could be more clearly distinguished and excluded from the count.

Winter $(1980,1976)$ assigned ages to possums by examining their tooth wear. This is a very fast ageing method allowing for the analysis of large samples. The method is particularly useful in areas where possums can not be killed. However, as tooth wear largely depends on the abrasiveness of utilised food items, the exposure patterns of dentine and pulp of molar teeth may vary significantly between habitats.

\subsubsection{Morphological condition of possums in the Karori Reserve in spring}

This study compared the relative condition or health of possums from various areas of the Karori Reserve. This was achieved by:

A. comparing morphological condition indices of possums from different areas and habitats within the reserve. An age and sex independent morphological condition index based on weight was calculated by dividing the actual weight of each possum by the weight estimated for its age class; and,

B. comparing morphometric measurements of adult male and female possums from different areas and habitats within the reserve. As the probability of catching too many juvenile possums in a particular area increases as the sample size decreases, potentially biasing results, all juvenile possums had to be removed from the sample. In order to identify all juvenile possums, each sex 
was discriminated individually into juvenile ( $<2$ years) and adult ( $>=2$ years) age groups. Possums of unknown age were assigned to age classes by using the weight to length by age relationship of animals with known ages. Multivariate comparison of adult possums based on their morphometric measurements could then be performed to compare the condition of individuals in different areas of the reserve.

These investigations were considered important because possums in particularly good condition may accept poisoned bait less readily (Bamford and Martin 1971) and their reproductive output is likely to be high (Tyndale Biscoe 1973, How 1979, Bell 1981, Green and Coleman 1984, Cowan 1993, Husheer 1994). More care should therefore be taken monitoring areas that have contained possums in particularly good condition for last survivors.

Possum adult to juvenile ratios may also identify areas where possums have been controlled before. Trapping or poisoning is likely to result in an over-representation of young animals (Brockie, Bell and White 1981) suggesting density dependent changes in survival, particularly of juveniles (Cowan 1993). Furthermore, the morphological condition of survivors will tend to increase and a "compensatory response" of the controlled population in the form of an increased reproductive output can be expected (Batcheler 1968, Hickling and Pekelharing 1989, Husheer 1994). Poorly performed possum control may also lead to bait shyness and general neophobia (Morgan 1995, Warburton 1996) and has the potential to jeopardise the planned eradication programme. 


\subsection{Methods}

\subsubsection{Data collection}

Between September and November 1995, the Karori Sanctuary Trust and the Wellington Regional Council controlled possums in the Karori Reserve in a combined effort to ameliorate the damage to stands of native tree fuchsia (Wright 1996). As a control method, the Regional Council used hydrogen cyanide paste $(\mathrm{HCN})$ in the Lower Reserve and the Karori Sanctuary Trust used cyanide paste and Victor 1 leg hold traps in the Upper Reserve.

For this study, body length, total length, sex, colour, and weight of 145 possums killed during this control operation was measured. Body length was measured by running a flexible tape mid dorsally from the tip of the snout to the base of the tail and total length was measured from the tip of the snout to the tip of the tail. Body weight was taken to the nearest 10 grams using a $5 \mathrm{~kg}$ Pesola spring balance. Possums stomachs were collected to study the diet of possums in spring.

From 27 to 31 October 1995, 37 possums were caught on lines 1-3 (Areas 1 and 2) in the Upper Reserve. In total, 14 stomachs were taken and the exact location of these possums recorded.

On 3 November 1995, cyanide paste was used to kill 62 possums on line 4 in the Lower Reserve (Area 4). In total, 7 stomachs were taken, but because of the way this cyanide operation was conducted, the exact location of each stomach taken could not be determined.

From 6 November 1995, 49 leghold traps on lines 5-7 were lured with flour containing aromatic cinnamon and raspberry and set over 3 successive nights (Areas 2 and 3) and 46 possums were caught. In addition to the usual measurements, the aspect and vegetation type surrounding each trap and the tree species on which each trap was set was also recorded.

Map 5 shows the vegetation types and the location of traplines in each of the four study areas of the Karori Reserve. 
Map 5: Karori Reserve traplines and study areas October - November 1995

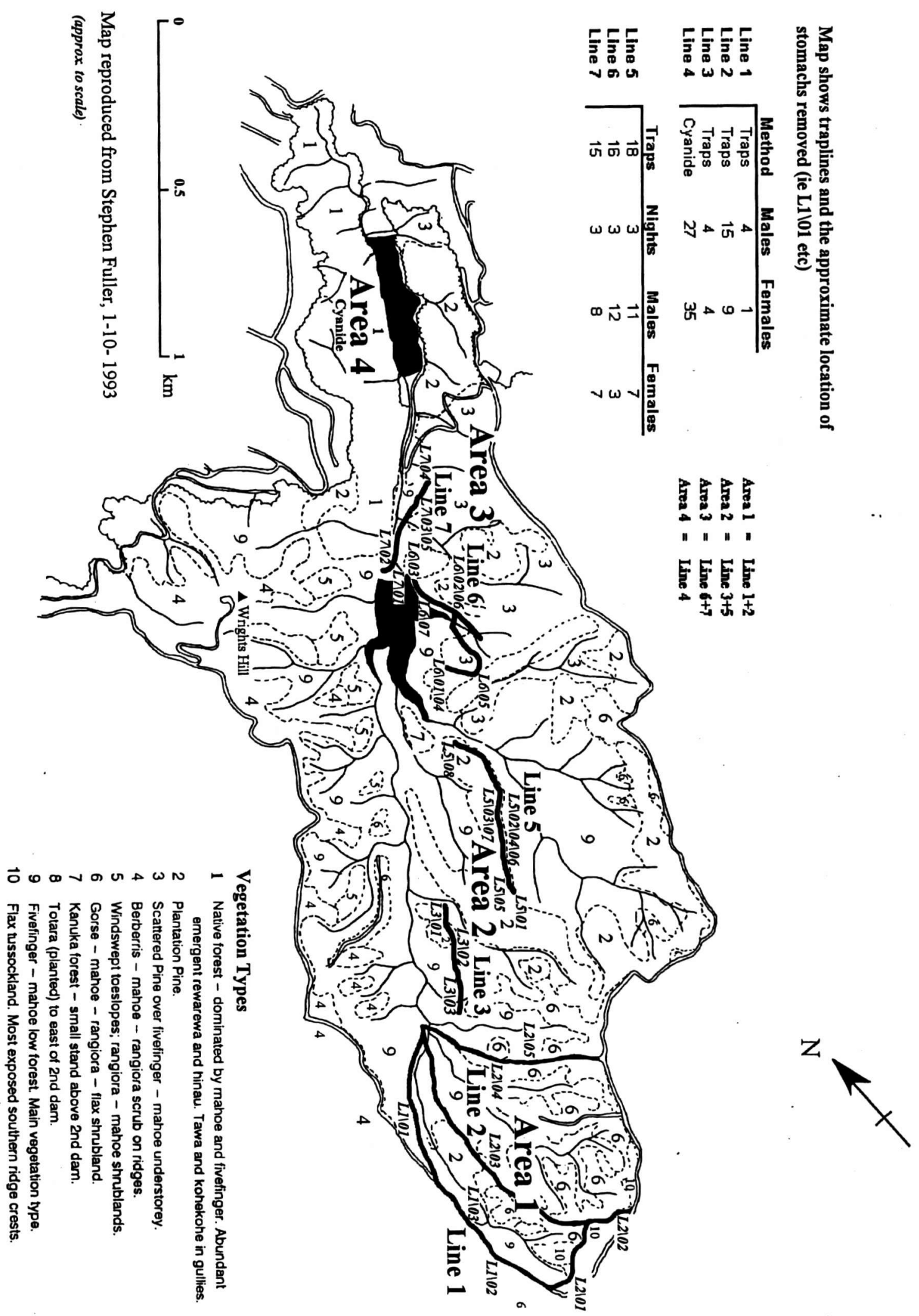




\subsubsection{Ageing}

In the present study reliable age data were needed to be fitted against weight to calculate an sex and age independent condition index and for discriminating possums accurately into juvenile and adult age groups.

Of the possums caught on lines 4 to 7, 52 animals (24 males and 28 females) were decapitated, their heads tagged and then stored for two months in the forest in styrofoam boxes. During this time fly maggots consumed most tissues around the skulls which facilitated the extraction of teeth without damaging them.

Two ageing methods were used and compared. First, Winter's (1976) method of assessing tooth wear was used for assigning ages to all 52 possums. To be consistent with the method proposed by Winter the upper left $\mathrm{M}^{1}$ was taken for age estimation and the exposure patterns of dentine and pulp of molar teeth examined under a disecting microscope. Teeth were grouped into seven wear classes which corresponded to ages, that is wear class 1 corresponded to a possum 0-1 years of age.

To test the accuracy of this method the upper left $\mathrm{M}^{2}$ and if not available, the upper right $\mathrm{M}^{2}$ were extracted and sectioned using Pekelharing's (1970) etching and staining method. Extracted teeth were glued with Araldite to $1 \mathrm{~cm}^{3}$ custom wood blocks and tag numbers were written on these blocks for later identification. The anterior or posterior surface of each tooth was ground using 180 grain and 400 grain carborundum paper and polished on hard cardboard. The thickest part of the cementum pad between the roots was accurately reached by frequently observing the surface through a binocular dissecting microscope (x 40 magnification). Teeth were decalcified in $90 \%$ formic acid, neutralised in diluted ammonium hydroxide, stained in highly diluted thionin (with extreme care taken not to overstain), fixed in diluted ammonium hydroxide and the surfaces preserved with DePex mounting medium. After preparation, the annually deposited opaque and translucent cementum layers sheathing the roots of the permanent teeth could be examined.

The translucent layers were counted on four different occasions. Three animals were excluded from the sample as their teeth were not readable with any accuracy. A final age (in years) was assigned to each tooth on a fifth occasion by combining the trend of the four previous readings and a final 
assessment of each tooth. Finally, the four trials were tested using ANOVA for a difference in mean readings.

The final age assessments using Pekelharing's (1970) and Winter's (1976) methods were also compared for a difference in mean readings.

\subsubsection{Calculating a morphological condition index (MCI)}

To determine individual morphological condition indices for the 49 possums of known age, growth curves were constructed for each sex from a non-linear regression function using the mean weight increment in relation to age (NONLIN module in the SYSTAT computer package, Wilkinson 1990). The actual weight of each individual possum was then converted to a proportion of the weight for its sex and age group as predicted from the fitted non linear regression function to calculate an age and sex independent morphological condition index.

A number of growth curves may be fitted to non-linear regression functions. Yang et al. (1978) compared five logistic growth functions (Gompertz, logistic, von Bertalanffy, Mitscherlich and modified Weibull) and proposed the use of the modified Weibull function as the most flexible means to express empirical growth. Frampton and Nugent (1992) and Nugent (1989) developed this method further for fallow deer. They used the Weibull function to calculate age and sex independent condition indices for individual animals allowing for comparison of population responses to specific environmental effects. Fraser and Sweetapple (1993) used the method for red deer and Husheer (1994) adapted the method for possums to compare the condition of two populations in differing habitats.

For this study the modified Weibull curve

$$
\text { weight }=\mathbf{a}^{*} \exp -\mathbf{k} * \operatorname{age}^{\wedge} \mathbf{i}
$$

as recommended by Frampton and Nugent (1992) was used to fit the data where:

\section{$a=$ the upper asymptote of weight}

$\mathbf{k}=\mathbf{a}$ shape parameter determining the tension of the curve between birth and asymptote (a low value corresponds to a less rapid increase of the curve)

$\mathbf{i}=\mathbf{a}$ scale parameter determining at which level the rate of increase will start to decline. 


\subsubsection{Discriminant analysis}

Since age was determined with relative certainty for 49 possums, multivariate discriminant analyses based on sex, weight and body length (tip of the snout to the base of the tail) could be used to allocate individual possums into age groups. This procedure was performed in order to remove bias from catching too many juveniles with weight to length measurements below the upper asymptote in a particular area. Only adult male and female possums from various areas within the reserve would be compared in a multivariate test.

The MGLM module in the SYSTAT computer package (Wilkinson 1990) was used to calculate the probability that a possum with known sex and body length to weight measurements was either a juvenile ( $<2$ years) or an adult ( $>=2$ years) animal.

Female possums were discriminated into two age groups (age 1 year and age 2 years and more) since the fitted Weibull regression suggested that they reached their upper asymptote at the age of two. Male possums reaching their upper asymptote later in life were first discriminated into two age groups (age 1 year and age 2 years and more) and then into 3 age groups (age 1 year, age 2-3 years and age 4 years and more).

Once male and female possums were assigned an age group, a Wilks Lambda multiple Anova using body length and weight as variables was performed to test whether the discrimination was effective, that is, whether weight to body length overlap between age groups was insignificant enough to allow for meaningful discrimination into age groups.

A mean probability of correct assignment, which is the mean of the highest probability for each possum belonging to a particular age group was then calculated for each sex.

\subsubsection{Statistical comparison}

Once all adult male and adult female possums could be confidently separated from the total sample, statistical comparison of sub-populations within the reserve was possible. 
The aim of the multivariate comparison was to test whether the combined morphometric variables of body length, total length and weight were significantly different between the four sampled areas and also between male and female possums.

To allow fitting the data to the multivariate general linear model (MGLM), the linearity or interaction of the three variable means for male and female possums in areas 1 to 4 had to be established. Once linearity had been confirmed, the combined evidence from the three dependent morphological measurements could be used in this test.

A Wilks Lambda multiple Anova test was then performed to contrast morphometric differences between areas while allowing for possible differences between sexes and, in a second test, to distinguish mean differences between the sexes while allowing for possible differences between areas.

\subsection{Results}

\subsubsection{Ageing}

Winter's method of assessing the age of animals in the field reached very similar results to the more sophisticated etching and staining method described by Pekelharing (mean ages 3.15 years and 3.08 years respectively, $\mathrm{P}(\mathrm{T}<=\mathrm{t})$ two-tail $=0.702$, d.f. $=48)$. In this study, however, it was possible to examine tooth wear of animals under a dissecting microscope, which would have added to the accuracy of Winter's assessment technique. Cementum annuli of stained teeth were counted on four occasions. Mean ages varied between trials (range 2.75 years to 3.32 years) but the difference between trials was statistically not significant $(F=0.989, p=0.398,195$ d.o.f. $)$.

Even though cementum annuli are already visible in some specimens without etching and staining, assessment of unstained teeth underestimated the mean age of the population. This was concluded after analysis of unstained teeth which, averaging 2.65 years of age, were significantly lower than the mean ages determined using Winter's and Pekelharing's methods $(\mathrm{P}(\mathrm{T}<=\mathrm{t})$ two-tail $=0.0158$ and $<0.001$ respectively, d.f. $=48$ ). 


\subsubsection{Trapping results}

During the entire possum control operation, 149 possums were removed from the 37 hectare Lower Reserve area (4.03 possums tha) and approximately 1170 possums were removed from the 213 hectare Upper Reserve area (5.5 possums lha).

Once the possum control operation in the Karori Reserve had been completed, 49 leg hold traps were used between 7 and 9 November 1995 on three trap lines (Map 5). This was an area which had previously been controlled by the Karori Wildlife Sanctuary hunter. Tables 4 and 5 show the catch results on these three trap lines.

Table 4: Trap-catch data

46 possums were caught in 145.5 trap nights. (For each sprung trap half a trap night was subtracted). This resulted in a $31.5 \%$ (Std.Error $+/-4.06 \%$ ) catch rate. $\mathrm{M}=$ male, $\mathrm{F}=$ female, $\mathrm{FB}=$ female with backyoung, $\mathrm{FP}=$ female with pouchyoung.

\begin{tabular}{|c|c|c|c|c|c|c|}
\hline LINE 5 & Traps & $\bar{M}$ & $\mathbf{F}$ & FUB & FUP & Total \\
\hline $7 \backslash 11195$ & 18 & 6 & 1 & 0 & 0 & 7 \\
\hline $8 \backslash 11195$ & 18 & 2 & 4 & 1 & 0 & 7 \\
\hline \multirow[t]{2}{*}{$9 \backslash 11195$} & 18 & 3 & 1 & 0 & 0 & 4 \\
\hline & & & & & & 18 \\
\hline LINE 6 & Traps & $\bar{M}$ & $\bar{F}$ & FVB & FVP & Total \\
\hline 711195 & 16 & 5 & 0 & 0 & 0 & 5 \\
\hline $8 \backslash 11195$ & 16 & 5 & 0 & 1 & 0 & 6 \\
\hline \multirow[t]{2}{*}{$9 \backslash 11 \backslash 95$} & 16 & 0 & 2 & 0 & 0 & 2 \\
\hline & & & & & & 13 \\
\hline LINE 7 & Traps & $\overline{\mathbf{M}}$ & $\mathbf{F}$ & FVB & FUP & Total \\
\hline 711195 & 15 & 3 & 2 & 1 & 0 & 6 \\
\hline $8 \backslash 11195$ & 15 & 3 & 2 & 0 & 0 & 5 \\
\hline $9 \backslash 11195$ & 15 & 2 & 2 & 0 & 0 & 4 \\
\hline
\end{tabular}




\section{Table 5:}

Summary trapping results lines $5-7$

\begin{tabular}{cccc}
\hline Date & Traps & Possums & Possums\Trap \\
\hline $\mathbf{7 1 1 0 5}$ & 49 & 18 & 0.367 \\
$\mathbf{8} 11195$ & 49 & 18 & 0.367 \\
$9 \backslash 11195$ & 47.5 & 10 & 0.21 \\
\hline
\end{tabular}

There was no difference in trap success between lines $(p=0.78,48$ d.f.) and no difference in trapability between the three major vegetation types which are mature native forest $(n=10)$, regenerating native forest $(n=20)$ and pine forest over native understory $(n=19)(p=0.92,48$ d.f. $)$. However, as can be seen in Table 5, the catch rate declined markedly during the last night.

Because pine, mahoe and five finger represent the most abundant tree species in the reserve, they were often used to place traps. Most possums were caught on pine and five-finger trees ( $42 \%$ and $43 \%$ catch rates respectively), but the difference in catch rate between these two species and mahoe $(23 \%)$ was not statistically significant $(p=0.13)$.

\subsubsection{Morphological condition index}

The steeper female Weibull curve ( $\mathrm{k}=0.821$ for females against 0.690 for males) reflected the more rapid increase in weight of juvenile female possums. Females also had a lower asymptotic weight than males $(2.644 \mathrm{~kg}$ and $2.929 \mathrm{~kg}$ respectively). These two factors indicate that female possums grow faster and mature about one year earlier than males (Figure 3).

The corrected $\mathrm{r}^{2}$ value for the female weight to age function was noticeably lower than the corresponding male value $\left(\mathrm{r}^{2}=0.591\right.$ and 0.806 respectively). This discrepancy was probably caused by a combination of more variable weights for females together with the presence of relatively heavy females in the 2 year age class. This latter fact is also reflected in the higher $\mathrm{k}$ value for females. 
Fitted Weibull curve for female possums $(n=26)$

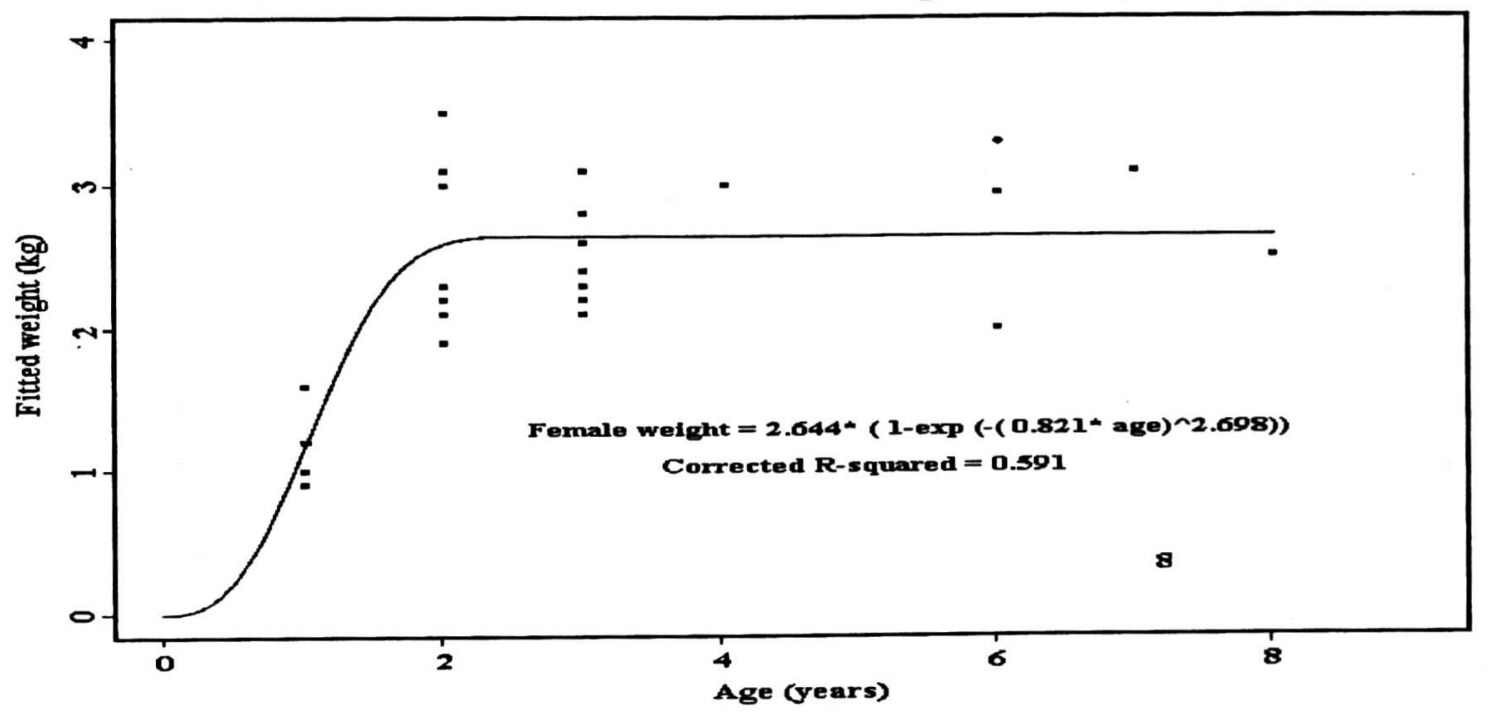

Fitted Weibull curve for male possums $(n=23)$
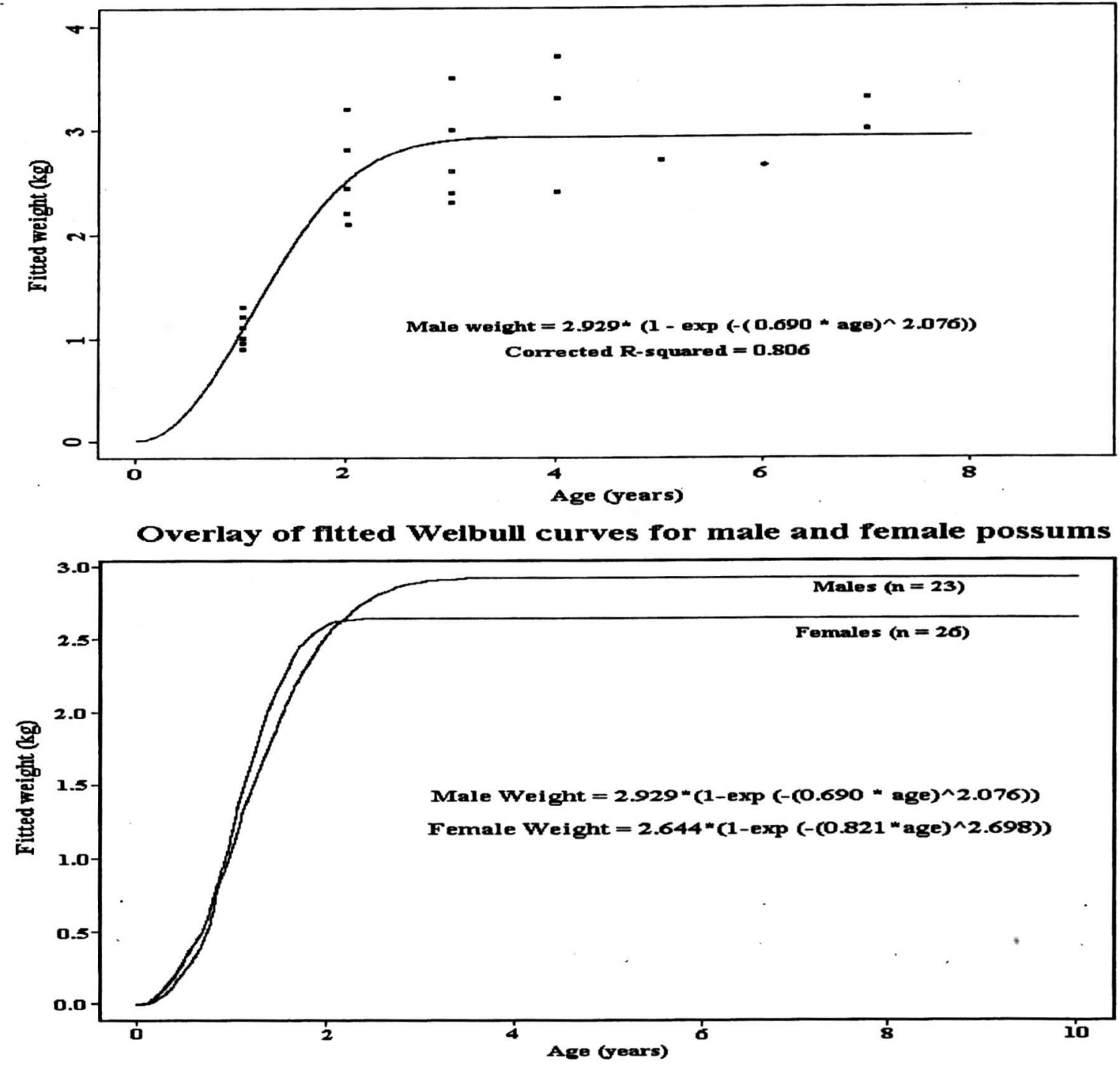

Figure 3: Weight of male and female possums plotted against age with Weibull curves fitted 
In Figure 4, the condition index is plotted against age to demonstrate the independence of the condition index from age. However, the regression $\left(r^{2}=0.08, p=0.043\right.$, d.f. $\left.=48\right)$ shows a significant correlation.

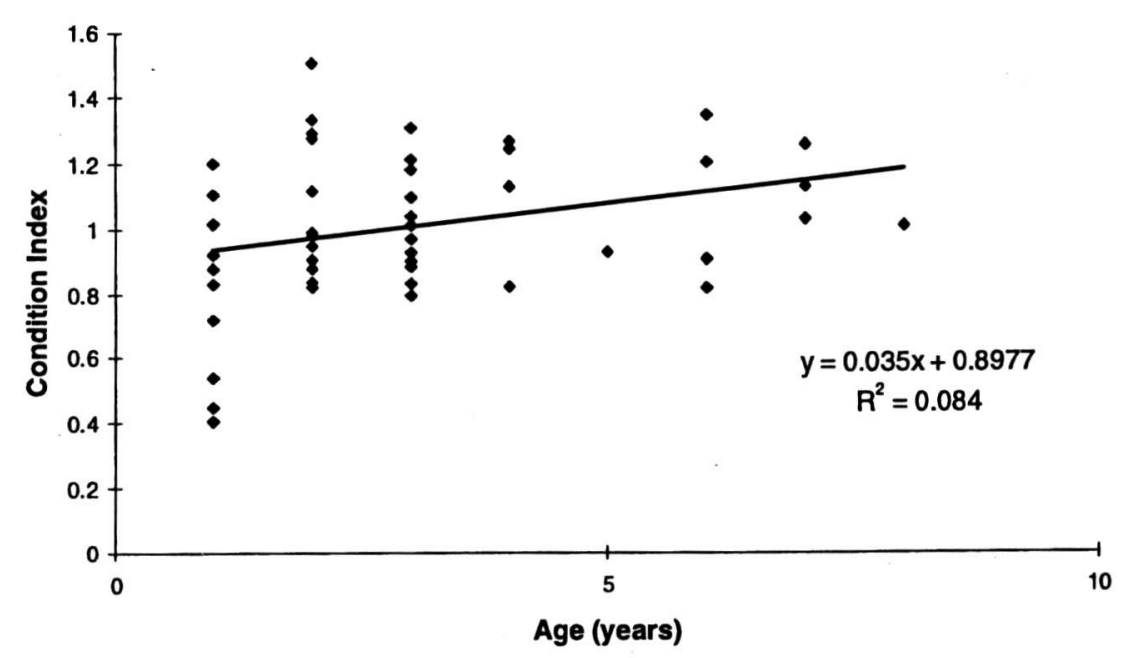

Figure 4: Condition index plotted against age.

Table 6 shows the differences in mean condition between possums of the Lower and Upper Reserve. Male and female possums of the Lower Reserve appear to be in a better condition (higher condition indices) than possums of the Upper Reserve, but the difference was only statistically significant for male possums $((\mathrm{P}(\mathrm{T}<=\mathrm{t})$ two-tail $=0.039)$.

Table 6: Testing differences in mean condition indices line 4 against lines $5+6+7$

\begin{tabular}{l|c|c|c|c|c|c}
\hline & Line 4 & Line 5 & Line 6 & Line 7 & Line 5-7 & P(T<=t) two-tail \\
\hline Males & 1.078 & & & & 0.946 & $\mathbf{0 . 0 3 9 *}$ \\
Females & 1.023 & & & & 0.993 & $\mathbf{0 . 7 9}$ \\
Combined (Males and Females) & 1.044 & & & & 0.966 & $\mathbf{0 . 2 3 6}$ \\
Combined anova for each individual line & 1.044 & 0.932 & 0.959 & 0.991 & & $\mathbf{0 . 6 4 4}$ \\
\hline
\end{tabular}


There was no difference in condition between male and female possums $((\mathrm{P}(\mathrm{T}<=\mathrm{t})$ two-tail $=$ $0.839, \mathrm{t}=2.012$, d.f. $=47$ ), a result which confirmed the independence of the condition index from sex (Table 7).

Table 7: The differences in mean condition between male and female possums and the mean condition of barren female possums with female possums carrying pouch young.

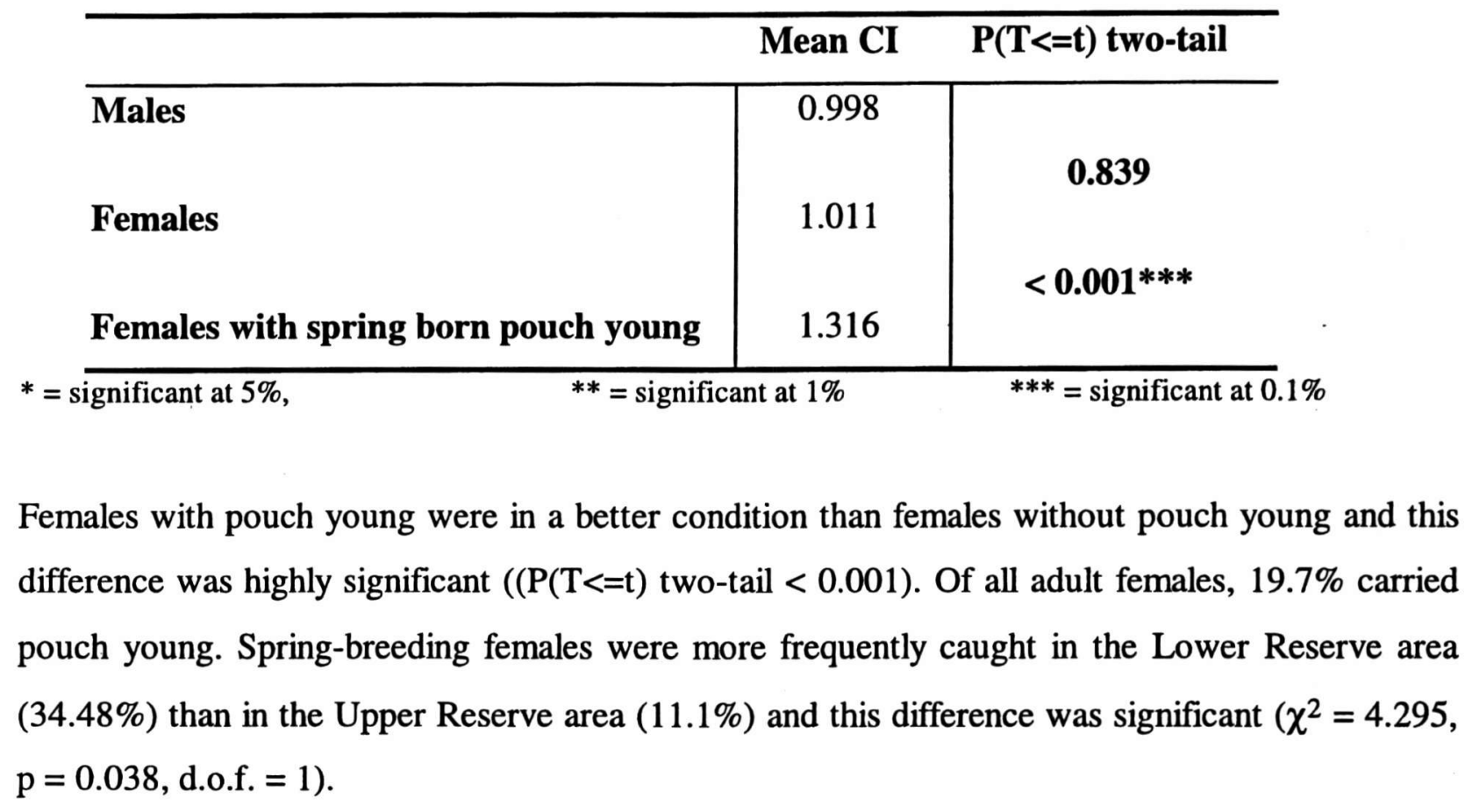




\subsubsection{Discriminating possums into age classes}

\section{Female possums}

Of the 66 females caught, 26 were of known age. The body length and weight measurements in relation to age of these 26 animals were used to separate the remaining 40 animals without known ages into appropriate age classes. As shown in Figure 5, female possums were discriminated into two age classes $(\mathrm{A}=$ juveniles $<2$ years and $\mathrm{B}=$ adults $>=2$ years $)$. The discriminant equation line in Figure 5 was established as: Weight $=38.4432-0.9013 *$ body length

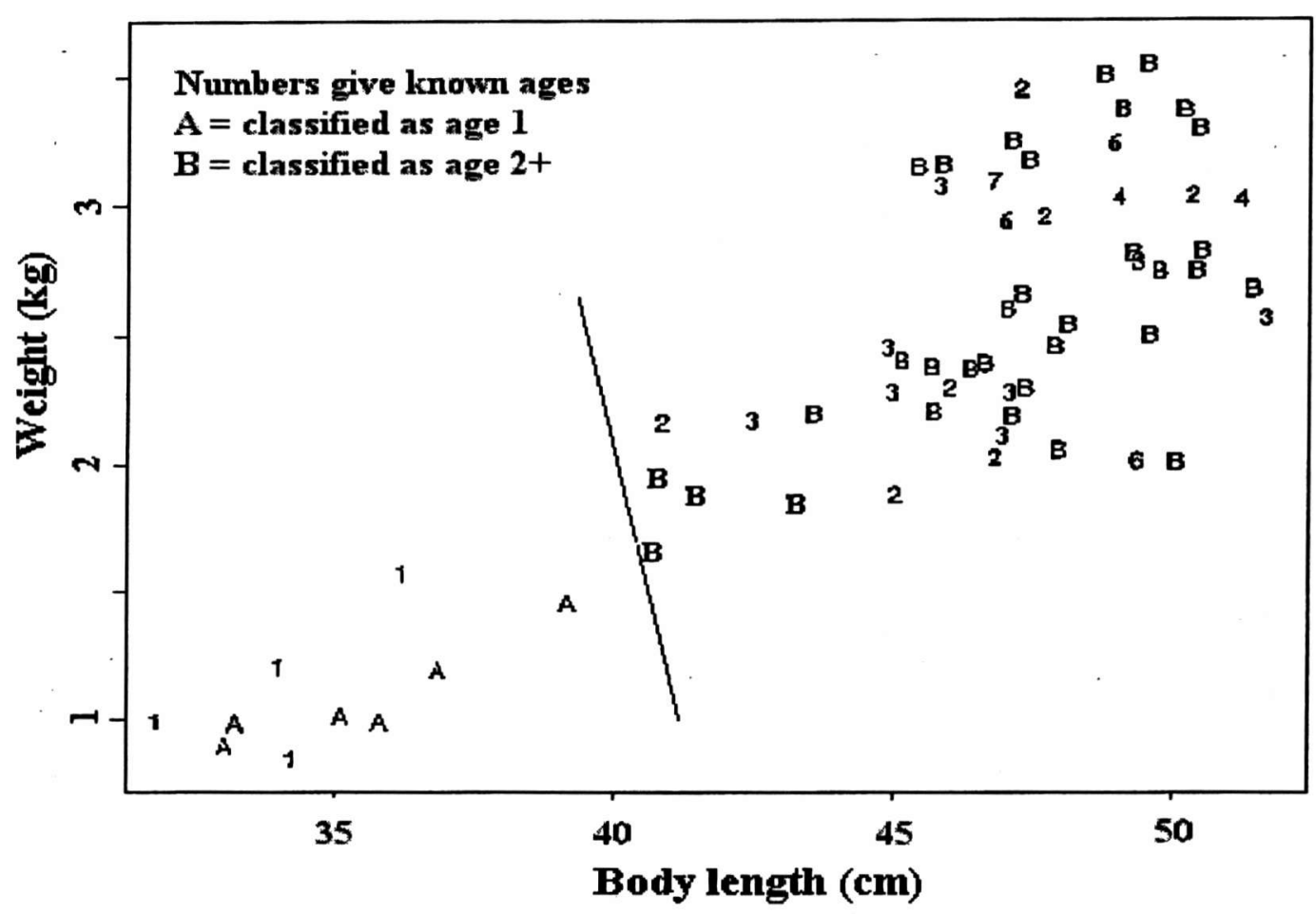

Figure 5: The weight to length relationship of female possums with known ages (numbers) is used to discriminate female possums with unknown ages into the age classes A and B. 


\section{Male possums}

Of the 79 sampled males, 23 had been accurately aged. Initially, male possums with unknown ages were also divided into two age classes $(\mathrm{A}=$ juveniles $<2$ years and $\mathrm{B}=$ adults $>=2$ years $)$ by using the body length and weight measurements of male possums with known ages. The discriminant line equation in Figure 6 separating male possums into two age classes was established as: Weight $=\mathbf{1 0 . 3 6 1 5} \boldsymbol{- 0 . 2 0 2 7} *$ body length

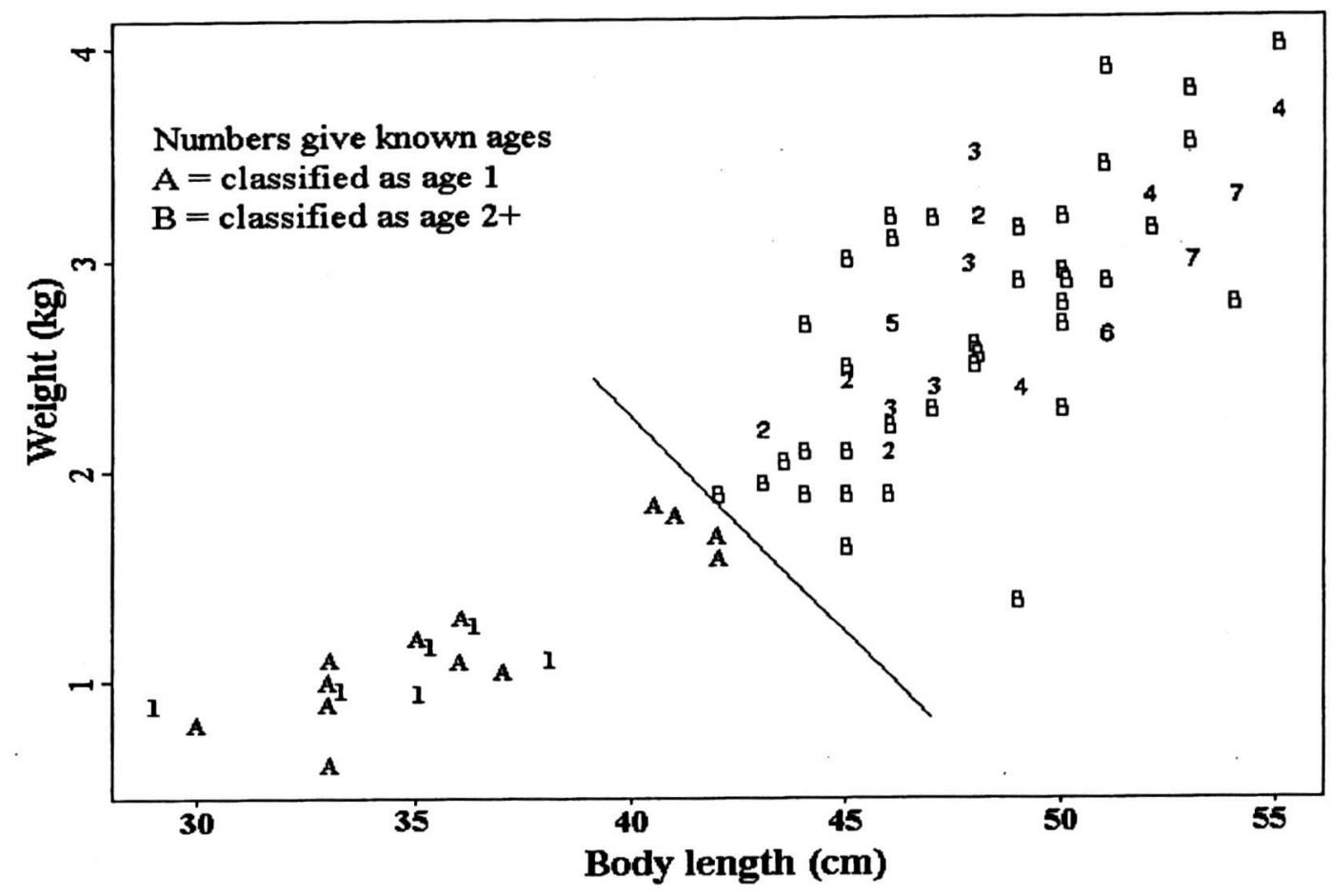

Figure 6: The weight to length relationship of male possums with known ages (numbers) is used to discriminate male possums with unknown ages into the age classes $\mathrm{A}$ and $\mathrm{B}$. 
A further analysis separated male possums into three age classes $(\mathrm{A}=$ juveniles $<2$ years, $\mathrm{B}=$ sub-adults 2 to 3 years and $C=$ adults 4 years and over). The discriminant line equations in Figure 7 were established as: Weight $=10.3615-0.2027 *$ body length for separating juveniles $<2$ years from sub-adults 2 to 3 years of age and: Weight $=24.4797-0.4457 *$ body length for separating sub-adults 2 to 3 years from adults 4 years of age and over.

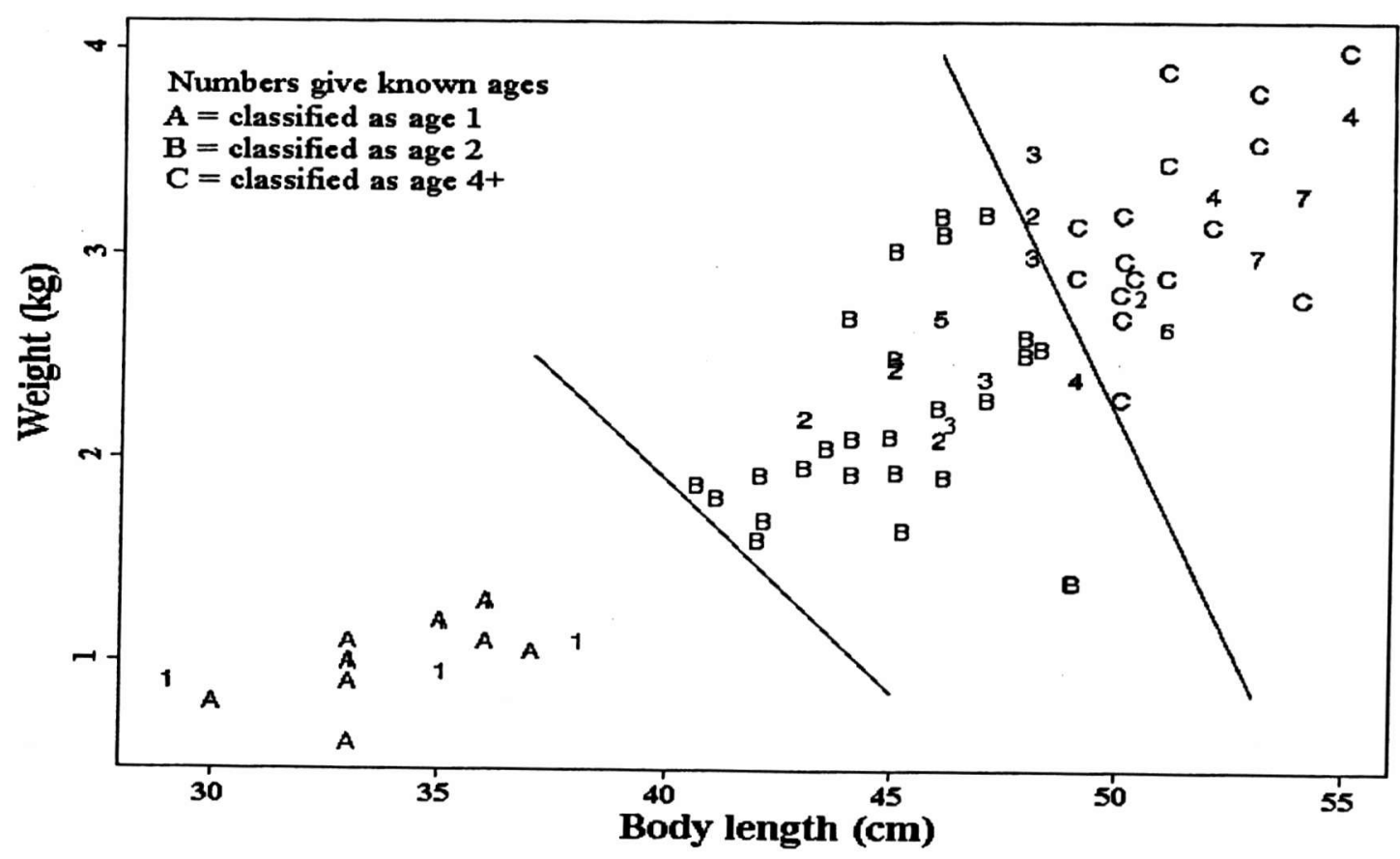

Figure 7: The weight to length relationship of male possums with known ages (numbers) is used to discriminate male possums with unknown ages into the 3 age classes A, B and C.

The body length and weight measurements of both the female and male possums could be used to accurately determine whether any specimen belonged to the juvenile or adult age group. Results from univariate tests of effects were highly significant for both variables body length and weight, and are shown in Table 8. 
The probability of being assigned into the correct age group was calculated for each animal. The mean probability of correct assignment was $99.2 \%$ and $99.6 \%$ for female and male possums respectively. The mean probability of correct assignment for male possums discriminated into three age groups was still high at $72 \%$.

Table 8: Results from univariate tests of effects showing that the variables body length and weight can be used to separate juvenile from adult possums in each of the three discriminant analyses.

\begin{tabular}{lccc}
\hline body length & F & p & d.f \\
\hline Females (2 classes) & 92.917 & $<\mathbf{0 . 0 0 1}$ & 23 \\
Males (2 classes) & 86.437 & $<\mathbf{0 . 0 0 1}$ & 21 \\
Males (3 classes) & 52.127 & $<\mathbf{0 . 0 0 1}$ & 20 \\
\hline
\end{tabular}

\begin{tabular}{lccc}
\hline weight & F & $\mathbf{p}$ & d.f \\
\hline Females (2 classes) & 34.459 & $<\mathbf{0 . 0 0 1}$ & 23 \\
Males (2 classes) & 73.434 & $<\mathbf{0 . 0 0 1}$ & 21 \\
Males (3 classes) & 40.945 & $<\mathbf{0 . 0 0 1}$ & 20 \\
\hline
\end{tabular}

A Wilks Lambda multivariate test of effects allowing for body length and weight indicated that both variables could also be used in combination to separate juvenile from adult possums. Test results are shown for each of the three discriminant analyses in Table 9.

Table 9: Results from Wilks Lambda multivariate analyses.

\begin{tabular}{lccc}
\hline Wilks Lambda body length and weight & F & $\mathbf{p}$ & d.f \\
\hline Females (2 classes) & 45.712 & $<\mathbf{0 . 0 0 1}$ & 2,23 \\
Males (2 classes) & 45.448 & $<\mathbf{0 . 0 0 1}$ & 2,20 \\
Males (3 classes) & 15.234 & $<\mathbf{0 . 0 0 1}$ & 4,38 \\
\hline
\end{tabular}




\subsubsection{Comparing male and female possums in four areas of the reserve}

Since juvenile possums could be accurately eliminated from the data set, a Wilks Lambda multivariate analysis based on the three variables weight, body length and total length could be used to test differences between sexes and differences between areas. A prerequisite for Wilks Lambda is the linearity of means for the variables which could be demonstrated for adult male and adult female possums ( $>=2$ years of age) in the four areas (Map 5). None of the three variable means displayed significant correlations, which was confirmed in a Wilks Lambda multivariate test of effects which combines all three variables $(F=0.27, p=0.982)$ while allowing for sex and area.

The summarised results for the three variables in areas 1 to 4 are shown in Table 10. The fitted means of male and female weight, body length and total length in the four areas in relation to actual means and the significance of deviation from the actual means are shown in Figure 8.

Table 10: Means and standard errors of the three morphometric variables weight, body length and total length in areas 1 to 4

\begin{tabular}{|c|c|c|c|}
\hline Weight & & Adult Males & Adult Females \\
\hline \multirow{5}{*}{ Area 1} & mean & 2.46 & 2.08 \\
\hline & S.E. \pm & 0.139 & 0.113 \\
\hline & $\mathbf{n}$ & 15 & 7 \\
\hline & Min & 1.4 & 1.7 \\
\hline & Max & 3.2 & 2.5 \\
\hline \multirow{5}{*}{ Area 2} & mean & 2.7 & 2.405 \\
\hline & S.E. \pm & 0.117 & 0.097 \\
\hline & $\mathbf{n}$ & 11 & 10 \\
\hline & Min & 2.1 & 1.9 \\
\hline & Max & 3.3 & 2.8 \\
\hline \multirow{5}{*}{ Area 3} & mean & 2.58 & 2.45 \\
\hline & S.E. \pm & 0.145 & 0.108 \\
\hline & $\mathbf{n}$ & 15 & 10 \\
\hline & Min & 1.65 & 2 \\
\hline & $\operatorname{Max}$ & 3.55 & 3 \\
\hline \multirow{5}{*}{ Area 4} & mean & 3.06 & 2.89 \\
\hline & S.E. \pm & 0.153 & 0.088 \\
\hline & n & 17 & 29 \\
\hline & Min & 1.9 & 2 \\
\hline & $\operatorname{Max}$ & 4 & 3.6 \\
\hline
\end{tabular}


Table 10 continued: Means and standard errors of the three morphometric variables in areas 1 to 4 .

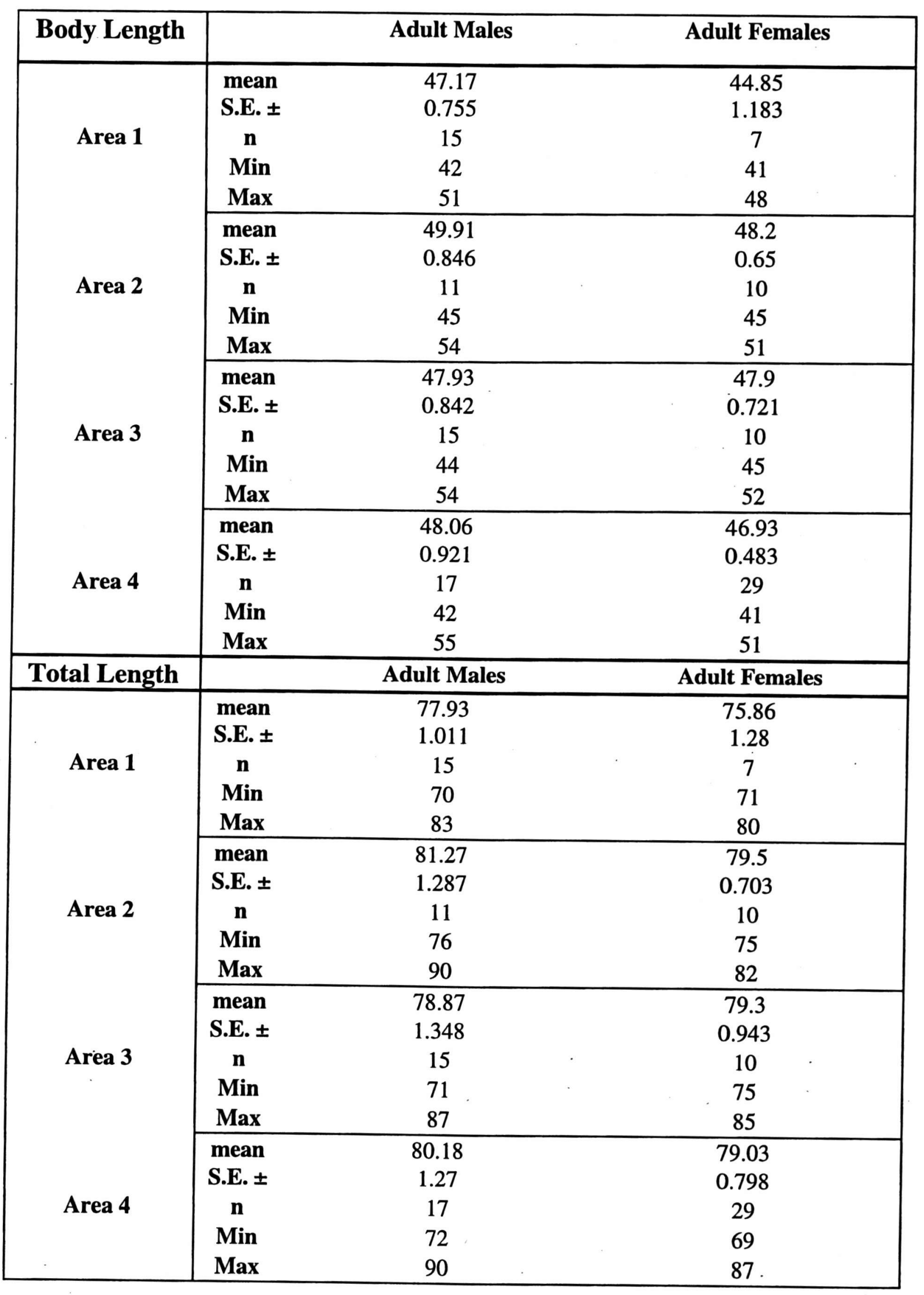



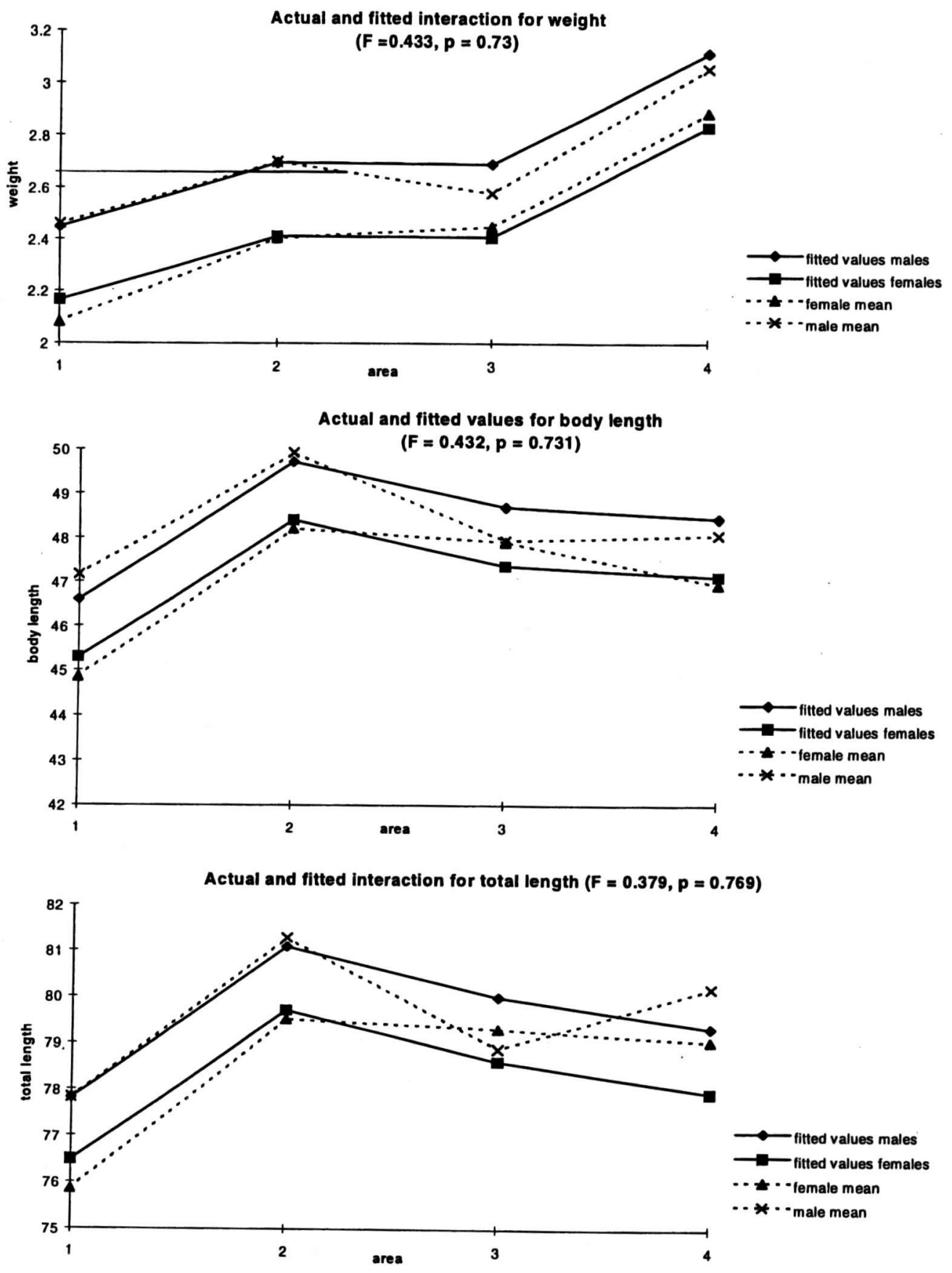

Figure 8: The fitted means of male and female weight, body length and total length in the four areas in relation to their actual means showing non significant correlations $(p>0.5)$. 
Since the linearity of means was confirmed, the data for all three morphometric variables was combined in order to:

- test differences between sexes while allowing for variations between the four areas; and,

- test differences between areas while allowing for variations between male and female possums.

Results of test statistics showing the significance of differences of mean values are shown in Table 11:

Table 11: Differences of the morphometric variables weight, body length and total length between male and female possums in the four areas. Mean values are shown in Table 10, the differences between sexes were calculated while allowing for differences between areas, and the differences between areas were calculated while allowing for the differences between sexes.

\begin{tabular}{lcc}
\hline weight & F & p \\
\hline Sex & 7.905 & $\mathbf{0 . 0 0 6}$ \\
Area & 10.893 & $<\mathbf{0 . 0 0 1}$ \\
\hline body length & & \\
\hline Sex & F & $\mathbf{p}$ \\
Area & 4.729 & $\mathbf{0 . 0 3 2}$ \\
\hline & 3.714 & $\mathbf{0 . 0 1 4}$ \\
\hline total length & & \\
\hline Sex & $\mathbf{F}$ & $\mathbf{p}$ \\
Area & 2.503 & $\mathbf{0 . 1 1 7}$ \\
\hline
\end{tabular}

Sex

There were significant differences between male and female possums in the four areas in terms of possum weight and body length. However, differences between male and female total lengths were not statistically significant. In particular, males were significantly heavier than females. Combining all three morphometric variables and allowing for differences in areas, the overall effect of sex was still significant (Wilks Lambda $F=2.924, \mathrm{p}=0.037$ ). 


\section{Area}

The obvious differences between areas (Figure 8) were confirmed when all three variables were combined. Allowing for the differences between male and female possums, the overall effect of area resulted in highly significant test statistics (Wilks Lambda $\mathrm{F}=8.774, \mathrm{p}<0.001$ ). The variables, body length and particularly weight, differed across the areas, but again there were no statistically significant differences in total length (Table 11).

Results indicated that "area" was more significant than "sex" in explaining the observed differences in mean weight and body length.

\section{Colour phases}

Of all adult possums caught in the reserve, $81 \%$ were grey in colour. As weight appeared to be the most significant variable explaining variations between sexes and between areas, the weights of black possums were compared with those of grey possums to detect any bias introduced by this morphological variation.

However, there were no significant differences in the weights of black and grey adult males and also the weight of black and grey adult females did not differ significantly $(t=0.92, p=0.36$, d.f. $=56$ and $t=-0.03, p=0.97$, d.f. $=54$ for male and female adult possums respectively). In addition there was no difference in condition between the two colour phases $(t=0.92, p=0.51$, d.f. $=47)$. 


\section{Ratios}

Of the 145 possums analysed, 114 animals (58 males and 56 females) were classed as adults. Results are shown in Table 12.

Table 12: Summary of adult to juvenile ratios in areas $1-4$.Overall there were 3.4 adults possums caught to every juvenile possum.

\begin{tabular}{|l|c|c|c|c|}
\hline & Area 1 & Area 2 & Area 3 & Area 4 \\
\hline Total adult males & 15 & 12 & 15 & 16 \\
Juvenile males & 4 & 3 & 3 & 11 \\
\hline Ratio & 3.75 & 4.00 & 5.00 & 1.45 \\
\hline
\end{tabular}

\begin{tabular}{|l|c|c|c|c|}
\hline Adult females & 2 & 6 & 8 & 15 \\
with back young & 3 & 3 & 2 & 4 \\
with pouch young & 2 & 1 & 0 & 10 \\
\hline \hline Total adult females & 7 & 10 & 10 & 29 \\
Juvenile females & 3 & 1 & 0 & 6 \\
\hline Ratio & 2.33 & 10.00 & - & 4.83 \\
\hline
\end{tabular}

\begin{tabular}{|l|c|c|c|c|}
\hline Adults total & 22 & 22 & 25 & 45 \\
Juveniles total & 7 & 4 & 3 & 17 \\
\hline Ratio & 3.14 & 5.50 & 8.33 & 2.65 \\
\hline
\end{tabular}

The lowest adult to juvenile ratio was observed in area 4 and the highest adult to juvenile ratio was observed in area 3. However, differences between the adult to juvenile ratios in the four areas were not statistically significant $\left(\chi^{2}=3.902, p=0.27\right.$, d.f. $\left.=3\right)$. 


\section{Sex ratios}

The highest male to female ratio was observed in area 1 and the lowest male to female ratio was observed in area 4 , but again differences were not statistically significant $\left(\chi^{2}=5.62, p=0.132\right.$, d.f. $=3)$.

Table 13: Summary of sex ratios in areas $1-4$. The overall sex ratio was 1.2 males to every female.

\begin{tabular}{lccccc}
\hline & Area 1 & Area 2 & Area 3 & Area 4 & Total \\
\hline Males & 19 & 15 & 18 & 27 & 79 \\
Females & 10 & 11 & 10 & 35 & 66 \\
\hline Ratio & 1.90 & 1.36 & 1.80 & 0.77 & 1.20 \\
\hline
\end{tabular}

\subsection{Discussion}

\subsubsection{Ageing Techniques}

Considering the laborious and imprecise procedures of all the available ageing techniques (Husheer 1994) and considering the requirements for this study, Winter's ageing method provided a fast and relatively reliable means of assigning ages to possums. Assuming that there are generally no morphometric differences once possums have reached their upper asymptote for a particular dimension, accurate ages for adult possums were not required. As this study aimed to analyse geographic variations, it seemed appropriate to employ the more economic approach to possum ageing. For future studies it would suffice to age a subsample of possums using Winter's method and to confirm these readings by ageing an even smaller subsample of possums using Pekelharing's etching and staining or Clout's freezing microtone technique. Any teeth within the critical 1 to 2 year age class could be routinely verified before assigning them to a final age class. Based on their morphometric measurements all other possums could then be classified into age classes using discriminant analyses. This process may dilute microgeographic differences when possums of very poor condition fall into the 1 year age class. However, the ages of possums with low probabilities of correct assignments could be further scrutinised in 
order to finalise their allocation. For this study the mean probabilities of correct assignments showed that such a bias was highly unlikely.

\subsubsection{Trapping}

The observed catch rate of $31.5 \%$ on trap lines 5 to 7 was surprisingly high, especially considering that the area had recently been used for trapping by the Karori Sanctuary Trust hunter. From September 1995, this hunter had killed about 450 possums on the north-west facing slopes along the true right of the upper Kaiwharawhara Stream, and had trapped an additional 95 possums along the spur of trap line 5 (Area 2). The hunter operated 100 leg hold traps on this spur in the nights from 17 to 19 October, just two weeks before trapping started for this study and achieved a catch rate of $31.7 \%$. The hunter then moved his traps into the vicinity of trap lines 6 and 7 (Area 3), caught an additional 55 possums during two nights, achieving a $27.5 \%$ catch rate.

Considering this recent trapping history in the area, a 31.5 percent post-operational catch rate is extremely high. It is even higher than what would be expected from a lowland forest community that had received no possum control at all ${ }^{3}$.

The data raise the question: How much was gained by removing a proportion of the possum population considering the prospect of the planned eradication campaign?

Assuming Orongorongo lowland forest possum densities of 12.3 possums/ha (Brockie 1982), the removal of about 5 possums per hectare from the Karori Reserve would have left at least $50 \%$ of the probable carrying capacity, or a breeding population in the order of approximately 7 animals per hectare.

\footnotetext{
${ }^{3}$ In 1995, the Wellington Dept. of Conservation assessed the pre-operational densities of uncontrolled possum populations in four lowland forest reserves. Catch rates for these surveys were as follows:

1. Hemi Matenga Memorial Park $\quad 17 \%$

2. Makahika Scientific Reserve $\quad 16 \%$

3. Rocky Hills Sanctuary Area $\quad 20 \%$

4. Paraparaumu Scenic Reserve $\quad 18 \%$
} 
Tyndale Biscoe (1973) emphasised the augmented breeding potential of artificially depleted possum populations, which are often well in excess of the requirements for immediate replacement. His suggestion finds support through the evidence that:

- Males are more easily trapped and disappear at a higher rate than females, thus increasing the proportion of potentially breeding individuals (Green 1984);

- The reproductive output of females in good condition is likely to be augmented leading to spring and double breeding (Bell 1981, Green and Coleman 1984, Cowan 1993, Husheer 1994); and,

- The density dependent survival of juvenile possums is also going to accelerate the recovery of the reduced population (How 1979).

In addition to an increased breeding potential and decreased juvenile mortality, high reinfestation levels will further augment population recovery. Re-invasion from surrounding habitats is a function of the exponentially increasing boundary to area ratio, which presents an inherent possum control problem in small reserves and areas where possums were only locally removed.

Open and dry areas with large scattered trees offer good possum habitat and den sites. Cowan (1989) found more than $90 \%$ of all den sites in the Orongorongo Valley in trees larger than $50 \mathrm{~cm} \mathrm{cbh}^{4}$. The availability of suitable den sites has also been suggested as a density dependent mortality agent (Green 1984, Triggs 1982, Clout 1977). If hunters target these easily accessible and open habitats supporting high possum densities, they will create localised vacuums of reduced densities in areas offering abundant den sites and ample food supplies. Efford (1995) found that over $10 \%$ of tagged possums in the periphery of an intensively controlled area near Dunedin shifted towards or into the vacant space during three months following control.

The vegetation on the spur along line 5 and most of line 6 consisted of large branching bishop pines with an understory of native plant species. Line 7 followed the Kaiwharawhara Stream below the Upper Reserve dam through a vegetation of mahoe and fivefinger with interspersed tree fuchsia. In November, pine trees finish shedding their pollen and the deciduous tree fuchsia come into leaf. In this regard, all three lines 
sampled possums in habitats where highly utilised seasonal food plants and mature denning trees were available. This partly explains the very similar trap successes (Tables $4+5$ ) and very high catch rates on lines 5 to 7 . Reinfestation levels into these areas are probably even more pronounced than observed elsewhere (Efford 1995) as peripheral possums are encouraged to migrate from less suitable into optimal habitats. Possums were caught on highly preferred trees (i.e. pine) as often as on less preferred trees (i.e. mahoe), suggesting that the suitability for climbing (circumference and softness of the bark) is more important than the palatability of the tree's foliage. For trapping this means that the strategic location of a tree and not the tree species should determine which tree is selected for placing a trap on.

The objective of alleviating browse pressure on tree fuchsia by removing a proportion of the possum population in the reserve seemed to have failed. Benefits were very short term and almost negligible, but the costs may have been high.

In the initial control period the Karori Sanctuary hunter frequently abandoned his hydrogen cyanide lines because he claimed they "rained out". In other words, he expected very low kills because his cyanide was leached out by the rain and lost toxicity.

Possums consuming sub-lethal amounts of cyanide learn to recognise and avoid the toxin. Cyanide paste is easily detectable by possums as it produces cyanide gas (HCN). In forests where cyanide had been used for several years, Warburton (1996) found up to $60 \%$ of possums were cyanide-shy. Warburton and Drew (1994) showed in pen trials that cyanide shyness was not a result of bait aversion (most possums still ate non toxic bait) but a direct rejection of the toxin.

Morgan (1995) found 64\% of captive possums refused cereal 1080 baits once they had been fed sub-lethal doses. Three months later, most possums were still reluctant to ingest such baits. Changing the flavour or toxin did not change the observed avoidance behaviour but when the bait type was changed from cereal based pellets to carrots, most possums ate the bait again. Morgan's (1995) experiment confirmed Warburton and Drews' (1994) observation that possums, rather than becoming neophobic, actually

\footnotetext{
${ }^{4}$ circumference at breast height
} 
learnt to recognise the bait. Avoidance behaviour could be increased by adding the green dye of the original sub-lethal baits thus further underpinning the learnt recognition behaviour. By simulating the spread of learnt and innate behavioural resistance, Hickling et al. (1996) and Hickling (1995) showed that learnt aversion persisted a year or more and had the potential to reduce the efficacy of annual control by more than $30 \%$.

This evidence has important implications for the Karori Reserve because the objective is not sustained maintenance control but eradication. Using toxins in an irresponsible manner, as may have happened in the reserve, will lead to poison and even trap and human shyness and some animals may now be difficult to kill. Considering the task of eradicating possums from the reserve the population should be kept as naive towards control methods as possible. For this reason the control operation was most definitely not worth the effort nor the cost.

\subsubsection{Comparing the condition and morphometrics of possums in four areas of the reserve}

All possums were obtained from a single and relatively small catchment. Therefore environmental variables influencing possum condition and size, such as annual precipitation and temperature, are unlikely to have effected the observed differences. As genetic differentiation of subpopulations is unlikely in such a small survey area, this factor can also be discarded as an explanation for the observed spatial variations. Vegetation types and associated food supplies, aspect and solar radiation, available shelter and protection from exposure, are key environmental variables determining quality of habitat. These variables, together with the likely exposure of possums to human impact and control, may best explain the observed microgeographic variations in possum growth and condition in the Karori Reserve.

\section{Condition Index}

The condition index calculated in this study was shown to be independent of sex. However, the regression of condition index with age showed a significant correlation indicating that the index was not independent of age. This deviation from the expected may have originated from the small sample size but is more likely to show that the 
Weibull regression line overestimated the weight increment of juvenile possums and levelled off too soon. This result suggested that more accurate results could be expected from multivariate comparisons based on morphometric measurements and using the total sample size.

Husheer (1994) calculated condition indices for possums in Hohotaka and Waihaha using the. Weibull regression. He found possums in Hohotaka grew until they were 3-4 years of age, whereas possums in Waihaha did not stop growing until 6 to 7 years of age. He suggested seasonal food restrictions as a likely explanation for the slower growth of Waihaha possums. However, in his study Waihaha possums were heavier than Hohotaka possums, making seasonal food shortage an unlikely explanation for the more extended period of growth.

Being based on a large sample size, the shape and scale of Husheer's growth regression curves represent very accurate possum growth trajectories. However with increasing age the sample size declined and not many possums over 8 years of age were sampled.

A better explanation for the apparently continuing growth is that old possums had to be of heavy weight and in good condition earlier in their lives in order to survive this long. The mean weight of the population increases with age, only because possums of poorer condition and lighter weight are gradually lost from the population. The average possum therefore stops adding weight (stops growing) before the upper asymptote of weight is reached. This implies that the growth process may be completed much earlier than interpreted from Husheer's non-linear regressions.

Efford and Hearfield (1992) found from data collected in the Orongorongo Valley between 1966-91 that body weight of possums increased with age up to 4 years while population numbers and condition were largely maintained. Bell (1981) found possum recruitment in the same study to barely compensate for the mortality of older possums. Female breeding success was relatively low with spring births being rare.

In this study, male possums reached a higher asymptotic maximum but it took them about one year longer to arrive at that level. Male possums increased with age up to 
three years and female weight increased with age up to two years. Bearing in mind the relatively small sample size this suggests rapid growth. However, it also has to be emphasised that by weighing animals with their stomachs, a bias towards the time of capture had been incorporated. A possum caught at dusk is prevented from feeding and may be significantly lighter than if it was caught at dawn and had fed throughout the night.

\section{Morphometrics}

The multivariate morphological comparison of mature male and female possums from various areas of the reserve reveals that "area" is a more important denominator for size and weight than "sex". Considering that male possums are on average larger and heavier than female possums, this result emphasises the importance of microgeographic variations in determining possum growth and condition in the reserve.

\section{(a) Weight}

Possums of the Lower Reserve area were on average heavier than possums further up the valley. The relatively small Lower Reserve area is likely to provide a larger variety of foods than the upper reaches of the catchment. The vegetation surrounding the Lower Reserve consists of mature native forest along the north-western face, pine forest along the south-eastern face, gorse and broom dominated shrublands at the northern end, and a mixture of native and exotic plants in gardens of the urban surround. The native forest provides a wide array of palatable food plants (kohekohe, fuchsia, titoki, supplejack etc.). These food sources are complemented by the seasonal availability of exotic food items such as pine pollen, gorse and broom flowers. In addition, fruit, vegetables and ornamental garden plants from the suburban environment may also be available to Lower Reserve possums.

No weight differences were identified between black and grey colour morphs. However, fewer black possums were caught in the Karori Reserve than recorded in other locations of the Wellington region (Wodzicki 1950, Cowan 1990). Black possums were introduced from Tasmania where the genes associated with melanism are linked to high humidity environments and wet forests (Kean 1971). Grey. possums were introduced 
from mainland Australia but mixing of the two stocks has occurred in New Zealand (Pracy 1974). In the reserve, most possums were grey indicating that the genes expressing the black phenotype and any linkage of genes responsible for tolerating high levels of humidity were of no selective advantage. As the two main colour morphs interbreed in the relatively small reserve, many black possums are likely to be heterozygous for this trait. This would explain their morphological similarity to the majority of grey possums.

\section{(b) Ratios}

Food availability may only partly account for the observed weight gradient and the higher fecundity of possums in the Lower Reserve. There was also a higher proportion of females and juveniles caught in the Lower Reserve than in the sampled areas of the Upper Reserve. This evidence suggested that the Lower Reserve possums displayed most profoundly the characteristic compensatory response symptoms of a population maintained below its carrying capacity. Both the environmental conditions and the control of possums in the Lower Reserve contribute to these observed differences.

\section{(c) Fecundity}

Female spring breeding occurrence was significantly higher in the Lower Reserve (34.48\%) than in the Upper Reserve (11.1\%) further supporting the evidence of a compensatory response. However, the overall fecundity of Karori possums was high, suggesting a healthy population in good condition. As possums were only sampled once in spring the precise proportion of females breeding in autumn could not be established. However, many females were still lactating suggesting that they had just weaned off their young. Of all adult females sampled in the reserve $18.2 \%$ still carried back young, and $19.7 \%$ of adult females carried spring born pouch young.

In comparison with other studies, Green (1984) found that females in colonising populations and populations in exotic forests or pasture/scrub habitats tend to breed in spring more often (mean 13\%, range 2-33\%) than females in established populations in indigenous forest (mean $=1 \%$, range $0-3 \%$ ). The mean contribution of spring births to total yearly births was $18 \%$ for seven Australian studies (Green 1984). 
The main season of birth in New Zealand and Australia is in the autumn months of April, May and June (Crawley 1973, Hocking 1981, How 1981, Bell 1981, James 1985, Cowan 1993, 1984), when 80 - 100\% of all adult female possums breed. Even though autumn breeding seems not to be adversely affected by density and quality of habitat (Cowan 1993, 1984), these variables largely determine the occurrence of spring births. Spring breeding, which can be associated with early breeding in the previous autumn, is characteristic of colonising populations where the quality of habitat and low densities produce females of high body weight and good condition (Green 1984). This suggestion is supported by the trends observed in this study. It appears that food supplies ultimately determine the reproductive rate and success of possums.

Considering the independence of the autumn birth pulse from habitat and density, it seems reasonable to assume that most female possums carrying pouch young in Karori in 1995 were breeding for the second time. As stated above, the overall contribution made by spring births to the total reproductive output of Karori possums is high by New Zealand standards. Lower Reserve possums contributed most to this output.

\subsection{Summary:}

Possums within the Karori Reserve display marked microgeographic morphological variations exceeding that expected through sexual dimorphism. This finding confirmed the first hypothesis that possums would be in better morphological condition in the Lower than in the Upper Reserve. These variations are likely to be induced by lower possum densities maintained through poisoning of animals in the Lower Reserve area. This is likely to enhance the condition of the forest as stated in the second hypothesis of this chapter. Even though the second hypothesis could not be tested, the combination of more mature forests with lowered possum densities in the Lower Reserve area is likely to enhance the quality of possum habitat. The more mature forest of the Lower Reserve recovers from possum browse and will provide a larger variety of possum foods than the regenerating forest in the upper reaches of the catchment. These two factors, forest maturity and lowered possum density, will contribute significantly to the differences observed between areas. 
Possums in the Lower Reserve were significantly larger and more fecund than possums of the Upper Reserve which confirmed the first hypothesis. They were also of better morphological condition. These two factors together with a higher proportional representation of females and juveniles in the Lower Reserve, supporting the third hypothesis, suggests a compensatory response of the population to sustained possum control.

Possums were smallest along the windswept southern fringes of the Upper Reserve which is again likely to be a reflection of the relatively poor habitat quality. However, comparing the Karori possum population as a whole with other study areas revealed that animals matured quickly (males take three years and females two years to reach their upper asymptote for weight).

Also, the reproductive output of the Karori Reserve possum population as a whole was high with $19.7 \%$ of all females carrying spring born pouch young. This overall effect can largely been accredited to the heterogeneous vegetation cover of the urban fringe offering a variety of seasonally abundant food plants. Interspersed large pine trees offer good denning sites in a dry environment and provide shelter and protection. Also possum numbers in the Upper Reserve area are likely to have been markedly reduced through both legal and illegal trapping and poisoning over recent years. 


\section{Chapter 4}

\section{Spring food of possums in the Karori Reserve}

\subsection{Introduction}

The spring diet of possums caught in the Karori Reserve was assessed to estimate how much of the observed defoliation of fuchsia trees could be attributed to possum browse. A further aim was to determine the seasonal importance of other plant species utilised by possums. Possums have been known to travel long distances to feed in areas offering seasonally abundant food sources (Sherley 1992, Triggs 1982), and such areas could be targeted particularly in the final stages of a planned eradication program.

There are various methods of determining the impact of herbivores on food plants. These methods include direct observation, and the indirect assessment of diet by stomach or by faecal analysis. Possums are nocturnal animals spending $80-85 \%$ of their time in the upper tree canopies (Cowan 1990) and only 8.9\% of their time on the ground (McLennan 1984). This arboreal habit makes direct observation of their feeding behaviour extremely difficult. Therefore, in this study an indirect method was adopted which involved the macroscopic analysis of stomach contents of possums caught in the 1995 control operation. This method was adopted because plant materials found in stomachs are more readily identifiable than plant fragments found in faeces, which makes the proportional contribution of a plant species encountered in a stomach a better reflection of the proportion to which the plant species was utilised.

A major problem with the analysis of faeces is the differential digestibility of food plants, for this complicates the interpretation of the data (Owen and Norton 1995, Fitzgerald 1976). In order to correct for the differential digestibility of ingested food items, Dunnet et al. (1973) developed an index of digestion for species commonly eaten by possums. This allowed them to deduce the proportions in which species were eaten from the proportions of leaf fragments found in the faeces. While acknowledging that the corrected results were more 
accurate, Fitzgerald (1976) emphasised the limitations of such indices because of variables inherent in the plant, the animal eating the plant and the technique used to prepare faeces for microscopic examination. All these variables were beyond the control of the researcher.

In stomach content analysis, the differential digestibility of food items is less of a problem (Speed 1986). Because food items found in stomachs have not yet completed the digestive process, they retain their natural colours and characteristics and can be assessed under a dissecting microscope, often under low magnification. Stomach contents are therefore likely to reflect more accurately what was actually ingested by the animal.

\subsection{Methods}

Forty-nine possum stomachs were collected in conjunction with the Wellington Regional Council and Karori Wildlife Sanctuary Trust possum control operation. Stomachs were individually labelled and preserved in $70 \%$ isopropanol for later laboratory analysis.

As most stomach content analyses are slow and time consuming, a simple point analysis method was employed. The method was adopted from a standard vegetation sampling

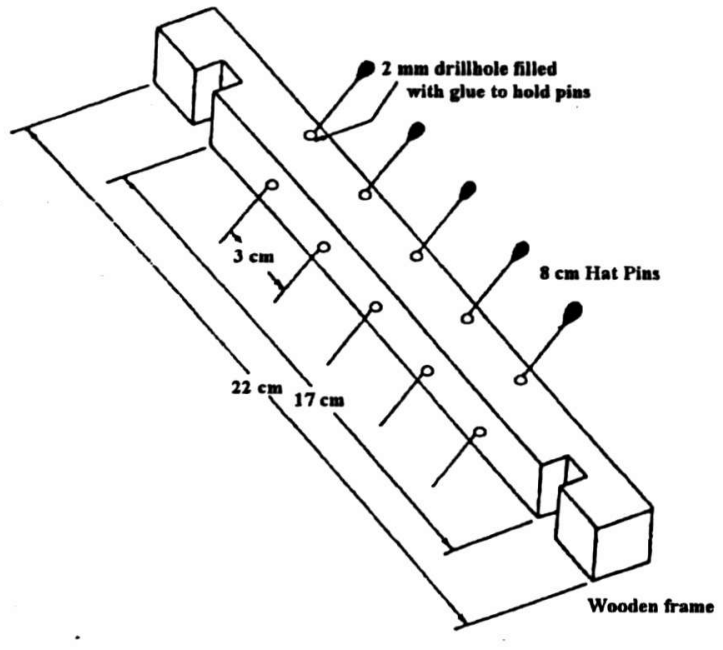

Figure 9: Rear view of the sampling device. technique developed by Chamrad and Box (1964) for rumen contents. This method uses a frame containing five regularly spaced metal pins, placed through a wooden bar at a 45 degree angle as the sampling device (Figure 9). This device is fitted to slide along the rim of a laboratory tray (Figure 10). The length of the rim is graduated into 20 equal units to allow for 20 locations of the sampling frame. Each sampling run therefore consists of 100 observations, five (the pins) by twenty (the graduations), recording scored plant materials as a percentage occurrence. 
To simplify identification of plant materials each stomach content was washed through a $2 \mathrm{~mm}$ sieve to remove all particles too small for direct identification under a dissecting microscope. To reduce bias from preferentially selecting particularly large particles, the filtrate in the $2 \mathrm{~mm}$ sieve was then washed through a $4 \mathrm{~mm}$ sieve into the laboratory tray so that all scraps of leaf in the tray ranged from

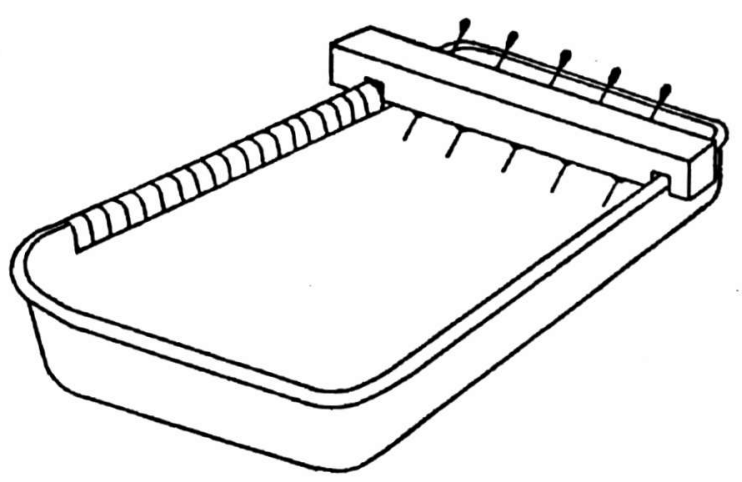

Figure 10: Laboratory tray with 20 graduations on its rim for locating the positions of the sampling device. approximately $2 \mathrm{~mm}^{2}$ to $4 \mathrm{~mm}^{2}$.

Water was added to the filtrate until the solution reached the metal pins of the sampling device.

The method of selecting leaf scraps was based on the assumption that the proportional representation of species was the same for all leaf fragment size classes. It is possible however, that certain plant species are more susceptible to fragmentation than others, or simply of very small size. Indeed, it was noticed that many stomachs contained large amounts of a yellow paste, which was later identified as Pinus muricata pollen. As this pollen was far too small to be scored, a percentage of the pollen volume was estimated for each stomach where pollen was encountered. Once the pollen was washed out, the remaining food particles of appropriate size class were analysed.

Plant fragments were selected by positioning the wooden bar of the sampling device on one of the graduations marked along the rim of the sampling tray and removing the plant fragment closest to each pin. This process of selection was repeated each time the bar was repositioned along the graduations. The selected plant fragments were transferred into an observation dish filled with a small quantity of water. Plant species were identified by studying features such as leaf margins, hairs, venation patterns, oil glands and the colour and texture of fragments. The identification was carried out using reference samples of plant species collected in the Karori Reserve. Reference samples were prepared from fresh leaf material which was macerated and stored separately for each plant species in $70 \%$ 
isopropanol. Victoria University of Wellington herbarium specimens were also consulted for species identification.

\subsection{Results}

Map 6 shows the percentage occurrence of the most abundant plant fragments and the percentage of possums that ate these plants for each of the four areas. Of the 49 possum stomachs collected, 33 stomachs contained fresh food fragments which could be used for analysis. The remaining 16 stomachs were virtually empty and could not be used for analysis.

Leaves represented the most abundant food items though flowers (mainly of the broom Cytisus scoparius) and pollen of the bishop pine (Pinus muricata) were also an important dietary component.

In total, 21 plants contributing $94.4 \%$ of all plant fragments were identified to species level. However, as all monocots were grouped and not further identified $(0.41 \%$ of all scored leaf fragments) and as some flowers, fruits, ferns, leaves and petioles could not be identified (another 3\% of all scored leaf fragments), the total number of plant species is likely to have been somewhat higher.

On average, four plant species per stomach were identified (range 1 to 11). However, many species occurred in very small quantities and could have been unintentionally ingested by the possums. Excluding all food fragments contributing less than or equal to $5 \%$ to any one stomach reduced the average number of plant species per stomach to three (range 1 to 6). Even though more than 21 plant species were eaten, the two most preferred species, Fuchsia excorticata and Cytisus scoparius, contributed over $40 \%$ of leaf fragments in the possum diet.

The bulk forage for most possums came from a single plant species. Of all possums caught, $73 \%$ had obtained half their forage from a single plant species and $48.5 \%$ had obtained more than $3 / 4$ of their forage from a single plant species. 
Of all scored fragments fuchsia leaves (Fuchsia excorticata) and broom flowers (Cytisus scoparius) were encountered most often (21.2\% and $19.1 \%$ respectively, refer Table 14$)$. Other identified fragments belonged to wineberry (Aristotelia serrata) $8.8 \%$, karamu (Coprosma robusta) 7.8\%, barberry (Berberis darwinii) 7.7\%, houndstongue (Phymatosorus diversifolius) 6\%, fivefinger (Pseudopanax arboreus) petioles $5.2 \%$, gorse (Ulex europaeus) flowers $4.4 \%$, and the tree fern mamaku (Cyathea medullaris) $4.2 \%$.

\section{Fuchsia:}

Fuchsia leaf fragments were encountered in all four sampling areas. Fuchsia was a dietary component in $39 \%$ of all sampled stomachs. Fuchsia was least utilised in areas 1 and 2 (Map 6) where the tree is relatively rare. In areas 3 and 4, fuchsia was the major food item and was encountered in $50 \%$ and $83 \%$ of all stomachs respectively. Of the 13 possums caught with fuchsia leaf remains in their stomachs, four possums had browsed almost exclusively on fuchsia. Fuchsia contributed half the forage for a further three possums for the night when they were caught.

\section{Exotic plants:}

Of all species identified in the samples, $23 \%$ were not native. These plant species were broom (Cytisus scoparius), berberis (Berberis darwinii), gorse (Ulex europeaus) bishop pine (Pinus muricata) and Trifolium species. Broom, berberis and gorse fragments contributed $31.3 \%$ of all scored plant fragments. 
Map 6: Main food items found in stomachs of areas 1 to 4 .

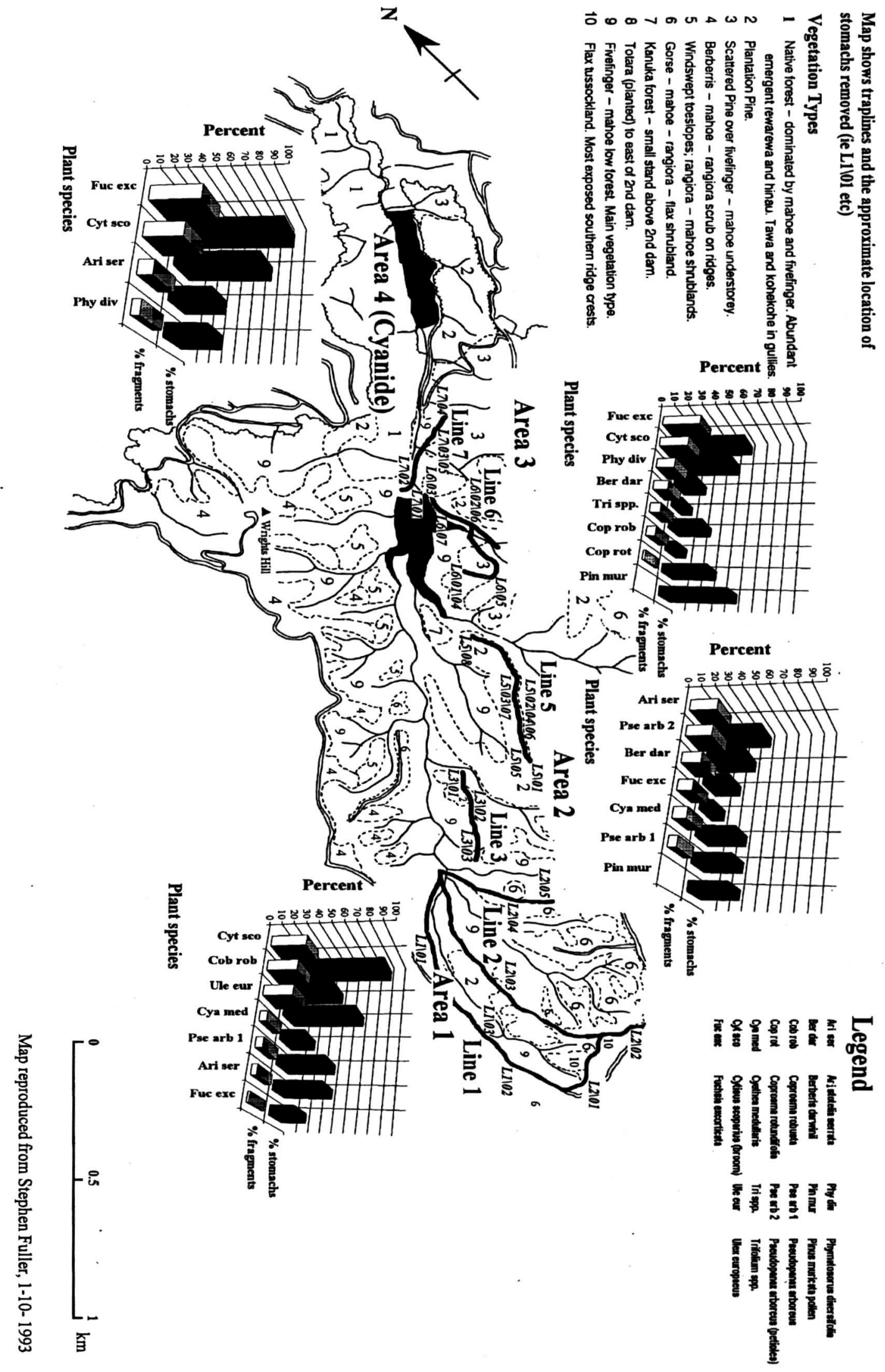


The contribution of pine fragments and Trifolium was negligible. However, as pine pollen could not be scored in the plant fragment category, this underestimates the total contribution of exotic plants to possum diet. Of all sampled stomachs, $27 \%(n=9)$ contained pine pollen. On average, pollen made up $72 \%$ of the contents of these stomachs. Of the nine possums utilising this food source, six possums had foraged exclusively on pine pollen the night they were caught. Possums foraging on pine pollen were only caught in areas 2 and 3 (Map 6; Table 15). 
Table 14: List of species encountered in stomachs of Karori Reserve possums caught in November 1995. Each stomach contributed 100 plant fragments to the total sample. On average, four plant species per stomach were encountered (see text).

$$
\mathbf{n}=33 \text { stomachs }
$$

Fuchsia excorticata

Cytisus scoparius (broom) flowers and leaves

Aristotelia serrata

Coprosma robusta

Berberis darwinii

Phymatosorus diversifolius

Pseudopanax arboreus (petioles)

Ulex europeaus (flowers)

Cyathea medullaris

Pseudopanax arboreus (leaves)

Trifolium spp.

unidentified petiole

unidentified leaves

Pine needles + particles

Coprosma rotundifolia

Blechnum discolor

Ripogonum scandens

Asplenium bulbiferum

Monocotyledons

unidentified fern

unidentified fruit

\begin{tabular}{l}
\hline Weinmannia racemosa \\
\hline unidentified flower \\
\hline Brachyglottis repanda \\
\hline Melicytus ramiflorus \\
\hline Podocarpus totara \\
\hline Carpodetus serratus \\
\hline Asplenium polyodon
\end{tabular}

Pinus muricata pollen

\section{$\%$ plant fragments \% of stomachs}

21.21

39

19.14

42

8.80

24

7.79

12

7.70

15

6.03

12

5.18

4.41

9

4.29

9

3.27

18

2.67

21

2.11

2.10

15

1.18

33

0.64

0.52

0.41

0.41

0.41

0.41

0.37

0.30

0.23

0.19

0.11

0.07

0.04

21

12

6

6

3

9

0.04 
Table 15: Summary of major plant species identified from possum stomachs in areas 1 - 4 (Map 6). (Species contributing less than or equal to 5\% of plant fragments have been omitted.)

\section{Area $1(n=5)$}

Cytisus scoparius (flowers)

Coprosma robusta

Ulex europeaus (flowers)

Pseudopanax arboreus (leaves)

Cyathea medullaris

Cytisus scoparius (flowers)

Ulex europeaus (flowers)

Coprosma robusta

Pseudopanax arboreus (leaves)

Aristotelia serrata

Cyathea medullaris

Fuchsia excorticata

Ripogonum scandens

Blechnum discolor

unidentified leaves

Brachyglottis repanda

Pine needles + particles

Average plant species per stomach

Area $3(n=12)$

Fuchsia excorticata

Cytisus scoparius (flowers)

Phymatosorus diversifolius

Berberis darwinii

Trifolium spp.

Coprosma robusta

Fuchsia excorticata

Pinus muricata pollen

Cytisus scoparius (flowers)

unidentified leaves

Coprosma rotundifolia

Trifolium spp.

Pine needles + particles

Phymatosorus diversifolius

Pseudopanax arboreus (leaves)

Monocotyledons

unidentified fern

\% Plant fragments
28.74
24.35
23.75
6.19
6.19

Percent of stomachs

80

60

40

40

40

20

20

20

20

20

20

20
Area $2(n=10)$

Aristotelia serrata

Pseudodopanax arboreus (petioles)

Berberis darwinii

Fuchsia excorticata

Cyathea medullaris

Pseudopanax arboreus (leaves)

Aristotelia serrata

Pseudodopanax arboreus (petioles)

Cyathea medullaris

Pseudopanax arboreus (leaves)

unidentified leaves

Pinus muricata pollen

Berberis darwinii

Pine needles + particles

unidentified fern
\% Plant fragments

20.96

19.98

14.87

11.57

10.57

6.61

Percent of stomachs

40

30

30

30

30

30

20

20

20

Average plant species per stomach

3

Area $4(n=6)$

\% Plant fragments

27.88

21.00

13.67

11.11

8.00

6.82

Percent of stomachs

50

50

42

42

33

25

25

17

17

17

17
Fuchsia excorticata

Cytisus scoparius (flowers)

Aristotelia serrata

Phymatosorus diversifolius

Fuchsia excorticata

Cytisus scoparius (flowers)

unidentified petiole

Aristotelia serrata

Phymatosorus diversifolius

unidentified leaves

Weinmannia racemosa

unidentified fruit

unidentified flower

Berberis darwinii

Melicytus ramiflorus

Podocarpus totara

Coprosma robusta

Pine needles + particles

unidentified fern

Carpodetus serratus

Cyathea medullaris
\% Plant fragments

38.67

29.50

11.50

6.67

Percent of stomachs

83

67

50

33

33

33

33

33

33

33

33

33

17

17

17

17

17 
European broom (mainly the flowers) was the most widely utilised exotic plant species and a dietary component in $42 \%$ of all sampled stomachs. Broom, which flowers from September to April (Webb et al. 1988), was most heavily utilised along the periphery of the reserve (areas 1 and 4) where it grows abundantly. Broom was not encountered in any stomachs from area 2, which consists mainly of a tall pine forest with native undergrowth. Broom was also an important food source in area 3 where it grows along the shoreline of the Upper Reservoir. Here, a whole suite of seral adventive species compete for the open space created by the lowered waterlevel.

No faunal remains were encountered in any of the stomachs analysed. Also, fruit $(0.4 \%$ of all fragments encountered in $9 \%$ of all stomachs) does not appear to have been an important dietary component in spring for possums in the reserve.

\subsection{Discussion}

To determine the impact of possums on particular food plants, it is important to analyse their diet in order to deduce food preferences and to quantify the availability of food plants within the animal's range. However, conducting a quantitative vegetation survey capable of determining the relative plant biomass of species affected by possums was outside the scope of this project.

For the relatively rare tree fuchsia which most abundantly occurred in the sampled possum stomachs, it was evident that the impact of possum browse must be severe. Though not formally quantified, I would estimate fuchsia to contribute less than $1 \%$ of the total foliage available in the reserve. In contrast, fuchsia leaves made up $21.1 \%$ of all leaf fragments and occurred in $39 \%$ of all stomachs, so that the species represented one of the most preferred spring foods.

The degree of utilisation of fuchsia foliage by possums correlated with the plant species occurrence and condition in the reserve. In spring, many fuchsia trees are completely defoliated by possums as soon as the deciduous trees develop leaves. This high level of defoliation was mainly observed in area 3 where fuchsia leaves will not be available as a 
food source to possums later in summer. In area 4, some fuchsia with healthy canopy is still present and fuchsia leaves represented the most preferred food item in this area.

The maintenance of lower possum population densities in the Lower Reservoir area may alleviate the impact on individual trees. In areas of the Upper Reserve, where more possums share less fuchsia trees, the browse impact may well exceed levels from which individual trees can recover.

Other native tree species also seemed to be over-represented in possum stomachs relative to their abundance in the forest. Wineberry (Aristotelia serrata) was found in $40 \%$ of all stomachs in areas 1 and 2, and represented the most abundant food fragment (21\%) in area 2. Also in area 4, wineberry was one of the major food items. However, mature wineberry trees are rare in the reserve and only saplings of this species are encountered relatively frequently along the bush margins.

Fivefinger (Pseudopanax arboreus) petioles represented $5.2 \%$ of all leaf fragments and were a particularly popular food source in area 2 (20\% of fragments in $30 \%$ of all stomachs). Even though fivefinger is relatively abundant in the reserve, the feeding behaviour of possums may have a severe impact on fivefinger, especially in spring. Extracting plant carbohydrates by severing leaf petioles is a particularly uneconomic way of feeding and relatively small quantities of petioles are likely to equate to large amounts of uneaten leaves. Large aggregations of entire compound fivefinger leaves dislodged from trees were frequently noticed on the ground and one can only speculate what long term effects this type of defoliation will have on the fivefinger population in the reserve.

\section{Importance of exotic plant species}

Fragments of exotic species accounted for a high proportion of possum diets in the reserve (23\% of species contributing $31.3 \%$ of fragments and pine pollen not included in the score). Whereas the bulk of native plant fragments in the diet were leaves, exotic species mainly contributed flowers and pollen. Major exotic plant components were the flowers of broom and gorse and the pollen of bishop pine. Broom was in full flower at the time of the survey and particularly abundant on the fringes of the reserve and along the periphery of the Upper 
Reservoir lake shore. In these locations, broom flowers were readily utilised by possums. Although gorse blooms throughout the year (Webb et al. 1988) it was significantly less utilised than broom. This finding corresponds with a study by Cowan (1990) who found few gorse flowers in possum diets in the southern Rimutaka Range in November.

Pine pollen was the most important food source for possums in areas 2 and 3 . It was remarkable how possums managed to extract pine pollen without also ingesting at least some of the coarse fibrous material from the catkins. The stomachs of some possums contained exclusively pollen which was apparent as a homogeneous yellow paste. As with fruits, pollen and flowers are rich in available carbohydrate and low in fibre and a source of readily available energy (Cowan 1990, Williams 1982). Because of the higher nutritional value of flowers and pollen, quantifying the relative amounts of leaf fragments in the diet has probably underrated the importance of the contribution exotic species make to the total energetic requirements for possums in the reserve.

Pekelharing (1993) found large stands of the exotic tree, black locust (Robinia pseudoacacia), totally defoliated and attributed this damage to possum browse. The largest aggregation of this tree species is located on the true right of an unnamed stream which enters the Upper Reservoir to the true right of the Kaiwharawhara stream. All trees in this stand are dead but epicormic growth and base coppicing is prolific. None of these leaves seemed browsed at the time of this study and no black locust leaves were ever encountered in any of the stomach samples. This absence suggests that the agent for the cohort mortality of black locust in the reserve may not be possum browse. Fuller (1996) suggested that strong north-westerly winds create atmospheric hazes potentially carrying significant salt loads and causing localised death and defoliation of plant species inadequately adapted to coastal exposure. These salt sprays have the potential to modify coastal vegetation. While this phenomenon could be an explanation for the observed black locust mortality, tree deaths can arise by a variety of other agents such as insect browse, fungal disease, pathogens, ground disturbance and climatic disturbances such as droughts and wind exposures (Pracy 1973). 


\section{Comparison with other diet studies}

Results confirmed the general perception that possums are selective generalists, adapted to consume a very wide range of foods. This behaviour is considered a persisting response from their native Australian habitat where many plants produce secondary compounds to deter browsing animals (Fitzgerald 1984). In that environment, possums have to spread their feeding over a number of plant species to prevent the accumulation of toxic compounds in their tissues (Freeland and Winter 1975). These animals are therefore likely to select seasonally available food plants by considering both the nutritional values and the presence of deterring plant allelochemicals like phenols, fluoroacetates and terpenes.

In New Zealand, a remarkably wide range of plant species have been listed as possum food items, including 70 indigenous tree species, 20 ferns, a few vines and epiphytes, as well as grasses and sedges (Green 1984). However, the selection of diet varies widely, and regional and temporal inconsistencies of diet preference upset most generalisations. It appears fair to generalise that only a few plant species are utilised at any one place and time. This selective foraging degrades the botanical integrity of many native plant communities. As the most preferred plants become increasingly rare, possums readily switch to other available plant species which were previously unbrowsed (Brockie 1992).

\section{Fuchsia}

Possum diet reflects the local and seasonal availability of plant species (Green 1984) and this is likely to lead to marked seasonal variations in diet over the year. Being deciduous, fuchsia is mainly available in spring when the trees come into leaf and when impacts on this tree species can be expected to be most severe. Fuchsia has been known to be heavily browsed throughout New Zealand and commonly appears on top of the list of preferred food items, particularly in earlier studies when the plant species was still abundant. Mason (1958) found fuchsia to be the most preferred food plant in the Orongorongo Valley. Twenty-five years later, Fitzgerald (1976) did not find any traces of this tree species in the faeces of possums, and reported that fuchsia, along with some other tree species, was no longer abundant anywhere within her study area. The fuchsia population was reduced to a few scattered plants which were constantly browsed but not abundant enough to appear in any of the samples. Gilmore (1965) found fuchsia to be the most favoured food plant on Banks Peninsula; leaves, flowers and fruit were all eaten. Owen and Norton (1995) found 
fuchsia to be one of the four most important food plants in a Nothofagus forest near Haast. However, by quantifying the relative biomass they found fuchsia relatively unimportant with a proportional abundance of less than $0.01 \%$. During the summer months, the preference index (Nugent 1990) of fuchsia in this forest type was calculated to be 0.89 emphasising the impact possums must have on this relatively rare forest tree. Purchas (1975) analysed the stomach contents of 34 possums in the Otari Reserve, Wellington, between February and May but did not encounter any fuchsia remains. However, he found that the few fuchsia trees surviving along the banks of the Kaiwharawhara stream were severely browsed.

In this study, fuchsia was most sought after in area 4 (Map 6), where the total number of potential food species is largest but where possums confined their diet to the fewest species. This particularly opportunistic feeding behaviour demonstrates how possums concentrate almost entirely on highly preferred food plants while these plants are in season. For fuchsia the disparity between its occurrence in the diet and its availability in the environment is likely to cause a decline in abundance if possum numbers are not controlled to a certain level. Judging by the canopy condition of fuchsia in area 3 versus area 4, the possum density threshold under which fuchsia could persist is likely to be somewhere between the possum densities of these two areas.

Although fuchsia may be able to maintain its current status in area 4, possums utilising this seasonal food source are altering the quality of habitat for forest birds which may depend on this key food resource. Fuchsia flowers and fruit are known to provide important seasonal food supplies for such native birds as tui (Prosthemadera novaezeelandiae) and kereru (Hemiphaga novaezeelandiae) These bird species were once common in the Wellington area, and are now much rarer (Parrish 1984). 


\section{Exotic species}

Pinus radiata pollen accounted for extremely high proportions of possum diets in studies conducted by Triggs (1982) and Clout (1977) between July and September in pine forests. In the pine dominated vegetation types of the Karori Reserve, bishop pine (Pinus muricata) still carried some pollen in November and still represented an important food item. However, November must be the very end of season for Pinus muricata pollen, and earlier in winter this food source is probably even more heavily utilised.

Triggs (1982) found pine pollen utilisation correlating with a sharp decline of pasture grasses, which were an important component in possum diet between May and June. Clout (1977) analysed monthly samples of possum stomachs in a pine plantation near Tokoroa between July and December and found grasses to account for less than $5 \%$ of plant species eaten. Fitzgerald (1976) found pasture plants (mainly Trifolium spp.) to provide some food but did not consider this food item very important. In this study, monocotyledons accounted for a little more than $3 \%$ of all fragments, but this food source may be more important before the pine pollen season begins.

\section{Other dietary components}

Fruits, which are as important as leaves in late autumn (Mason 1958), were only eaten in small amounts, probably because not many trees carry fruit this early in spring. The importance of readily digestible high energy food items such as fruit has been demonstrated by Bell (1981) who found a significant correlation between the annual crop of hinau (Elaeocarpus dentatus) fruit and possum body weight and reproductive success in autumn.

No faunal evidence was found in any of the stomachs. However, invertebrates have been regularly found in possum stomachs or faeces in other studies (i.e. Fitzgerald 1976, Gilmore 1965). Cowan and Moeed (1987) found $48 \%$ to $73 \%$ of faeces collected in the Orongorongo Valley forest containing invertebrate remains; mostly stick insects, cicadas and wetas. Even though in most instances invertebrates comprised only a small part of the animal's diet, Cowan (1987) emphasised the potential impact possums may have on native invertebrate populations. 


\subsection{Conclusion}

Results from stomach content analysis have clearly shown that possum browse must be one of the main causes for the observed fuchsia defoliation. Browse sign of boring insects on fuchsia leaves has also been observed and it is possible that the additional browse pressure exerted by possums on the trees disrupts a fragile balance. In area 4 , where possums have been regularly controlled by the Wellington City Council, fuchsia seemed in reasonable health. Although fuchsia was much utilised by possums in this area, possum numbers seemed low enough for the trees to persist. However, as fuchsia is also an important seasonal food source for fruit and nectar feeding native birds, diet overlap for its fruit and flowers is highly probable.

Exotic plants accounted for a significant proportion of the spring possum diet in the reserve. Whereas most leaves originated from native plants, the exotic species contributed mainly carbohydrate rich flowers and pollen. Pine pollen contributed much to the possums energetic requirements so it seems that the areas of pine forests with native undergrowth should be particularly targeted in mid winter for the final stages of the planned eradication campaign. 


\section{Chapter 5}

\section{Assessing the tree condition of the susceptible canopy species Fuchsia excorticata and Pseudopanax arboreus}

\subsection{Introduction}

Chapter 4 discussed the selective feeding behaviour of possums which has degraded the botanical integrity of many native New Zealand plant communities and which has drastically reduced the abundance of trees such as fuchsia (Fuchsia excorticata) in many parts of the country (Rose et al. 1993, Campbell 1990, Coleman et al. 1985, Batcheler 1983, Veblen and Stewart 1980, Fitzgerald and Wardle 1979, Fitzgerald 1976, Wardle 1973). In the Karori Reserve, fuchsia was identified as one of the major possum spring food items. This chapter attempts to determine how trees of fuchsia and five-finger (Pseudopanax arboreus), another preferred species, tolerate this level of browse pressure. This chapter also investigates if the removal of 1219 possums from the reserve between September and November 1995 ameliorated possum impacts on these indicator tree species.

In 1993, C.J. Pekelharing (Weeds and Pests Division, Landcare Research, Christchurch) assessed the canopy condition of fuchsia, five-finger, wineberry (Aristotelia serata) and kamahi (Weinmannia racemosa) trees in the Karori Reserve. In total, 47 trees were permanently marked. The survey, which was commissioned by the Wellington City Council (Contract Report LC 9293/68), assessed possum impacts on key indicator species by ranking the severity of those impacts. Mr. Pekelharing has generously supported the present study and made his data available for the re-survey of the marked trees.

The Karori Reserve contains the largest aggregation of native tree fuchsia in the Wellington District. Scattered fuchsia trees are established within the original native forest remnant on the very steep western slopes of the Lower Reserve area, along the Kaiwharawhara Stream between the lower and upper dams, along the Kaiwharawhara 
Stream above the upper dam and within the gullies of the Wrights Hill tributaries (refer to Map 2 for geographic details).

Five-finger is a major component of the regenerating secondary mixed hardwood forest, where it occurs in association with other seral species such as mahoe (Melicytus ramiflorus), hangehange (Geniostema rupestre), rangiora (Brachyglottis repanda), broadleaved coprosmas (Coprosma grandifolia, C. lucida and C. robusta) and kawakawa (Macropiper excelsum).

Fuchsia excorticata is a gynodioecious (female and hermaphrodite) and deciduous tree which is endemic to New Zealand (Delph and Lively 1985). Being bird pollinated and dispersed, the seeds of this "forest nomad" (Lusk and Ogden 1992) are often encountered in forest soil samples. Fuchsia is well adapted to colonising and restoring canopy gaps created by wind-thrown trees, landslides and flooded streams. In these situations, fuchsia utilises the detritus of debris fans and stabilises the disturbed areas before more mature forest associations return (Mark et al. 1964, Dawson 1988).

In the Wellington District, fuchsia is found from sea level to the timber line. While fuchsia remains relatively unmodified in the Tararua Ranges above 700 metres altitude (pers. obs.), the species becomes increasingly rare below this altitude. Once common within lowland forest associations (Mason 1958), its gradual disappearance there has been linked to higher possum densities within lowland forest communities (Fitzgerald 1976, Campbell 1990).

Five-finger (Pseudopanax arboreus) is a dioecious lowland forest tree that is common throughout New Zealand. Five-finger flowers from June to August and abundant fruit can often be seen from August to February (Allen 1982). It is a fairly light demanding tree and commonly occurs within shrubby forest regrowth (Dawson 1988). Five-finger is also associated with the colonising stages of forest succession. Lusk and Ogden (1992) suggested that as the lighter crowns of short-lived broadleaved species senesce they provide the light environment in which more mature forest associations can develop. 
Fuchsia is recognised as a highly palatable tree species and is thought to have few chemical defences to deter browsers (Froude 1980). Five-finger leaves are often severed by possums in order to extract the carbohydrate rich fluids in the petioles. This feeding behaviour is mainly observed in spring. As an evolutionary adaptation seral plant species tend to invest their energy resources into short-lived fast growing leaves instead of diverting energy into the production of defensive allelochemicals (Owen and Norten 1994, Sims and Fritz 1990). The ability of a plant to withstand heavy browsing ultimately depends on this degree of adaptation. For example, mahoe is browsed throughout the year but appears to be able to produce new growth almost immediately. The long-lived and slow growing northern rata (Metrosideros robusta) on the other hand, develops new foliage in a very short period immediately after flowering and so can compensate for browsing only at this time, even though it is browsed throughout the year (Fitzgerald and Wardle 1979). For the deciduous fuchsia, the most important growth phase occurs in early spring when stored energy is used for the growth of new buds and leaves. Even though fuchsia can produce new leaves throughout summer, continued defoliation impacts on its growth rate and reproductive output. Delayed growth also leads to a disadvantage when competing with other species in its forest association for space and light in the canopy.

\subsection{Methods}

In March 1993, C.J. Pekelharing assessed possum impacts in 13 permanent vegetation plots in the Karori Reserve. In total, 32 fuchsia trees, 10 five-finger trees, 2 kamahis and 3 wineberry trees were assessed. For each of the 13 plots, a permolat cross and a numbered aluminium tag, nailed to one of the trees, marked the plot centres. The area of each plot was defined by a circle with a radius of 20 metres around each plot centre. Within these circles, a sample of fuchsia, five-finger, kamahi or wineberry trees were also numbered with an aluminium tag and marked with a single piece of permolat. From the centre tree, the distance and bearing to all marked trees within each plot was measured and recorded to facilitate relocation.

Assessment of trees followed a method outlined by Payton and Pekelharing (1993). As this draft methodology paper left much of the ranking of variables to individual interpretation, descriptors were added to each rank as follows: 


\section{Assessing a tree or a stem}

A tree was recorded if its trunk did not branch below breast height. The trunk of such a tree was marked with a tag at breast height and its circumference measured at the nail holding the tag. The whole tree was assessed.

A stem was recorded as where the trunk of a tree branched into two or more leaders below breast height. In these instances, only one of the related leaders was tagged and measured at breast height and only this part of the tree was assessed.

For any tree or stem the following was recorded:

\section{The foliage density index (FDI)}

Standing at a vantage point from where the densest remaining patch of foliage could be assessed, the amount of foliage cover was compared with a chart showing foliage densities in ten $10 \%$ increments (i.e. $5 \%-15 \%-25 \%$ to $95 \%$ ).

\section{Dieback in the upper canopy and dieback for the whole tree}

The amounts of defoliated twigs and branches were assessed for the upper canopy and for the whole tree. The severity of dieback was ranked as follows:

$0=$ none discernible,

1 = light, only a few defoliated twigs visible,

$2=$ moderate, several twigs to no more than half the tree canopy defoliated,

3 = heavy, more than half the canopy defoliated,

$4=$ severe, more than three quarters of the canopy defoliated. 


\section{Browse in the upper canopy and browse for the whole tree}

The extent of possum browse in the upper canopy and for the whole tree was also assessed. The proportion of leaves showing possum browse signs was expressed as follows:

$0=$ no browsed leaves discernible,

1 = light, only a few leaves showing possum browse,

$2=$ moderate, several leaves to no more than half the remaining leaves showing obvious possum browse,

3 = heavy, more than half of the remaining leaves showing obvious possum browse,

$4=$ severe, more than three quarters of the remaining leaves showing obvious possum browse.

\section{Trunk use}

The frequency of scratches and bark biting marks on the trunks were ranked as follows:

$0=$ no possum sign visible,

$1=$ light use, only a few scratches on trunk,

$2=$ moderate use, several scratches and /or bark bites visible on trunk,

$3=$ heavy use, trunk shows many scratches and scars indicating that it serves as a tree for territorial marking.

\section{Incidence and abundance of flowers and fruit}

Both flowers and fruit were ranked according to their abundance:

$0=$ no flowers or fruit discernible,

1 = light crop, only a few flowers or fruit visible,

2 = moderate crop, several flowers or fruit or occasional clusters of flowers and fruit on various branches visible,

3 = abundant crop, most branches carry flowers or fruit in more than "moderate" abundance,

$4=$ heavy crop, almost or virtually the whole canopy clustered with flowers or fruit.

In addition to the canopy assessments, the presence of epicormic recovery from either base (coppicing) or from the trunk of assessed trees or stems (epicormic growth) was recorded. 
All trees initially surveyed in March 1993, were re-assessed in March 1995 and again in March 1996 using the method of scored ranks outlined above. Before re-assessing the trees in 1995, an opportunity arose to assist C.J. Pekelharing assessing trees in Otari Native Botanical Gardens, Wellington. Our judgements could thereby be "calibrated" which would reduce any observer bias between the initial survey in 1993 and the reassessment surveys in 1995 and 1996. Furthermore, re-assessments of trees were performed without knowledge of the previous year's results which also reduced the subjectivity of the method.

As each tree species has its own distinctive attributes in relation to the scored ranks, (i.e. a healthy fuchsia tree has a lighter crown than a healthy five-finger tree or perhaps, the incidence, degree and persistence of scratch and bite marks on trunks varies depending on the species), it was decided to analyse and compare ranks for each tree species separately. Since the sample sizes for wineberry $(n=3)$ and for kamahi $(n=2)$ were considered too low for meaningful statistical analysis, only fuchsia $(n=32)$ and five-finger $(n=10)$ ranks were compared. To contrast tree condition between years, paired 2 way Wilcoxon signed rank tests were employed. This analysis only used trees which still had foliage (FDI > 0) during the previous survey. This reduced the sample size from 32 fuchsia trees for the 1993 to 1995 browse assessment to 19 fuchsia trees for the 1995 to 1996 browse assessment. All 10 five-finger trees were still alive in 1996.

Because dieback ranks and browse ranks are inversely related (a completely defoliated tree would score a dieback rank of " 4 " and a browse rank of "0") only those trees which still had FDI's greater than " 0 " could be used for paired analysis. For fuchsia, this reduced the sample size to 19 trees for contrasting browse level changes between 1993 and 1995. In 1996, only 17 trees had FDI s greater than " 0 " which further reduced the sample size to this number for the 1995 to 1996 paired analysis for browse.

To identify significant changes over all three canopy assessment surveys, paired two way Friedman tests were used. Both the Wilcoxon signed rank test and the Friedman test are non-parametric statistical procedures available in the NONPAR module of the SYSTAT computer package (Wilkinson 1990). 


\subsection{Results}

All mean ranks, and standard deviations are shown in Table 16 and Table 17. The paired Wilcoxon test results for changes between 1993 and 1995, between 1995 and 1996 and between 1993 and 1996 are shown in Table 18. Friedman test results contrasting levels of change over all three assessments in the period from 1993 to 1996 are shown in Table 19.

Table 16: Means and standard deviations of ranks for assessed fuchsia trees (Note: In the initial 1993 survey only 23 trees were assessed for dieback.)

\begin{tabular}{|c|c|c|c|c|c|c|c|c|c|}
\hline & \multicolumn{3}{|c|}{1993} & \multicolumn{3}{|c|}{1995} & \multicolumn{3}{|c|}{1996} \\
\hline & mean & Std.dev. & $\mathbf{n}$ & mean & Std.dev. & $\mathbf{n}$ & mean & Std.dev. & $\mathbf{n}$ \\
\hline FDI & 49.38 & 23.27 & 32 & 25.47 & 28.24 & 32 & 33.91 & 37.17 & 32 \\
\hline Dieback upper canopy & 2.35 & 1.53 & 23 & 3.19 & 1.06 & 32 & 3.00 & 1.29 & 32 \\
\hline Dieback total & 2.39 & 1.34 & 23 & 3.31 & 0.90 & 32 & 3.19 & 1.06 & 32 \\
\hline Browse upper canopy & 1.44 & 1.65 & 32 & 2.00 & 1.20 & 19 & 0.59 & 0.71 & 17 \\
\hline Browse total & 1.31 & 1.53 & 32 & 1.95 & 0.97 & 19 & 0.82 & 0.81 & 17 \\
\hline Trunk use & 0.47 & 0.72 & 32 & 0.91 & 0.89 & 32 & 0.38 & 0.61 & 32 \\
\hline Flower & 0.03 & 0.18 & 32 & 0.03 & 0.18 & 32 & 0.00 & 0.00 & 32 \\
\hline Fruit & 0.22 & 0.55 & 32 & 0.03 & 0.18 & 32 & 0.00 & 0.00 & 32 \\
\hline
\end{tabular}

Table 17: Means and standard deviations of ranks for assessed five-finger trees $(n=10)$

\begin{tabular}{|l|ccc|ccc|ccc|}
\multicolumn{3}{c}{} & \multicolumn{3}{c}{1993} & \multicolumn{3}{c}{1995} & \multicolumn{3}{c|}{1996} \\
& mean & std.dev. & $\mathbf{n}$ & mean & std.dev. & $\mathbf{n}$ & mean & std.dev. & $\mathbf{n}$ \\
\hline FDI & 68.00 & 11.60 & 10 & 71.00 & 9.66 & 10 & 85.00 & 8.17 & 10 \\
Dieback upper canopy & 1.83 & 0.41 & 10 & 1.70 & 0.95 & 10 & 1.70 & 0.95 & 10 \\
Dieback total & 1.17 & 0.41 & 10 & 1.80 & 0.63 & 10 & 0.90 & 0.99 & 10 \\
Browse upper canopy & 0.00 & 0.00 & 10 & 1.20 & 0.79 & 10 & 0.40 & 0.70 & 10 \\
Browse total & 0.00 & 0.00 & 10 & 1.00 & 0.67 & 10 & 0.40 & 0.70 & 10 \\
Trunk use & 0.60 & 0.84 & 10 & 0.70 & 0.68 & 10 & 0.70 & 0.68 & 10 \\
Flower/fruit combined & 2.20 & 1.48 & 10 & 1.70 & 1.16 & 10 & 1.10 & 1.10 & 10 \\
\hline
\end{tabular}


Table 18: Wilcoxon signed ranks test results showing probabilities of differences between individual surveys. Differences of $p>0.05$ are not significant.

\begin{tabular}{|c|c|c|c|c|c|c|}
\hline \multirow[t]{2}{*}{ Fuchsia } & \multicolumn{2}{|c|}{1993 with 1995} & \multicolumn{2}{|c|}{1995 with 1996} & \multicolumn{2}{|c|}{1993 with 1996} \\
\hline & p-value & $\mathbf{n}$ & p-value & $\mathbf{n}$ & p-value & $\mathbf{n}$ \\
\hline FDI & $<0.001$ & 32 & 0.001 & 19 & 0.03 & 32 \\
\hline Dieback upper & 0.003 & 23 & 0.161 & 19 & 0.003 & 23 \\
\hline Dieback total & 0.001 & 23 & 0.405 & 19 & 0.005 & 23 \\
\hline Browse upper & 0.0138 & 19 & 0.001 & 17 & 0.834 & 17 \\
\hline Browse total & 0.0013 & 19 & 0.001 & 17 & 0.973 & 17 \\
\hline Trunk use & 0.022 & 32 & 0.0323 & 19 & 0.564 & 32 \\
\hline Flower & 1 & 32 & 0.3173 & 19 & 0.317 & 32 \\
\hline Fruit & 0.084 & 32 & 0.3173 & 19 & 0.038 & 32 \\
\hline \multirow[t]{2}{*}{ Five-finger } & \multicolumn{2}{|c|}{1993 with 1995} & \multicolumn{2}{|c|}{1995 with 1996} & \multicolumn{2}{|c|}{1993 with 1996} \\
\hline & p-value & $\mathbf{n}$ & p-value & $\mathrm{n}$ & p-value & $\mathbf{n}$ \\
\hline FDI & 0.317 & 10 & 0.004 & 10 & 0.006 & 10 \\
\hline Dieback upper & 0.317 & 6 & 1 & 10 & 0.317 & 6 \\
\hline Dieback total & 0.034 & 6 & 0.047 & 10 & 0.18 & 6 \\
\hline Browse upper & 0.01 & 10 & 0.046 & 10 & 0.102 & 10 \\
\hline Browse total & 0.008 & 10 & 0.084 & 10 & 0.102 & 10 \\
\hline Trunk use & 0.783 & 10 & 1 & 10 & 0.739 & 10 \\
\hline Flower/fruit & 0.381 & 10 & 0.119 & 10 & 0.088 & 10 \\
\hline
\end{tabular}

Table 19: Friedman paired analysis of variance test results showing probabilities of differences over the three surveys from 1993 to 1996. Differences of $\mathrm{p}>0.05$ are not significant.

\begin{tabular}{|c|c|c|c|c|c|c|}
\hline \multirow[t]{2}{*}{ Fuchsia } & \multicolumn{3}{|c|}{ all trees } & \multicolumn{3}{|c|}{ survivors 1996} \\
\hline & test stat & p-value & $\mathbf{n}$ & test stat & p-value & $\mathbf{n}$ \\
\hline FDI & 20.922 & $<0.001$ & 32 & 16.794 & 0.001 & 17 \\
\hline dieback upper canopy & 7.891 & 0.019 & 23 & 4.909 & 0.086 & 11 \\
\hline dieback total & 13.031 & 0.001 & 23 & 8.591 & 0.014 & 11 \\
\hline browse upper canopy & - & - & - & 13.794 & 0.001 & 17 \\
\hline browse total & - & - & - & 12.971 & 0.002 & 17 \\
\hline trunk use & 4.75 & 0.093 & 32 & 5.059 & 0.08 & 17 \\
\hline flower & 0.047 & 0.977 & 32 & 0.088 & 0.957 & 17 \\
\hline fruit & 0.984 & 0.611 & 32 & 0.088 & 0.957 & 17 \\
\hline
\end{tabular}


Table 19: continued

Five-finger
\begin{tabular}{|l|c|c|c|}
\hline FDI & 13.85 & $\mathbf{0 . 0 0 1}$ & 10 \\
dieback upper canopy & 0.25 & $\mathbf{0 . 8 8 2}$ & 10 \\
dieback total & 7 & $\mathbf{0 . 0 3}$ & 10 \\
browse upper canopy & 7.35 & $\mathbf{0 . 0 2 5}$ & 10 \\
browse total & 6.65 & $\mathbf{0 . 0 3 6}$ & 10 \\
trunk use & 0.05 & $\mathbf{0 . 9 7 5}$ & 10 \\
flower/fruit combined & 3.2 & $\mathbf{0 . 2 0 2}$ & 10 \\
\hline
\end{tabular}

\section{Fuchsia}

\section{FDI}

Figures 12a and 12b show how FDI scores were ranked in the 1995 and 1996 surveys. The photographs also illustrate the drastic canopy deterioration of some trees since they were first assessed. In 1993, all 32 assessed trees had FDI ranks greater than "0". In 1995, thirteen trees (41\%) were dying and completely defoliated. By 1996, another four trees had completely lost their foliage. While one tree crown showed signs of recovery, the number of completely defoliated trees increased to 15 individuals (47\% of the original sample) in 1996.

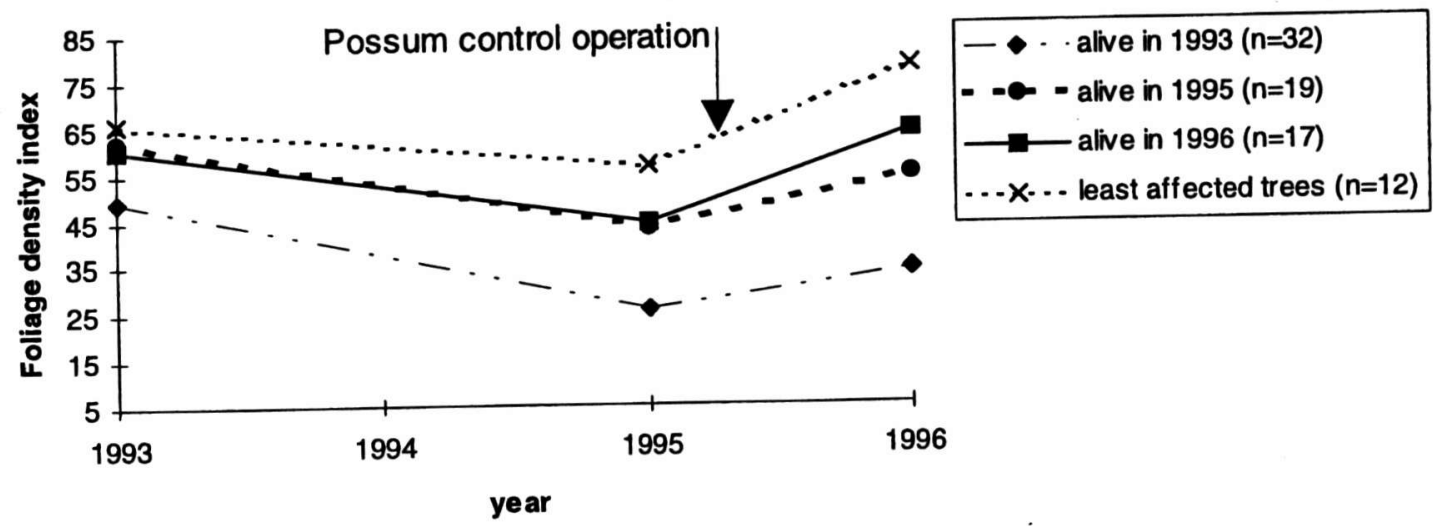

Figure 11: Changes in FDI from 1993 to 1996. As most defoliated trees did not recover in 1996, the FDI for the total sample only increased slightly. The least affected trees responded most to the possum contol operation. 
Considering the total sample of 32 trees, the decrease in FDI between 1993 and 1995 was highly significant (Table 18). However, the canopy condition for those trees which had FDI's greater than "0" in 1995 improved significantly $(\mathrm{p}=0.001)$ from 1995 to 1996 when their FDI scores even exceeded the 1993 results $(p=0.03)$.

Surprisingly, twelve trees $(37.5 \%)$ seemed to be less affected than the other sampled trees. Their FDI's decreased significantly but less dramatically from 1993 to $1995(\mathrm{p}=0.013)$ and also exceeded their original FDI scores in $1996(\mathrm{p}=0.002)$. All healthy trees were located between Scout Hall and the upper dam, along the northern upper lake shore close to the upper dam, and along the Kaiwharawhara Stream between upper and lower dam. Map 7 shows the location of plots and zones of relative possum impact.

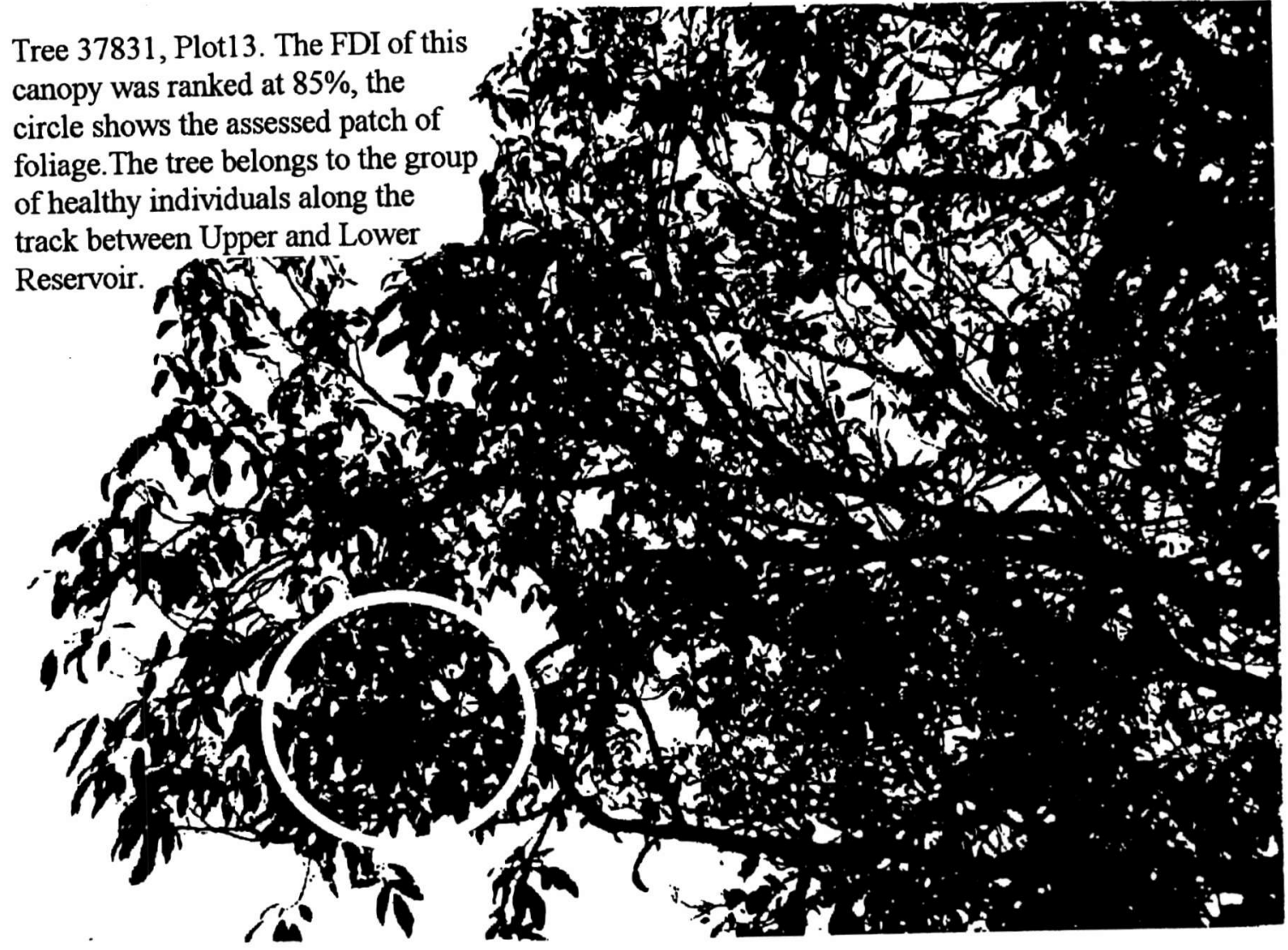

Figure 12a 
Tree 37825 , Plot 11 . The FDI of this canopy was ranked at $5 \%$, the circle shows the assessed patch of foliage. The canopy of this tree, located at the north-western end of the upper lake, had only moderate dieback and a FDI of 65\% in 1993.

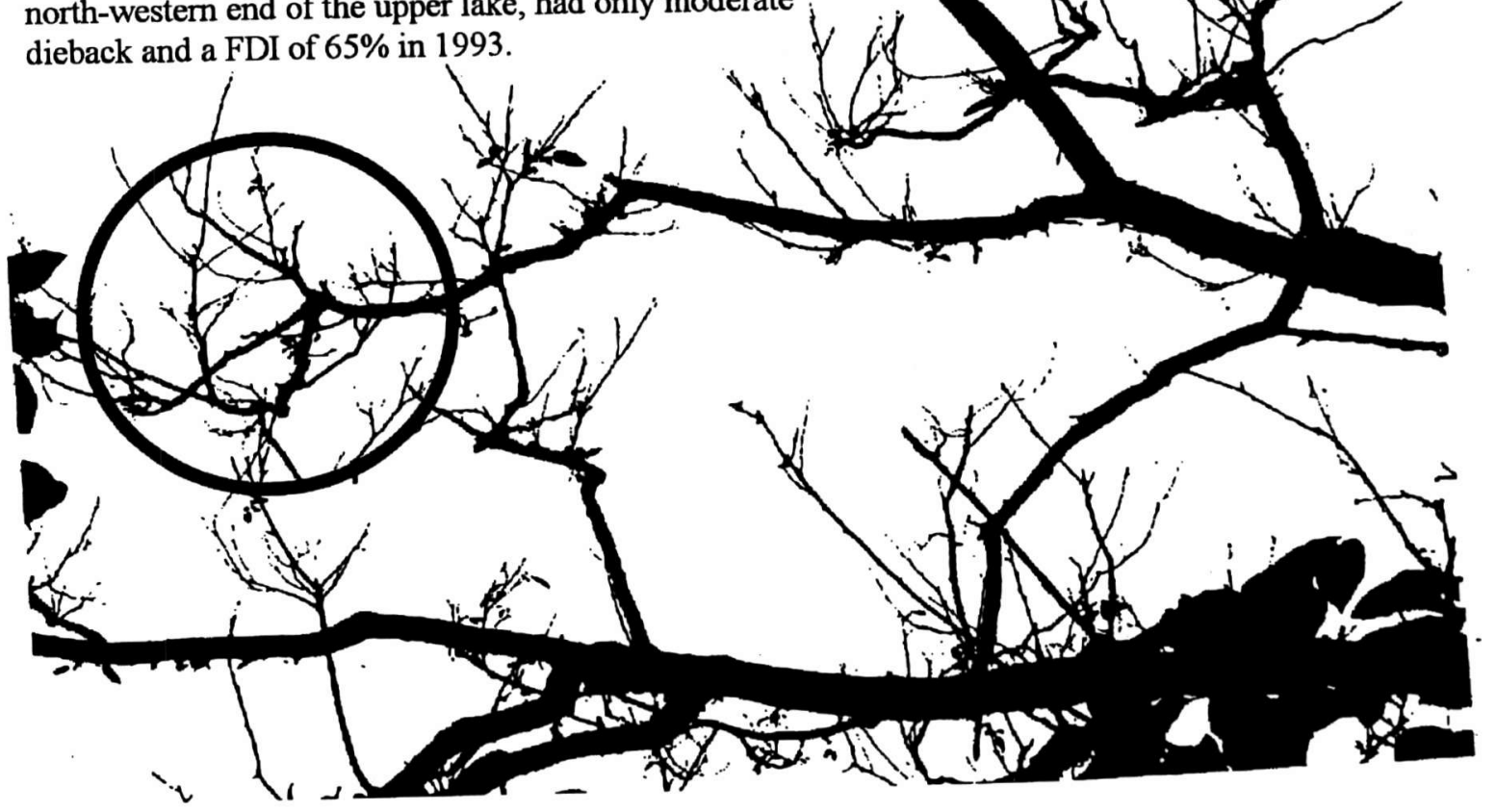

Figure 12b

Tree 37826, Plot 12.The canopy of this tree, located at the north-western end of the upper lake, did not show any dieback and had a FDI of $65 \%$ in 1993 . In 1995 , this tree was completely defoliated and species like geniostema and supplejack used the bare branches for support and gradually closing the gap, which was once occupied by this tree fuchsia.

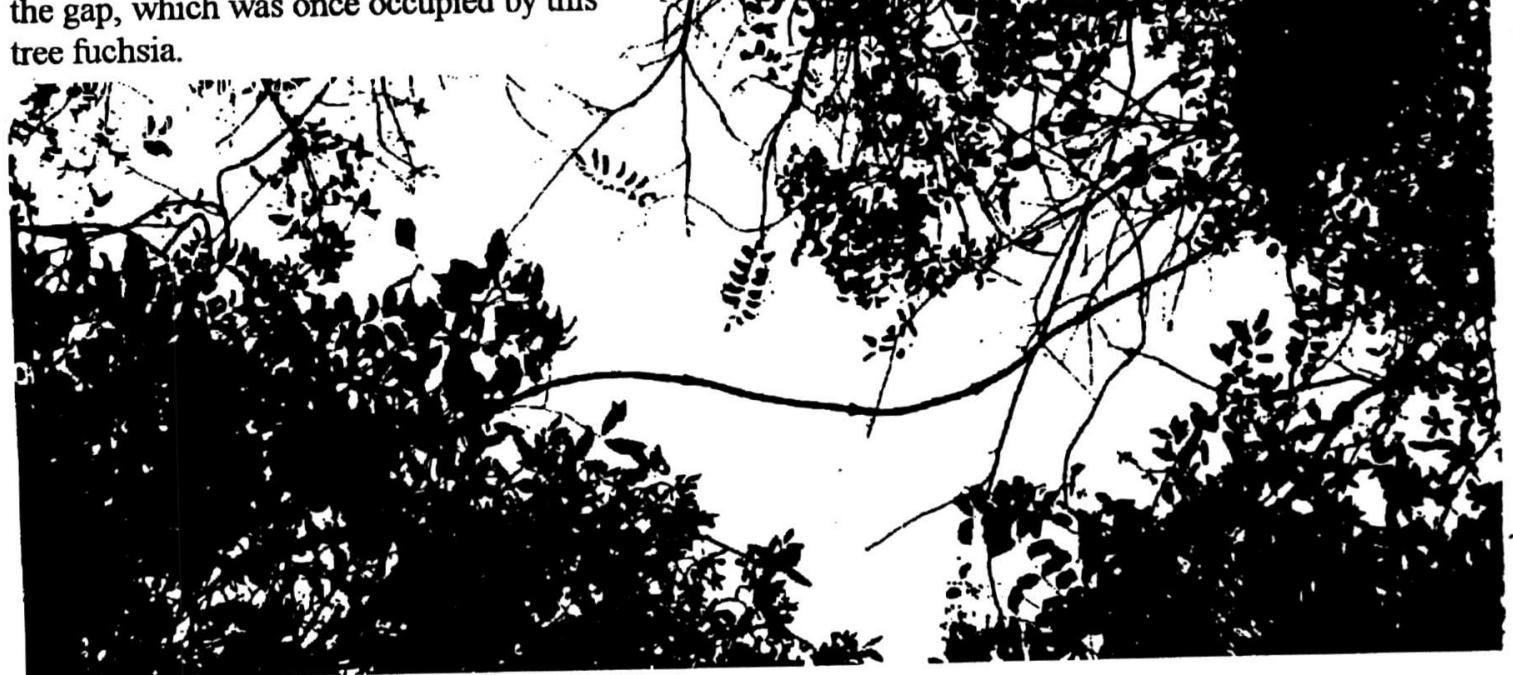

Figure 12c

Figures 12 a-c: Photographs of fuchsia canopies showing how FDI ranks were scored in the 1995 and 1996 surveys. Photographs were taken in March 1995. 


\section{Dieback}

Overall, the increase in dieback between 1993 and 1995 was highly significant (Table 18). In 1996 most crowns of surviving trees showed some recovery, which was reflected in a significant increase in FDI but not in a statistically significant decrease in dieback (Table 18).

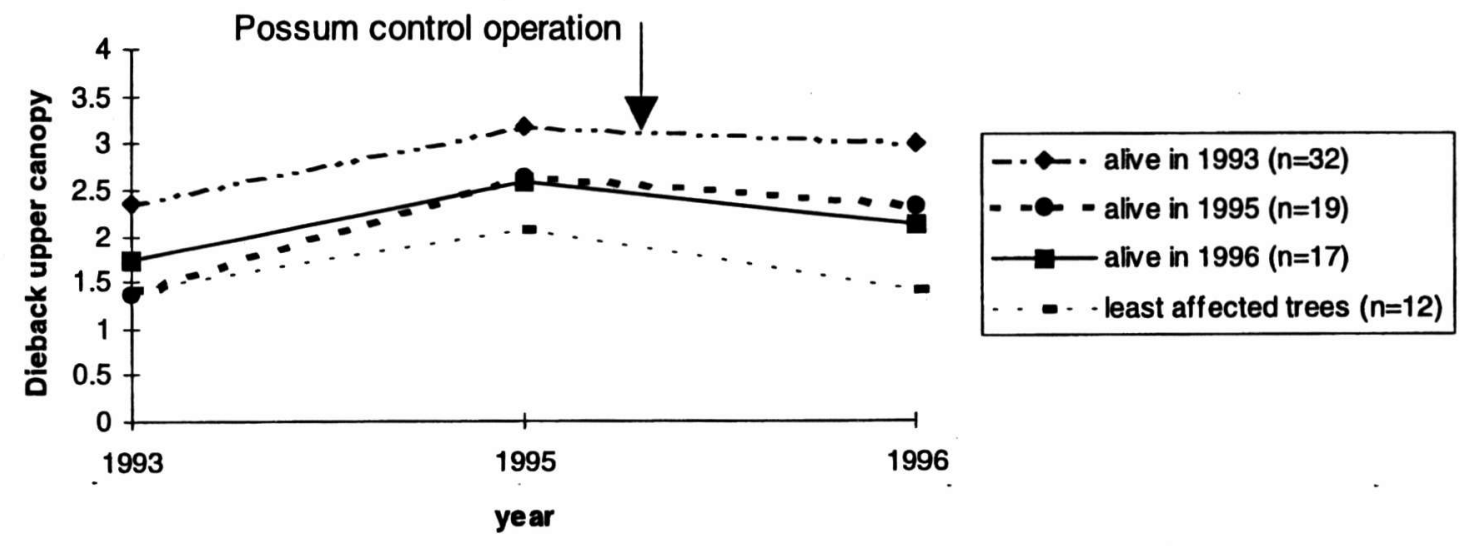

Figure 13: Changes in dieback in the upper canopy from 1993 to 1996 . Whereas dieback for the total sample only decreased slightly the trees least affected in 1995 showed the most significant recovery

In 1993, most trees (84\%) showed moderate to heavy signs of dieback. Eight trees (25\%) showed severe signs of dieback. Seven of these trees were completely defoliated in 1995, being located along the Kaiwharawhara Stream above where it flows into the upper lake as well as along the track leading to Wrights Hill (Zone C on Map 7). Only five trees showed no discernible sign of dieback in 1993 . Two years later, three of these trees were heavily to severely affected, and in 1996 two trees were completely defoliated. The canopy of one of these individuals, tree 37825 , is illustrated in Figure $12 \mathrm{~b}$.

At the other extreme, dieback for the twelve healthy survivors of fuchsia slightly increased in 1995 ( $\mathrm{p}=0.083$ ) but after the possum control operation their canopies recovered to 1996 levels $(\mathrm{p}=0.02)$. None of the three assessments had dieback ranks in their upper canopy that exceeded "moderate". The upper canopy dieback did not change significantly $(p=0.248)$ during the three assessments. 


\section{Browse}

In 1993, C.J. Pekelharing observed browse sign on 53\% of the sampled fuchsia trees. In 1995, browse sign was noted on all but one of the surviving 19 trees (94.74\%), and in 1996 browse sign was observed on 10 of the surviving 17 trees $(59 \%)$.

Possum browse for the 17 survivors was significantly higher in 1995 than in either 1993 or 1996 (Tables 17 and 18). The overall change was also highly significant (Table 19). However, scored browse impacts were similar for the 1993 and 1996 assessments $(p=0.83$, Table 18).

\section{Trunk-use}

The incidence of scratch and bite marks on fuchsia trunks doubled from 1993 to 1995 but decreased again to equivalent 1993 levels in 1996. The degree of trunk use followed a similar pattern but only exceeded "moderate" levels in two instances which were recorded in 1995. Both the increase of bite and scratch marks in 1995, and the subsequent decrease of bite and scratch marks in 1996 were significant (Table 18). However, for the 12 least affected trees the degree of bite and scratch marks did not decrease significantly $(p=0.705)$ in the period from 1995 to 1996 (Figure 14)

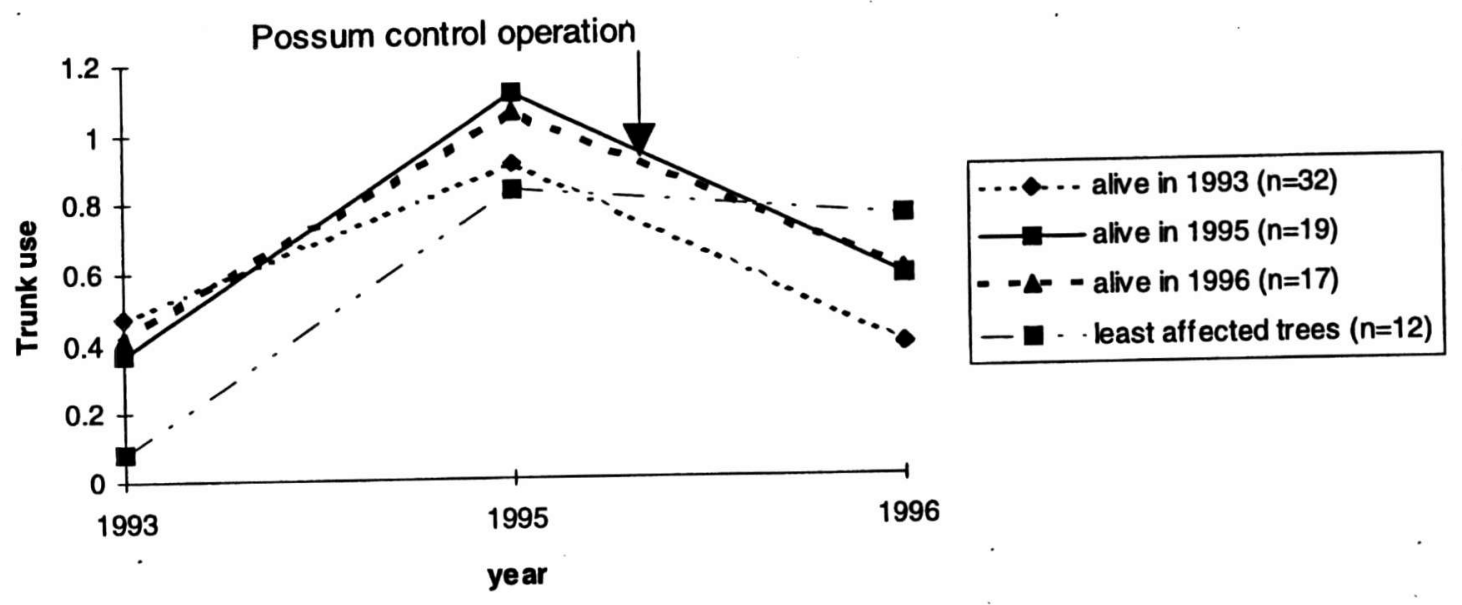

Figure 14: Changes in the degree of trunk use from 1993 to 1996. After controlling possums in 1995, the degree of trunk use only decreased when considering the entire sample but not when considering the 12 trees which appeared least affected in 1993. 
Considering the entire sample, there was no difference in the degree of bite and scratch marks between 1993 and 1996. Overall, the degree of trunk use did also not change significantly throughout the three assessments $(p=0.093)$.

\section{Flowering and fruiting}

Fuchsia flowers in spring and fruit develop in summer. A few remaining flowers were observed on one tree in March 1993 and on another tree in March 1995. Other than that no flowers were observed as late in the season as March.

Also, fruit was rarely observed in any of the years. In March 1993, five trees (16\%) carried fruit. None of these trees had dieback levels exceeding "moderate" or FDIs lower than " 55 ". In 1995, four of these trees were severely defoliated and their canopies had not recovered in 1996. The fifth tree belonged to the group of healthy survivors.

Of the nineteen trees surviving in 1995, only one tree carried fruit. This tree also belonged to the group of healthy survivors. In 1996, no fruiting was observed at all. Because of the low observed fruiting incidences, analysis of results showed no significant change in the degree of fruiting over the three assessments. However, comparisons of 1993 with 1996 results suggests a significant decline in the degree of fruiting $(\mathrm{p}=0.038, \mathrm{n}=32)$. 
Map 7: Approximate location of variable area plots in the Karori Reserve. Possum impact zones are shaded: In zone A all fuchsia trees were still alive in 1996. In zone B fuchsia mortality was less than $30 \%$, in zone C fuchsia mortality exceeded $70 \%$.
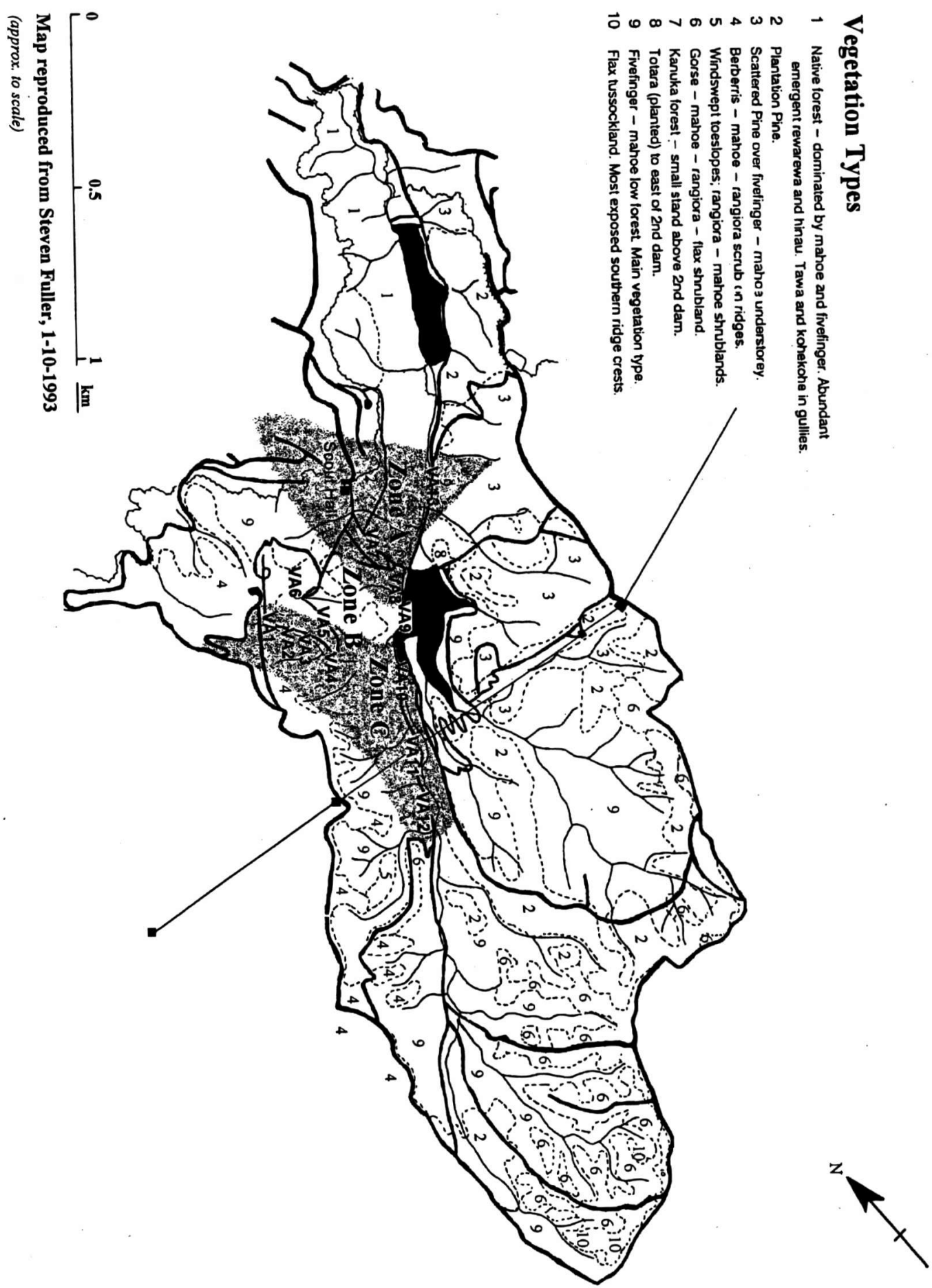


\section{Five-finger}

\section{FDI}

All ten assessed trees were still alive in 1996. Between 1993 and 1995 an increase in FDI was observed, but this was not statistically significant $(\mathrm{p}=0.317)$. However, the FDI of all ten five-finger trees increased significantly from 1995 to $1996(\mathrm{p}=0.001)$ and also the rise of FDI over the three assessments was highly significant (Table 19).

\section{Dieback}

There was no statistical difference in dieback in the upper canopy over the three assessments $(p=0.88)$. However, total dieback increased significantly in 1995 but decreased below 1993 levels in 1996. The change in total dieback over the three assessments was also statistically significant $(\mathrm{p}=0.03)$.

\section{Browse}

In 1993, C.J. Pekelharing observed no browse sign on any of the sampled five-finger trees. In 1995, browse sign was noted on eight of the 10 trees. In 1996, browse sign was observed for three of the ten trees. Although the degree of browse never exceeded "moderate" the change over the three assessments was significant (Table 19). However, the degree of browsing did not differ significantly comparing 1993 with 1996 results (Table 18).

\section{Trunk-use}

The degree of trunk use which never exceeded "moderate" levels, did not change significantly between years or over the three assessments (Tables 18 and 19). The incidence of scratch and bite marks increased by 20\% from 1993 to 1995 and remained at that level in 1996.

\section{Flowering and fruiting}

Five-finger has small, yellowish flowers which develop into small greenish fruit which later. turn black (Pekelharing 1995). As the change from flower to fruit is variable depending on the climatic conditions in any one year, the observed variation may originate from the differing initiations of flowering and fruiting seasons. Also, it is often difficult to differentiate between mature flowers and immature fruit as the process of change is continuous. For these reasons the flowering and fruiting data for the three assessments were pooled. Combined 
results showed no differences in either incidence or degree of flowering and fruiting between each of the three assessments or over all three assessments (Tables 17 to 19).

\subsection{Discussion}

Results show a drastic decline of fuchsia in the reserve. However, the initial sampling procedure which involved non-randomly selecting only living indicator trees may have overestimated the health of the fuchsia population in 1993. A more random selection procedure that sampled both dead and living fuchsia stems would most likely have reduced the discrepancy between 1993 and 1995 results. Nevertheless, the observed mortality rate is severe and unlikely to result from natural processes such as stand dynamics or successional senescence. The high percentage of fuchsia leaves in the diet of possums reflects the high level of browse pressure, especially when considering how little this species contributes to the total foliage biomass of the reserve. Even though dead and dying trees are also common in undisturbed natural New Zealand forests (Jane and Green 1993), the large proportions of small fuchsia trees with severe dieback and large fuchsia trees showing little possum damage further underpins the supposition that natural senescence cannot be the major reason for the drastic fuchsia decline in the Karori Reserve.

Possums feed on the spring growth and buds as fuchsia becomes available as a seasonal food source. This retards the tree's most important growth phase in early spring. As other surrounding trees like hangehange, mahoe and rangiora are not browsed by possums, they have a competitive advantage and often invade the canopy space which has previously been occupied by the dying fuchsia tree (Figure 12c). Supplejack (Ripogonum scandens) vines use the bare branches as support and further close the gap. Finally, the whole tree is located in the subcanopy. The photosynthetic area is reduced to a level where the tree cannot maintain its own tissues. The trunk starts to rot and the tree becomes increasingly susceptible to insect attack and pathogens and will eventually die. Other less palatable tree species will utilise the empty space and the fuchsia tree will not be replaced.

The end result of continuous possum browse on fuchsia and other highly palatable plant species such as kohekohe (Dysoxylum spectabile), wineberry, tutu (Coriaria arborea) and titoki (Alectryon excelsus) in Karori's forest is a less diverse plant community which will be 
dominated by unpalatable species such as red matipo (Myrsine australis), pigeonwood (Hedycarya arborea), rangiora, hangehange (Geniostema rupestre) and browse tolerant species such as mahoe and five finger. These species increasingly dominate this degraded low forest, which may also have significant consequences for Karori's bird life. Native seed dispersing birds such as tui and kereru encounter a less favourable habitat, and may gradually disappear from the forest. Many of the remaining tall forest trees in the Lower Reserve area such as tawa (Beilschmiedia tawa), hinau (Elaeocarpus dentatus) and kohekohe rely on the presence of birds for seed dispersal. As a secondary response, these trees may not be able to regenerate as long as possums continue to degrade components of this forest community.

However, the results suggest that the 1995 possum control operation has ameliorated some of the possum impacts on fuchsia trees in the reserve. For the fuchsia trees which were still alive in 1995, the severity of dieback, browse and trunk use declined. The mortality rate also declined after 1995, with only 2 deaths (11\%) from 1995 to 1996.

Being deciduous, fuchsia is only browsed during spring and summer and escapes predation in winter when possum foods are particularly scarce. This, together with its prolific ability to grow and reproduce vegetatively, gives fuchsia some resilience in withstanding continued browse damage. Fuchsia trees that collapse on unstable sites often grow epicormic stems from their prostrate trunks and thereby stabilise the substrate. In Karori, epicormic shoots are a common feature of fuchsia trees with defoliated and collapsed canopies. This is. a response to more light reaching the base of the trunks and may help some trees to survive continued defoliation. However, in most cases epicormic shoots are ephemeral and can only persist as long as the space in the canopy remains open. In 1996, the stems of many of the defoliated trees were dried out and stem borer infested which indicated that these trees would be lost and would not recover.

The surveys in 1995 and 1996 also showed how fast possums can kill healthy fuchsia trees which emphasises the uncertain future for the 17 surviving trees. Even though trunk use declined for the whole sample after possums had been controlled, the degree of trunk use remained at the same level for the 12 healthy survivors. This suggests that these trees are now increasingly attractive for the remaining possums. If possums in the main reserve are not controlled to Lower Reserve population densities, it is likely that fuchsia will disappear from 
the Upper Reserve before the erection of the exclusion fence renders the possum eradication campaign feasible.

The 12 fuchsia trees that survived with no more than "moderate" dieback in their upper canopy should be further investigated. Even though these trees showed increasing possum impacts in 1995, they showed no sign of obvious stress and, apart from the degree of trunk use, possum impacts decreased again in 1996. One individual tree (tag no.1202 on variable area plot 3) still appeared in reasonable health even though all other fuchsias in its vicinity had died. All other healthy survivors were located in the low impact zone shown in Map 7.

Coleman et al. (1980) noted that fuchsia and other tree species that were regarded as highly palatable were not browsed within a podocarp-mixed hardwood forest on Mt Bryan O'Lynn, Westland. Meads $(1976,1978)$ examined the possum browse damage to Metrosideros robusta tree canopies in the Orongorongo Valley, Wellington. He noted that possums used succulent resource trees which they marked by body scent and which they completely defoliated while only lightly browsing adjacent similar trees. This feeding behaviour may be determined by complex social interactions that are presently poorly understood. However, it may also be that the palatability varies between trees of the same species. The possible differential ability of fuchsia trees to produce deterring or distasteful leaf compounds should be investigated further by studying possible genetic variations between individuals of this population. If there was a particular genetic trait deterring possums from feeding on some individual fuchsia trees, then such genotypes could be useful for propagating the species in areas where possum browsing causes its decline.

The canopies of assessed five-finger trees do not appear to have been significantly affected by possums. Even though the foliage density increased after possums were controlled in 1995 , the amount of defoliated areas in the five-finger canopies did not change significantly. Overall, the amount of possum browse noticeably increased in 1995 but never exceeded the apparent tolerance level of five-finger. Five-finger leaves, flowers and fruit were not a major constituent in the possum diet in spring which can been explained by the way possums utilise this food source. Even though possum impacts on five-finger are likely to be underestimated by analysing stomach contents, the plant species is so abundant in the reserve that it will still be proportionally less targeted than fuchsia. However, once the most palatable species have 
disappeared, possums will switch to less attractive food items and will further alter the species composition of the forest. Because of the heterogeneous vegetation cover of the urban fringe offering a variety of seasonally abundant food plants, a change in plant species composition is unlikely to have an effect on possum population densities in the reserve. The trend towards a less diverse community of unpalatable plant species is therefore likely to be perpetuated if possums are not controlled or eliminated from the reserve. 


\section{Chapter 6}

\section{General discussion}

The first part of this study examined how environmental characteristics and human impacts influence possum abundance and condition in various areas of the reserve. The inverse relationship of abundance and condition was also discussed. The second part studied possum diet in the reserve and investigated how a sample of fuchsia and five-finger trees tolerated possum browse. Being an "applied" thesis, the study aimed to provide strategic directions for management and eventually eradication of possums from the reserve. The study also provided a baseline from which the recovery of tree fuchsia can be monitored once possums and other vertebrate pests have been excluded from the reserve.

The first part of this thesis showed how the density dependent mechanisms regulating population growth are less effective in controlled populations. This has been documented for many vertebrate populations maintained below the carrying capacity of their habitat (Usher 1988 , 1989). For possums, this "compensatory response" has been observed in many parts of New Zealand where population numbers of this species have been controlled (Batcheler 1968, Hickling and Pekelharing 1989, Husheer 1994).

In the Karori Reserve possums were highly fecund and the population density probably higher than in less urban habitats. Although fecundity and density are generally inversely related, this effect is likely to originate from the heterogeneous vegetation of the urban fringe. This habitat offers a large variety of native, exotic, and garden plants providing a staple food source throughout the year which is important for possums to maintain good health (Cowan 1990). However, the inverse relation of population "health" and density is a microgeographic reality in the reserve. Possum density was highest in the Upper Reserve. In this area, the north-western aspects, the pine forests with native undergrowth and the gorse and flax dominated shrublands supported the highest numbers. In the Lower Reserve the possum density was significantly lower. Here, possums were generally in better condition and of a higher body weight, the reproductive output was larger, and a higher proportion of females and juveniles was observed. Possums in the Lower Reserve area exhibited the compensatory response of a population maintained at low density. 
Possum control also seemed more effective in the Lower Reserve than in the Upper Reserve. Usher (1989) suggested that the success of control is inversely proportional to the dispersal ability of the invader. The innate dispersal behaviour of juvenile possums covering distances as far as 10 to 25 kilometres has been described by Clout and Efford (1984) and by Cowan et al. (1996) which demonstrates the colonising potential of this species. Given each juvenile possum has the same ability and readiness to disperse, then the secludedness of a controlled area will be one factor determining the rate of re-infestation. The Upper Reserve is more predisposed to possum immigration than the Lower Reserve which is protected by its urban boundary.

The population density of possums gradually increased from the Lower to the Upper Reserve. This correlated negatively with the declining condition of tree fuchsia. This observation would have implications for the management of this tree species if possums and other invaders were not to be eradicated in the near future. The feeding behaviour of possums seemed to be particularly opportunistic in the Lower Reserve where the total number of potential food species is largest but where possums confined their diet to fewer species, particularly fuchsia. Assuming that fuchsia survival solely depended on possum density, this result would approximately indicate the tolerance threshold of fuchsia in relation to possum densities. In the Lower Reserve, fuchsia persisted even though in this area the plant was most utilised by possums. The 1995 Wellington Regional Council (WRC) control operation in the Lower Reserve achieved a 75 percent kill (Meenken 1995), when 4.03 possums were removed per hectare. This equates to a pre-operational density of 5.37 possums per hectare for this area. The Karori Sanctuary Trust hunter removed 5.5 possums per hectare from the 213 hectare Upper Reserve. However, post-operational trap catch monitoring by the WRC suggested that the contractor had not made any impact on the possum population as the post-operational catch rate actually exceeded pre-operational results. If the removal of 5 possums per hectare over a short time period does not make any measurable difference, then the possum density of the Upper Reserve must have been very high. The standing crop of possum pellets was more than three times as high in the Upper than in the Lower Reserve suggesting densities of 15 to 20 possums per hectare. To reduce possums to a population size under which fuchsia in the Upper Reserve could recover would therefore require an operational kill of at least 80 percent. This is a performance target which 
can not realistically be achieved by one hunter controlling possums in an area of 213 hectares. The negative effects of an insufficiently supported control operation has been discussed in Chapter 3. The control attempt only slightly improved the situation for the fuchsia trees in the Upper Reserve area. However, the operation has probably introduced some bait aversion or even neophobia in the surviving population, which compromises the success of the planned eradication campaign.

Except for the significant impact of possums on fuchsia no conspicuous canopy dieback has been observed in the reserve. This observation was also noticed by Pekelharing (1993) who came to similar conclusions. The main possum initiated process of change in plant communities offering a diverse mix of possum palatable species, is the gradual depletion of the most preferred food plants (Nugent 1995, Campbell 1990).

In forest communities which are dominated by only a few possum preferred species, such as the southern rata and kamahi dominated forests of Westland, possums can also change the structural integrity of the forest (Wardle 1974, Coleman, Gillman and Green 1980, Batcheler 1983, Pekelharing and Reynolds 1983, Pekelharing and Batcheler 1990). The causal process leading to this change has been the subject of much debate. Veblen and Stewart (1982) suggested cohort senescence of even aged vegetation stands as the ultimate mechanism driving an endogenous shift in forest composition. Batcheler (1983) argued that the repeated coincidence of increasing possum numbers and canopy collapse, the absence of significant dieback in the absence of possums and the recovery of trees which were protected from possums could not be explained by stand dynamics alone, as implied by Veblen and Stewart. Batcheler and Cowan (1988) and Rose et al. $(1992,1993)$ suggested that catastrophic dieback in such plant communities occurred 15 to 25 years after possums had colonised an area. The widespread collapse of the main canopy species was initiated once possum numbers exceeded carrying capacity. High possum populations could not be sustained by the environment and possum numbers would drop to lower levels. The possum population would then proceed through a phase of irruptive oscillations (Thomas et al. 1993): Allowing for sufficient time, both possum densities and the amount of forage would decline to a level at which the possum population and a depleted plant community come closer to an equilibrium. Being regulated by food supplies rather than by social interactions, possum 
densities would depend on the production of forage in such a modified ecological system (Green 1984).

In plant communities such as in the Karori Reserve, a possum initiated structural collapse of the forest is unlikely. In this more diverse forest habitat, possums are likely to remove some species and gradually shift the composition of the forest to less species rich assemblages. This trend has been observed in the diverse Orongorongo Valley lowland forest where the most favoured plants have gradually disappeared from the diet (Fitzgerald 1976) and also from the forest (Campbell 1990). Conservatively assuming 10 possums per hectare for the entire Karori Reserve, the resident population will total approximately 2500 possums. It has been quoted that each possum consumes about $300 \mathrm{~g}$ wet wt. a day (Nugent 1995) which equates to an annual consumption of 274 tonnes of forage per year. As long as the habitat generates this amount (and nutritional quality) of palatable forage, possum densities will be maintained at that level. At the same time the browse pressure on the most preferred food plants also remains constant. If the browse intensity exceeds the browse tolerance of a possum favoured plant species, then this species will vanish from the community. Fuchsia only constitutes a seasonal species in spring and summer and is probably not very important as a food source in a season when alternative food sources are also abundant. Therefore, its gradual disappearance is unlikely to have an effect on possum numbers. In the Orongorongo Valley, possum numbers remained stable over the past 25 years while food plants such as titoki, fuchsia, tutu and toro have virtually disappeared from the forest (Nugent 1995, Cowan 1990). This shows how the highly preferred but depleted food plants have little importance in maintaining the overall well-being of the possum population. Conversely, this also emphasises the direct impact of possums on the vegetation of diverse forest communities. 
Considering the ecological complexity of interactions, possums may not be the only agent for the observed fuchsia decline. Manion's (1981) theory of forest decline suggests three factors contribute to the degeneration of forest communities. According to Manion (1981) there must be:

- a predisposing factor which in itself does not initiate the process of decline;

- a factor which incites the decline and thereby puts additional pressure on the predisposed tree;

- a contributing factor which drives the process to completion.

For the fuchsia trees in the reserve, the predisposing factor may be the age of trees and the seral stage of the second growth forest. It is difficult to determine a single inciting factor, but there are many long and short term environmental sources of stress such as wind, drought and salt spray which can incite a decline. The contributing factor driving the decline to completion may be a combination of browsing animals and insects. Pathogens often take advantage of the already weakened and dying trees and eventually bring the process of decline to completion. Assuming similar predisposing and inciting factors for all fuchsia trees in the reserve, Manion's theory suggests that the combination of high level possum and insect browse in the Upper Reserve can bring the decline process to completion: In the Lower Reserve, possum browse as an additional contributing factor is not severe enough to drive the process of decline. This suggests that possums may not be the only cause of decline but the ultimate agent responsible for the observed fuchsia decline.

Prior to the possum eradication campaign on Kapiti Island, Atkinson (1992) marked 18 fuchsia trees and possum-proofed an additional two fuchsia trees with aluminium bands which possums could not climb. All unbanded trees were dead within 5 years after marking them. The banded trees remained healthy indicating that possums were the ultimate cause for the fuchsia collapse observed at this site. After eradicating possums from Kapiti Island, the total number of forest birds, especially tui, bellbird, whitehead and robin increased rapidly (Lovegrove 1987). The consequent increase of fuchsia fruit consumption by nectar feeding birds such as tui and bellbird would have been significant in ensuring widespread dispersal of 
seeds from the remaining parent trees. As a consequence, Atkinson (1992) predicted the abundance of fuchsia would increase in the future. A similar recovery can be expected once possums are excluded from the Upper Reserve providing that seed dispersing birds are present. Fuchsia regeneration will further depend on the site attributes and seral characteristics of the vegetation at any one location. Considering the maturity of the second growth forest in the reserve, it is unlikely that fuchsia will recover to densities which may have been present in the early successional stages of this forest.

Whereas most fuchsia trees in the Upper Reserve succumbed to the high level of browse pressure, some fuchsia trees remained untouched. Similar observations were made by Atkinson (1992), who located largely unbrowsed fuchsia stands on Kapiti Island before possums were eradicated. Other fuchsia stands were severely affected. The reason for some fuchsia trees surviving in areas where all other trees died should be investigated further. In an evolutionary sense, these survivors may represent a gene pool of individuals which divert energy in the synthesis of defensive allelochemicals which may be distasteful to possums. Although this observation raises 'nope for fuchsia in areas where possumis will not 'be controlled, it also suggests that genetic variability may be lost in declining fuchsia populations. The long term effect of loosing a significant proportion of genotypes may be less encouraging as chance mortality factors assume greater importance (Atkinson et al. 1995). The loss of "r-selected" (MacArthur and Wilson 1967) individuals of this gene continuum, those which invest energy into fast growth of palatable foliage instead of defensive compounds may also have repercussions for native fauna depending on this food source. Indeed, if individual trees are less palatable for possums then the same may be true for native birds and insects.

So far, only the direct impacts of possums on fuchsia in the reserve have been discussed. However, possums are part of a complex biological community in which they and other introduced fauna are linked with native flora and fauna via food and habitat webs (Innes 1995). Many possum impacts will therefore be indirect and difficult to be separated from . impacts of other fauna. As mentioned above, possums compete with birds for resources such as fruit and nectar. By denning in trees, they also compete with birds for roost and nest sites. Eradicating possums and re-introducing native birds to the reserve may revive links between native plants and their co-evolved birds which often function as pollination and seed dispersal 
agents. Eliminating rodents as well should create the preconditions for forest regeneration. The pathway of such regeneration in a mainland island situation such as the Karori Reserve will remain unpredictable. Studying these pathways of forest regeneration without the influence of vertebrate invaders and identifying the principle rules of biotic interaction will remain the greatest research challenge for the Karori Wildlife Reserve.

Possums also compete with insects for foliage. Dugdale (1975) found 92 percent of New Zealand cold tolerant plant genera have monophagous insects. This high degree of host-plant specificity suggests that many of the monophage associations have evolved over a very long period of time. For some genera restricted to nationally declining plant species, these insects are as much under threat as their hosts. Fuchsia is the host of three monophagous genera including defoliators, stem borers and sap suckers (Dugdale 1975). While the declining fuchsia population has little impact on possum numbers, these fuchsia-associated monophages will decline together with their host which further reduces the biological diversity of the reserve.

Even though possums co-exist with many other vertebrate pests in the reserve, they probably comprise a greater biomass than all other vertebrate pests combined. High numbers of possums will result in low numbers of other herbivores, as possums compete for vegetable matter with all herbivores and first-stage decomposers. Duncan (1994) suggested that as possums cause floristic changes in species composition toward less palatable species, this change will also affect amphipods. Any reduction in amphipod biomass will affect insect carnivores and insectivorous birds such as whiteheads and robins. This suggests that the rapid increase of these bird species on Kapiti Island (Lovegrove 1987) may have been an indirect response to the possum eradication.

Amphipods provide one of the main routes for the lignocellulosis of plant waste. In contrast to possums, amphipods deposit their lignin rich faeces and mineral rich urine well below the soil surface and usually within the vicinity of the feeding roots of plants. Diverting this process of mineralisation away from amphipods into possums will therefore lead to an impoverished soil structure resulting in a poorer nutrient return to plants (Duncan 1994). 
These examples of possum impact and predicted response to their exclusion only scratch the surface of more complex feedback loops between the dynamics of the plants and the dynamics of animals. Many of these feedback loops have evolved in isolation and over long periods of time which has generated a high degree of species specialisation in New Zealand (Simms and Fritz 1990, MacArthur and Wilson 1967). Possums and other vertebrate pests have disrupted these feedback loops and have thereby redirected the stochastic path of evolution (Caughley 1989). Because many of the original components and prerequisites are now missing, the removal of all vertebrate pests from the Karori Reserve will not simply reimpose these feedback loops and the system is therefore unlikely to return to its previous state. Instead, the removal of introduced biota and introduction of native biota will create a new system which, allowing for sufficient time, will develop its own unique feedback loops. "Restoring" in the sense of recreating what has been lost may therefore be an unrealistic task (Simberloff 1990). The project should ultimately aim to establish ecological functionality, using the endemic components which have long been lost from this area. This should be the major goal for this mainland island project. 


\section{Chapter 7}

\section{Eradicating possums from the Karori Reserve}

In Chapter 6, the impacts of possums on their environment and the effects of the environment on possums were discussed with particular reference to the Karori Reserve. This chapter presents recommendations for a possum eradication plan in this area. However, as possums are not the only mammalian species to be eradicated, an integrated pest eradication plan including all pest species will be outlined in Chapter 8 .

The Karori Wildlife Sanctuary Trust aims to establish an enclosed urban "mainland island" for the conservation of threatened or rare native New Zealand species in the Karori Reserve. The success of the project hinges on the erection of a predator proof fence which takes account of all site requirements of the Karori Reserve. Such a fence has now been designed (Fuller and Gorman 1997). The project further depends on the successful eradication of all introduced animal pests once construction of the fence has been completed. In the long term, the project depends on the maintenance of this pest free status.

Pivotal to the success of the possum eradication campaign is a network of tracks covering the entire area. During the Kapiti Island possum eradication campaign, $800 \mathrm{~km}$ of tracks were established. The cutting and maintenance of this length of track accounted for a large percentage of total effort and materials used in the Kapiti operation (Sherley 1992). In the Karori Reserve this task could be implemented even before the fence has been erected. A track-grid could be used to train volunteers, to estimate the time and workforce required to service the grid during the eradication campaign and to efficiently assess and monitor the abundance of pest species in the reserve before, during and after the operation. As possums take advantage of tracks and vegetation openings for ease of movement (Sherley 1992), the establishment of a grid system would also habituate possums to its availability and to humans using it. A system of tracks is particularly important in areas where dense vegetation hinders access. In the Karori Reserve, these areas include the mature native forest of the Lower Reserve (vegetation type 1), and the windswept gorse and flax dominated shrublands along the southern and western periphery of the catchment (vegetation types 6 and 10). Within the 
mature native forest of the Lower Reserve, possums were in particularly good morphological condition. The windswept gorse and flax dominated shrublands of the Upper Reserve were characterised by high mean faecal pellet counts suggesting high possum densities. These vegetation types are both difficult to access and habitat to possums which, due to their abundance or condition, may require more effort for their eradication.

In the Karori Reserve, possums are the most abundant vertebrate pest in terms of biomass and possibly even in terms of individuals per hectare. Because of their abundance and arboreal habit, possums are less exposed to standard ground control methods such as poisoning and trapping than ground feeding animals. They may therefore be the herbivorous species most difficult to eradicate. On the other hand, aspects of the life-history of possums such as their low reproductive rate, the lack of breeding by one-year old females (Cowan $1992,1985)$ and the size of their home ranges facilitates their eradication.

For eradicating possums from the Karori Reserve a variety of eradication techniques have to be employed. Each technique must take account of the changing site conditions and animal densities so that the very last animal can be removed.

In the first stage of the operation, possum densities should be significantly reduced by administering a poison which does not evoke any bait aversion or shyness. A widely used toxin for mammalian pest control is the second generation anticoagulant brodifacoum, which is traded under the brand name "Talon" (ICI Crop Care, Richmond, New Zealand). This toxin prevents the clotting of blood and animals typically die through haemorrhaging in the gut. Because Talon bait is slow acting, animals do not have to be pre-fed in order to be habituated to the bait.

Acute toxins such as cyanide or mono-sodiumfluoroacetate (1080) have the advantage that they kill animals rapidly. These toxins therefore prevent the animal from consuming a dosage well in access of the lethal requirement. Being more economic, acute poisons have the disadvantage that animals ingesting a sub-lethal dose can become bait shy, as they associate feeling unwell with eating the bait (Morgan et al. 1995, Hickling 1995). 
Because of the length of time between ingestion and onset of symptoms animals will not associate feeling unwell with the consumption of brodifacoum. By the time symptoms become apparent animals have usually ingested more than a lethal dosage. It is therefore recommended to administer cereal Talon bait in regularly spaced bait stations for the initial population reduction phase of the operation. To maintain the momentum of this first stage, no particular skills are required but to keep bait stations filled at all times.

The second stage of the campaign aims to remove possums which have not responded to the poisoning operation, while monitoring population densities as possum numbers decline. As some possums may be bait-shy, generally neophobic or just cautious in utilising unnatural food sources and as rodents may consume some of the bait, the bait interference rate from stations will not be reliable to monitor the declining abundance of possums in the reserve. While bait stations are regularly filled and the bait disappearance rate is monitored, the second stage of the eradication campaign should use regularly spaced traps on the gridsystem. Traps account for possums which have not responded to the poison. Assuming that each possum has the same probability of being caught in a leg-hold trap, this also delivers robust monitoring results when possum numbers are low. As a device, the Victor 1.5 leghold trap is recommended. Being larger than the commonly used Victor 1 leg hold trap, the Victor 1.5 model increases the trap area on the ground and thereby the chance of catching possums. This larger trap also minimises the possible event of possum escapes due to its greater jaw tension.

The third stage of the eradication campaign is concerned with the removal of last survivors. This final stage poses the greatest challenge and monitoring the presence of possums in the reserve will now be most important. Both the traps and bait stations should be monitored by a team particularly assigned to this task. At the same time, last surviving possums will be tracked down using specifically trained dogs. As no ground dwelling non target species are present in the Karori Reserve, as there were on Kapiti Island, dogs do not have to be constrained and can be used to their full potential. The systematic search for last survivors has to be supported by an appropriate number of dogs and handlers. This last stage of the possum eradication campaign will require the highest level of skill and has to be executed by a professional work-team. 
The exact timing of the whole operation has to be planned well in advance. Tasks for each operational day have to be identified and staff requirements have to be met. Being largely driven by a volunteer workforce, it is important to plan for the ability and availability of volunteers to do particular jobs on particular days. Volunteers have to be trained for the tasks they are required to do. Although the handling of anticoagulant poisons does not require a licence, workers need to be made aware of general heath and safety procedures regarding the use of the poison in remote locations. Workers involved in the trapping campaign must be instructed in the proper setting of traps and in the disposal of animals. This is important to prevent possum escapes from traps, to minimise cruelties to animals, and to prevent injury to trap operators.

It is important to ensure that each day's task is supported by the appropriate number of workers. Ideally, a core of full-time staff responsible for individual work teams and tasks should be available from start to finish of the project. Monitoring and immediate processing of data should be undertaken by work teams especially assigned to this task. Detailed accounts of previous eradication campaigns have been published for possums on Kapiti Island by Sherley (1992) and Cowan (1992). The combined information gained during the Kapiti possum operation should form the framework for the eradication campaign in the Karori Reserve. 


\section{Chapter 8}

\section{The multispecies eradication campaign}

The eradication of a whole range of pest species from a mainland island area has never been attempted in New Zealand or anywhere else in the world. In New Zealand this is also the first endeavour to prevent mammalian re-infestation in a mainland situation by constructing a specifically designed fence. Despite the lack of empirical knowledge, the Karori Reserve has all the prerequisites for a successful multispecies eradication campaign. The reserve is close to an urban centre with an enthusiastic volunteer base, it offers easy access from many locations, and the valley is of relatively small size and has no faces, gullies or bluffs too steep to be traversed. Assuming a properly planned and resourced operation the eradication campaign should be successfully completed within six months of commencement.

In the 1996 Draft Development Plan (Sec.8.1.3.), the Karori Sanctuary Trust states as its goal the "eradication of all introduced animal pests or reduction of populations to a level where they have no impact on the indigenous flora and fauna." However, maintaining any pest population at low levels can only be achieved by ongoing pest control, or by modifying the habitat so that it becomes increasingly unsuitable for the pest species in question. The only mammalian pests which could be controlled once the wildlife reserve has been established are hares (Lepus europaeus occidentalis) and feral ungulates such as goats (Capra hircus) and cattle. Hares are not abundant in the reserve and as they prefer open farmland, they pose no real threat to the realisation of the project. In case there are goats or cattle in the reserve, numbers will also be low. As these animals are large and conspicuous, their control or eradication by experienced goat hunters can still be attained once the main eradication campaign has been completed.

This final chapter will consider the implications of eradicating all major vertebrate pest species including herbivorous mammals such as possums, ship rats (Rattus rattus), Norway rats (Rattus norvegicus), house mice (Mus musculus), and rabbits (Oryctolagus cuniculus cuniculus), and carnivorous mammals such as stoats (Mustela erminea), ferrets (Mustela furo), weasels (Mustela nivalis vulgaris), cats (Felis catus) and hedgehogs (Erinaceus europaeus occidentalis). Information relevant to their eradication is summarised in Table 20. 
The eradication of herbivorous mammals should pose the greatest challenge, because in contrast to the group of carnivores, their habitat will improve as their numbers decline. As prey numbers decline, predators will have to range further, switch prey to non target species and should become increasingly susceptible to trapping and secondary poisoning. As the preferred poison, brodifacoum should be used for all herbivorous mammals in the reserve. Brodifacoum accumulates in the liver of poisoned animals. While it may take longer than a week for an animal to die, moribund individuals are easy prey for predators such as cats and mustelids. The density of predators in such an environment will significantly decline through secondary poisoning. This will ameliorate the possible effects of prey switching on birds in the reserve.

The operation should begin with a widespread poison campaign using an anticoagulant poison. Both mice and rats tend to enlarge their home ranges with decreasing density, that is, the range size of rodents is inversely related to density (Innes and Skipworth 1983, Fitzgerald 1981, Karl and Moller 1981). This behaviour increases the probability of encountering a bait station or trap as the eradication campaign proceeds. Also, rats have been known for their preference to feed at sites already used by conspecifics and for their responsiveness to intraspecific pressure to feed on the same food source as other rats (Taylor and Thomas 1993). These aspects of rodent behaviour significantly increase the chances of annihilating the last individuals in the most critical final stage of the eradication campaign. The grid size for trapping and poisoning and the time-frame of this integrated eradication project is determined by the target species with the smallest home range and the most prolific reproductive rate. In the Karori Reserve, these logistic decisions have to be based around the biology of mice and ship rats. 
Table 20: Summary of information and references relevant for the eradication of mammalian pests in the Karori Reserve.

\begin{tabular}{|c|c|c|c|c|c|c|c|}
\hline Pest Species & Home ranges & Reprod. season & Characteristies & Eradication attempt & Method used & Monitoring & Source/Author \\
\hline Possum & $1.3 \mathrm{ha}-1.9 \mathrm{ha}$ & autumn and spring & nocturnal, arboreal & Kapiti Island & $\begin{array}{l}\text { Aerial } 1080, \\
\text { trapping, shooting }\end{array}$ & $\begin{array}{l}\text { trapping, } \\
\text { detection by dogs }\end{array}$ & $\begin{array}{l}\text { Cowan 1990, Atkinson } \\
\text { 1992, Sherley } 1992 .\end{array}$ \\
\hline Ship rat & $\begin{array}{l}\text { minimum of } 0.54 \\
\text { ha. on Steward Isl. }\end{array}$ & September to April & $\begin{array}{l}\text { nocturnal, arboreal, } \\
\text { excellent smell,touch, } \\
\text { hearing and taste }\end{array}$ & \begin{tabular}{|l} 
Tawhitinui Island \\
\end{tabular} & & & Hickson et al. 1986 \\
\hline $\begin{array}{c}\text { Norway rat } \\
. \\
\end{array}$ & $\begin{array}{l}2.6 \mathrm{ha}-4.2 \mathrm{ha} \text {. on } \\
\text { Noises Island }\end{array}$ & August to April & \begin{tabular}{|l|} 
nocturnal, can swim. \\
responsive to peer \\
pressure
\end{tabular} & $\begin{array}{l}\text { Noises, Moutohora, } \\
\text { Breaksea and Kapiti } \\
\text { Islands. }\end{array}$ & $\begin{array}{l}\text { ground and aerial } \\
\text { baiting, } 1080 \text { and } \\
\text { Brodifacoum }\end{array}$ & $\begin{array}{l}\text { bait interfe } \\
\text { ence, trapping. } \\
\text { observation }\end{array}$ & $\begin{array}{l}\text { Moors 1985, Taylor and } \\
\text { Thomas 1993, Jansen } \\
\text { 1993, Empson unpubl. } \\
\end{array}$ \\
\hline House mouse & average 0.6 . ha & seizes in winter & mainly nocturnal & Mana and Allport Islands & $\begin{array}{l}\text { ground baiting. } \\
\text { Brodifacoum and } \\
\text { Flocoumafen. } \\
\end{array}$ & $\begin{array}{l}\text { bait interference } \\
\text { and trapping }\end{array}$ & $\begin{array}{l}\text { Todd and Miskelly } 1997, \\
\text { Brown } 1993 .\end{array}$ \\
\hline Rabbit & approx. 1 ha & June to March & nocturnal & Moutohora Island & $\begin{array}{l}\text { ground and aerial } \\
1080 \text { and } \\
\text { Brodifacoum. } \\
\text { trapping } \\
\end{array}$ & observation & Jansen 1993 \\
\hline Hare & \begin{tabular}{|l|}
$29-53$ ha in \\
Canterbury \\
\end{tabular} & July to March & nocturnal, solitary & - & - & - & Flux 1990 \\
\hline Cat & \begin{tabular}{|l|} 
linear $4 \mathrm{~km}$ to $>6 \mathrm{~km}$ \\
in Orongorongo \\
Valley
\end{tabular} & spring to autumn & mainly nocturnal & - & - & - & Fitzgerald 1990 \\
\hline Stoat & $>60 \mathrm{ha}$ & \begin{tabular}{|l|} 
September to \\
November
\end{tabular} & nocturnal and diurnal & - & - & - & King 1990, King 1977 \\
\hline Ferret & $12.4 \mathrm{ha}-31.3 \mathrm{ha}$ & October to March & nocturnal & - & - & - & $\begin{array}{l}\text { Lavers and Clapperton } \\
1990\end{array}$ \\
\hline Weasel & $\begin{array}{l}\text { 1ha to } 25 \mathrm{ha} \text { in } \\
\text { Europe }\end{array}$ & October to March & nocturnal & - & - & - & King 1990 \\
\hline Hedgehog & 2.5 ha to $3.6 \mathrm{ha}$ & November to February & $\begin{array}{l}\text { nocturnal, solitary, } \\
\text { hibernate }<11^{\circ} \mathrm{C} \\
\text { temperature }\end{array}$ & - & - & - & Brockie 1990 \\
\hline
\end{tabular}

In 1989, mice were successfully eradicated from Allports (16 ha) and Motutapu (2 ha) Islands in the Marlborough Sounds using a 50 metre bait station grid. In 1989-90 mice were eradicated from the 217 ha Mana Island, Wellington, where densities had reached epidemic proportions of 23,000 animals per hectare (Hutton 1990). Because it was expected that mice living in rank grassland would have small home ranges (Todd and Miskelly 1997), bait stations were placed on a 25 metre grid. Being initially more labour-intensive to establish, a small grid size improves access and the means to ascertain the absence or presence of target species once they occur at low numbers. Also, a small grid size with a maximum number of bait stations exposes a greater number of individuals to bait. This will significantly curtail the operation which should be completed before animals such as mice commence breeding in spring. A swift operation will also ameliorate ecological flow on effects such as prey switching by mustelids. A succinct and intensive operation completed during one winter season will drastically increase the likelihood of success and will reduce non-target kills of birds such as morepork (Ninox novaeseelandiae) red-billed gull (Larus scopulinus) and Australasian harrier (Circus approximans). As none of the other known bird species in the 
reserve are likely to prey on moribund animals or to feed on carrion, the impact of the operation on these species should be negligible.

Considering the steep topography of the Karori Reserve (correction factor 1.22 for a 35 degree slope) and using a similar grid size as on Mana Island would require a network of about $121 \mathrm{~km}$ of track, a challenging but realisable task.

As a general approach for eradicating mammalian pests from the Karori Reserve the following strategy is recommended:

- train dogs outside the reserve to detect the presence of mice, rats, rabbits or possums for the last stage of the campaign;

- establish and maintain a bait station grid to be cut as close as economically posssible (i.e. $25 \times 25$ metres);

- establish and number bait stations for mice and rats on the closest possible grid spacing. As a bait station, a $110 \mathrm{~mm}$ diameter Novacoil drainpipe cut into $400 \mathrm{~mm}$ lengths has previously been successfully used;

- establish and number possum bait stations on a 50 metre grid spacing (i.e. Philproof Baitstations mounted on trees approximately 0.5 metres off the ground);

- simultaneously fill all bait stations in early autumn. Use Talon 50WB 15gram wax briquettes on tin foil dish for Novacoil stations and Talon cereal bait for possum bait stations;

- rebait all stations daily until a routine can be established, which ensures that bait stations are always filled;

- set Timms traps with at least $70 \mathrm{~mm}$ holes and bait these traps with sardines to kill any surviving cats or mustelids. This must be done once a significant drop off in Talon consumption from bait stations (especially from rodent stations) becomes noticeable;

- once bait consumption has significantly decreased, nibbled bait should be replaced with fresh bait. The use of baits must be recorded in a set format on sheets which refer to the location of the bait station; 
- once all poison take approaches low levels commence with index trapping on the grid system to monitor the presence of rodents and with an intensive trapping campaign to kill and monitor possum numbers. Concentrate on areas with highest bait take, or areas known to be particularly attractive to the target species;

- keep both traps and filled bait stations in place and monitor all devices continuously;

- systematically scan the whole valley for last survivors of each target species by using specifically trained dogs;

- as hedgehogs may hibernate from June to September (Brockie 1990) they should become a focal point of attention in the later phase of the programme. Hedgehogs can be killed in Timms traps as well as in leghold traps, especially when they are baited with fish, meat or egg;

- as rabbits do not feed from bait stations, they have to be eradicated using the same toxin but a different approach. Talon (or Pindone) should be applied in small heaps of 10 to 15 pellets on earth spits in all rabbit feeding areas. Using the grid system, all rabbit burrows have to be located. Once locations have been established, fumigants forming toxic gases such as phosphine, chloropicrin and carbon monoxide can be employed to kill rabbits in situ in a succinct operation;

- the eradication programme should be routinely monitored by observing the bait interference, by grid or transect trapping and by the employment of trained dogs at least for the following summer.

Except for possums, the relative population densities for the other target species have not yet been investigated. Considering the entire reserve, these species exist in diverse situations. As species interact with each other and with their natural and physical environment, there will be numerous variables determining the relative abundance of each species. Any eradication campaign must be based on a good prior knowledge of the ecology and abundance of the target species (Cowan 1990). Because a good network of tracks provides the infrastructure for pre-operational population assessments, the planning, establishment and maintenance of such a grid system must be a paramount management task in the summer.prior to the operation. The actual poisoning campaign should be executed during winter, when breeding of rodents ceases and when most animal populations reach their annual low point due to the increasing environmental stress. 


\section{Appendix A: Pellet data}

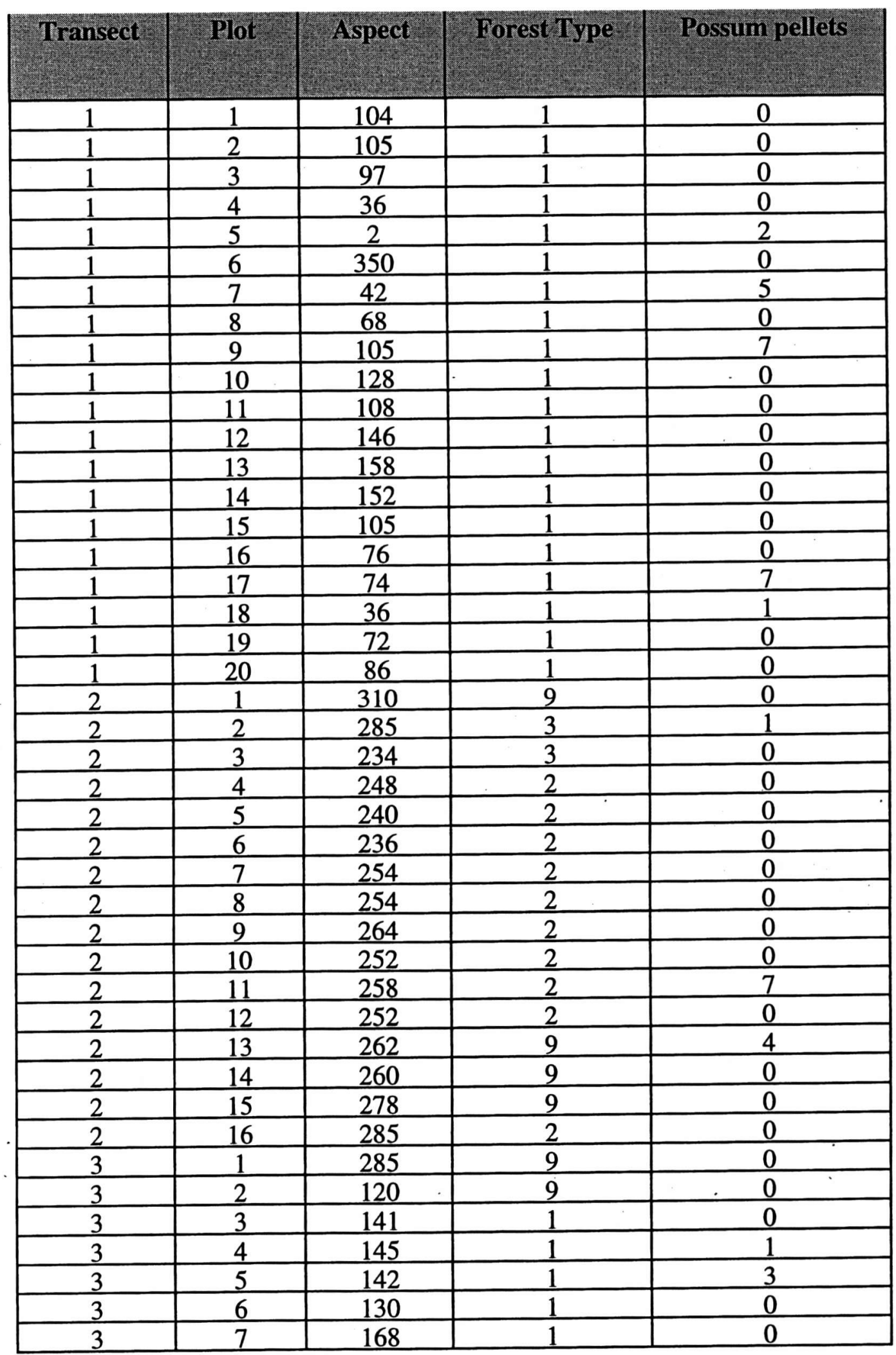




\begin{tabular}{|c|c|c|c|c|}
\hline Transect & Plot & Aspect & Forest Type & Possum pellets \\
\hline 3 & 8 & 176 & 1 & 0 \\
\hline 3 & 9 & 176 & 1 & 1 \\
\hline 3 & 10 & 200 & 1 & 2 \\
\hline 3 & 11 & 208 & 1 & 0 \\
\hline 3 & $\frac{12}{12}$ & 126 & 1 & 5 \\
\hline 3 & 13 & 112 & 1 & 1 \\
\hline 3 & 14 & 105 & 1 & 0 \\
\hline 3 & 15 & 70 & 1 & 0 \\
\hline 3 & 16 & 40 & 1 & 0 \\
\hline 3 & 17 & 105 & 9 & 0 \\
\hline 3 & 18 & & 9 & 9 \\
\hline 3 & 19 & 360 & 9 & 0 \\
\hline 3 & 20 & 382 & 9 & 0 \\
\hline 3 & 21 & 46 & 9 & 0 \\
\hline 3 & 22 & 56 & 9 & 0 \\
\hline 3 & 23 & 46 & 9 & 0 \\
\hline 3 & 24 & 105 & 9 & 0 \\
\hline 3 & 25 & 90 & 9 & 0 \\
\hline 3 & 26 & 60 & 9 & 0 \\
\hline 3 & 27 & 44 & 9 & 0 \\
\hline 3 & 28 & 10 & 9 & 6 \\
\hline 4 & 1 & 284 & 9 & 0 \\
\hline 4 & 2 & 280 & 9 & 0 \\
\hline 4 & 3 & 282 & 9 & 0 \\
\hline 4 & 4 & 308 & 9 & 2 \\
\hline 4 & 5 & 308 & 9 & 0 \\
\hline 4 & 6 & 302 & 9 & 0 \\
\hline 4 & 7 & 308 & 9 & 0 \\
\hline 4 & 8 & 334 & 9 & 3 \\
\hline 4 & 9 & 300 & 9 & 0 \\
\hline 4 & 10 & 328 & 3 & 2 \\
\hline 4 & 11 & 316 & 3 & 22 \\
\hline 4 & 12 & 310 & 3 & 8 \\
\hline 4 & 13 & 305 & 3 & 3 \\
\hline 4 & 14 & 310 & 3 & 9 \\
\hline 4 & 15 & 346 & 3 & 0 \\
\hline 4 & 16 & 75 & 3 & 3 \\
\hline 4 & 17 & 60 & 9 & 0 \\
\hline 4 & 18 & 62 & 9 & 0 \\
\hline 4 & 19 & 20 & 9 & 0 \\
\hline 4 & 20 & 16 & 9 & 4 \\
\hline 4 & 21 & 360 & 9 & 2 \\
\hline 4 & 22 & 360 & 3 & 0 \\
\hline 4 & 23 & 350 & 3 & 0 \\
\hline 4 & 24 & 260 & 9 & 0 \\
\hline 4 & 25 & 204 & 3 & 17 \\
\hline 4 & 26 & 180 & 9 & 0 \\
\hline 4 & 27 & 180 & 9 & 0 \\
\hline
\end{tabular}




\begin{tabular}{|c|c|c|c|c|}
\hline Transect & Plot & Aspect & Forest Type & Possum pellets \\
\hline 4 & 28 & 180 & 9 & 0 \\
\hline 4 & 29 & 180 & 9 & 0 \\
\hline 4 & 30 & 212 & 9 & 0 \\
\hline 4 & 31 & 142 & 9 & 0 \\
\hline 4 & 32 & 244 & 9 & 0 \\
\hline 4 & 33 & 244 & 9 & 0 \\
\hline 4 & 34 & 300 & 9 & 1 \\
\hline 4 & 35 & 300 & 9 & 3 \\
\hline 4 & 36 & 300 & 9 & 0 \\
\hline 4 & 37 & 308 & 9 & 3 \\
\hline 4 & 38 & 308 & 9 & 0 \\
\hline 4 & 39 & 308 & 9 & 1 \\
\hline 4 & 40 & 350 & 9 & 5 \\
\hline 4 & 41 & 320 & 9 & 0 \\
\hline 4 & 42 & 310 & 9 & 1 \\
\hline 4 & 43 & 308 & 9 & 0 \\
\hline 5 & 1 & 105. & 9 & 0 \\
\hline 5 & 2 & 56 & 9 & 0 \\
\hline 5 & 3 & 105 & 9 & 1 \\
\hline 5 & 4 & 105 & 9 & 4 \\
\hline 5 & 5 & 112 & 9 & 4 \\
\hline 5 & 6 & 134 & 9 & 0 \\
\hline 5 & 7 & 112 & 9 & 7 \\
\hline 5 & 8 & 114 & 9 & 0 \\
\hline 5 & 9 & 120 & 9 & 1 \\
\hline 5 & 10 & 128 & 9 & 6 \\
\hline 5 & 11 & 100 & 5 & 0 \\
\hline 5 & 12 & 90 & 5 & 0 \\
\hline 5 & 13 & 104 & 5 & 0 \\
\hline 5 & 14 & 118 & 5 & 0 \\
\hline 5 & 15 & 116 & 5 & 0 \\
\hline 5 & 16 & 118 & 9 & 0 \\
\hline 5 & 17 & 154 & 9 & 4 \\
\hline 5 & 18 & 140 & 9 & 0 \\
\hline 5 & 19 & 146 & 9 & 0 \\
\hline 5 & 20 & 142 & 9 & 0 \\
\hline 5 & 21 & 138 & 9 & 0 \\
\hline 5 & 22 & 154 & 9 & 0 \\
\hline 5 & 23 & 144 & 9 & 0 \\
\hline 5 & 24 & 188 & 9 & 1 \\
\hline 5 & 25 & 240 & 9 & 0 \\
\hline 5 & 26 & 254 & 9 & 0 \\
\hline 5 & 27 & 268 & 9 & 0 \\
\hline 5 & 28 & 160 & 9 & 0 \\
\hline 5 & 29 & 112 & 9 & 0 \\
\hline 5 & 30 & 114 & 9 & 1 \\
\hline 5 & 31 & 96 & 9 & 0 \\
\hline 5 & 32 & 64 & 9 & 0 \\
\hline
\end{tabular}




\begin{tabular}{|c|c|c|c|c|}
\hline Transect & Plot & Aspect & Forest Type & Possum pellets \\
\hline 5 & 33 & 73 & 9 & 0 \\
\hline 5 & 34 & 146 & 6 & 2 \\
\hline 5 & 35 & 46 & 6 & 0 \\
\hline 5 & 36 & 56 & 6 & 0 \\
\hline 5 & 37 & 50 & 9 & 2 \\
\hline 5 & 38 & 58 & 9 & 1 \\
\hline 5 & 39 & 86 & 9 & 0 \\
\hline 5 & 40 & 72 & 9 & 1 \\
\hline 5 & 41 & 74 & 6 & 0 \\
\hline 6 & 1 & 285 & 10 & 0 \\
\hline 6 & 2 & 285 & 11 & 5 \\
\hline 6 & 3 & 244 & 9 & 15 \\
\hline 6 & 4 & 275 & 9 & 0 \\
\hline 6 & 5 & 265 & 3 & 4 \\
\hline 6 & 6 & 270 & 3 & 0 \\
\hline 6 & 7 & 280 & 3 & 14 \\
\hline 6 & 8 & 270 & 9 & 0 \\
\hline$\frac{6}{6}$ & 9 & 265 & 9 & 0 \\
\hline 6 & 10 & 265 & 9 & 14 \\
\hline 6 & 11 & 270 & 9 & 4 \\
\hline 6 & 12 & 270 & 9 & 0 \\
\hline 6 & 13 & 268 & 9 & 0 \\
\hline 6 & 14 & 314 & 9 & 7 \\
\hline 6 & 15 & 10 & 9 & 3 \\
\hline 6 & 16 & 20 & 9 & 0 \\
\hline 6 & 17 & 8 & 9 & 0 \\
\hline 6 & 18 & 340 & 9 & 19 \\
\hline 6 & 19 & 280 & 11 & 10 \\
\hline 6 & 20 & 285 & 9 & 0 \\
\hline 6 & 21 & 280 & 9 & 1 \\
\hline 6 & 22 & 360 & 9 & 0 \\
\hline 6 & 23 & 46 & 9 & 0 \\
\hline 6 & 24 & 38 & 9 & 3 \\
\hline 6 & 25 & 18 & 9 & 16 \\
\hline 6 & 26 & 22 & 9 & 0 \\
\hline 6 & 27 & 10 & 10 & 1 \\
\hline 6 & 28 & 314 & 10 & 4 \\
\hline 6 & 29 & 355 & 10 & 0 \\
\hline 6 & 30 & 356 & 9 & 0 \\
\hline 6 & 31 & 16 & 9 & 0 \\
\hline 6 & 32 & 20 & 9 & 0 \\
\hline 6 & 33 & 332 & 9 & 3 \\
\hline 6 & 34 & 270 & 9 & 1. \\
\hline 6 & 35 & 312 & 9 & 2 \\
\hline 6 & 36 & 304 & 9 & 0 \\
\hline 6 & 37 & 328 & 9 & 1 \\
\hline 6 & 38 & 334 & 9 & 1 \\
\hline 6 & 39 & 320 & 9 & 0 \\
\hline 6 & 40 & 342 & 9 & 0 \\
\hline 6 & 41 & 328 & 9 & 0 \\
\hline 6 & 42 & 320 & 9 & 1 \\
\hline
\end{tabular}




\begin{tabular}{|c|c|c|c|c|}
\hline Transect & Plot & Aspect & Forest Type & Possum pellets \\
\hline 6 & 43 & 10 & 9 & 8 \\
\hline 6 & 44 & 60 & 9 & 2 \\
\hline 6 & 45 & 105 & 9 & 0 \\
\hline 6 & 46 & 105 & 9 & 0 \\
\hline 6 & 47 & 90 & 9 & 2 \\
\hline 6 & 48 & 76 & & 1 \\
\hline 6 & 49 & 100 & 3 & 3 \\
\hline 6 & 50 & 50 & 3 & 13 \\
\hline 6 & 51 & 352 & 3 & 10 \\
\hline 6 & 52 & 6 & 3 & 9 \\
\hline 6 & 53 & 20 & & 16 \\
\hline 6 & 54 & 350 & 9 & 0 \\
\hline 6 & 55 & 6 & 9 & 0 \\
\hline 6 & 56 & 38 & 9 & 1 \\
\hline 6 & 57 & 26 & 9 & 10 \\
\hline 6 & 58 & 38 & & 22 \\
\hline 6 & 59 & 14 & 3 & 47 \\
\hline 6 & 60 & 26 & 3 & 12 \\
\hline 6 & 61 & 34 & 3 & 10 \\
\hline 6 & 62 & 285 & 9 & 16 \\
\hline 6 & 63 & 254 & 9 & 2 \\
\hline 6 & 64 & 270 & 9 & 4 \\
\hline 6 & 65 & 280 & 9 & 1 \\
\hline 6 & 66 & 285 & 9 & 1 \\
\hline 6 & 67 & 285 & 9 & 0 \\
\hline 6 & 68 & 14 & 9 & 0 \\
\hline 6 & 69 & 50 & 9 & 0 \\
\hline 6 & 70 & 56 & 9 & 1 \\
\hline 6 & 71 & 94 & 9 & 0 \\
\hline 6 & 72 & 92 & 9 & 0 \\
\hline 6 & 73 & 90 & 9 & 4 \\
\hline 6 & 74 & 60 & 9 & 15 \\
\hline 6 & 75 & 70 & 9 & 1 \\
\hline 6 & 76 & 80 & 9 & 4 \\
\hline 7 & 1 & 3 & 9 & 10 \\
\hline 7 & 2 & 23 & 9 & 0 \\
\hline 7 & 3 & 21 & 9 & 1 \\
\hline 7 & 4 & 296 & 9 & 8 \\
\hline 7 & 5 & 8 & 9 & 0 \\
\hline 7 & 6 & 86 & 9 & 0 \\
\hline 7 & 7 & 108 & 9 & 0 \\
\hline 7 & 8 & 110 & 9 & 0 \\
\hline 7 & 9 & 96 & 9 & 0 \\
\hline 7 & 10 & 1.14 & 9 & 0 \\
\hline 7 & 11 & 110 & 9 & 0 \\
\hline 7 & 12 & 122 & 9 & 0 \\
\hline 7 & 13 & 108 & 9 & 0 \\
\hline 7 & 14 & 146 & 9 & 0 \\
\hline 7 & 15 & 148 & 9 & 0 \\
\hline 7 & 16 & 180 & 9 & 0 \\
\hline
\end{tabular}




\begin{tabular}{|c|c|c|c|c|}
\hline Transect & Plot & Aspect & Forest Type & Possum pellets \\
\hline 7 & 17 & 128 & 9 & 0 \\
\hline 7 & 18 & 118 & 9 & 0 \\
\hline 7 & 19 & 43 & 9 & 0 \\
\hline 7 & 20 & 60 & 9 & 0 \\
\hline 7 & 21 & 40 & 9 & 3 \\
\hline 7 & 22 & 36 & 9 & 3 \\
\hline 7 & 23 & 60 & 9 & 0 \\
\hline 7 & 24 & 114 & 9 & 3 \\
\hline 7 & 25 & 130 & 9 & 0 \\
\hline 7 & 26 & 100 & 9 & $n$ \\
\hline 7 & 27 & 160 & 9 & 0 \\
\hline 7 & 28 & 180 & 9 & 0 \\
\hline 7 & 29 & 20 & 9 & 0 \\
\hline 7 & 30 & 34 & 9 & 0 \\
\hline 7 & 31 & 70 & 9 & 0 \\
\hline 8 & 1 & 226 & 9 & 0 \\
\hline 8 & 2 & 235 & 9 & 0 \\
\hline 8 & 3 & 136 & 9 & 6 \\
\hline 8 & 4 & 296 & 9 & 0 \\
\hline 8 & 5 & 280 & 9 & 0 \\
\hline 8 & 6 & 285 & 9 & 0 \\
\hline 8 & 7 & 226 & 9 & 0 \\
\hline 8 & 8 & 245 & 9 & 0 \\
\hline 8 & 9 & 250 & 9 & 0 \\
\hline 8 & 10 & 262 & 9 & 0 \\
\hline 8 & 11 & 262 & 6 & 4 \\
\hline 8 & 12 & 268 & 6 & 0 \\
\hline 8 & 13 & 272 & 6 & 0 \\
\hline 8 & 14 & 285 & 9 & 9 \\
\hline 8 & 15 & 264 & 9 & 0 \\
\hline 8 & 16 & 285 & 6 & 16 \\
\hline 8 & 17 & 224 & 6 & 0 \\
\hline 8 & 18 & 246 & 6 & 0 \\
\hline 8 & 19 & 169 & 6 & 0 \\
\hline 8 & 20 & 170 & 9 & 11 \\
\hline 8 & 21 & 200 & 9 & 2 \\
\hline 8 & 22 & 220 & 9 & 6 \\
\hline 8 & 23 & 234 & 9 & 6 \\
\hline 8 & 24 & 254 & 9 & 19 \\
\hline 8 & 25 & 262 & 3 & 2 \\
\hline 8 & 26 & 275 & 3 & 7 \\
\hline 8 & 27 & 285 & 3 & 1 \\
\hline 8 & 28 & 276 & 6 & 30 \\
\hline 8 & 29 & 238 & 3 & 33 \\
\hline 8 & 30 & 190 & 9 & 2 \\
\hline 8 & 31 & 196 & 9 & 0 \\
\hline 8 & 32 & 242 & 9 & 0 \\
\hline 8 & 33 & 234 & 9 & 0 \\
\hline 8 & 34 & 246 & 9 & 0 \\
\hline 8 & 35 & 242 & 9 & 0 \\
\hline
\end{tabular}




\begin{tabular}{|c|c|c|c|c|}
\hline Transect & Plot & Aspect & Forest Type & Possum pellets \\
\hline 8 & 36 & 220 & 9 & 0 \\
\hline 8 & 37 & 208 & 9 & 8 \\
\hline 8 & 38 & 200 & 9 & 3 \\
\hline 8 & 39 & 228 & 9 & 6 \\
\hline 8 & 40 & 238 & 3 & 6 \\
\hline 8 & 41 & 250 & 3 & 0 \\
\hline 8 & 42 & 250 & 9 & 1 \\
\hline 8 & 43 & 256 & 9 & 2 \\
\hline 8 & 44 & 266 & 6 & 7 \\
\hline 8 & 45 & 252 & 3 & 1 \\
\hline 8 & 46 & 246 & 3 & 3 \\
\hline 8 & 47 & 232 & 3 & 0 \\
\hline 8 & 48 & 202 & 3 & 1 \\
\hline 8 & 49 & 214 & 3 & 0 \\
\hline 8 & 50 & 240 & 3 & 21 \\
\hline 9 & 1 & 354 & 9 & 0 \\
\hline 9 & 2 & 54 & 9 & 0 \\
\hline 9 & 3 & 44 & 9 & 10 \\
\hline 9 & 4 & 26 & 9 & 3 \\
\hline 9 & 5 & 5 & 9 & 0 \\
\hline 9 & 6 & 44 & 9 & 12 \\
\hline 9 & 7 & 6 & 3 & 6 \\
\hline 9 & 8 & 6 & 3 & 5 \\
\hline 9 & 9 & 22 & 3 & 7 \\
\hline 9 & 10 & 30 & 3 & 7 \\
\hline 9 & 11 & 32 & 3 & 0 \\
\hline 9 & 12 & 334 & 3 & 2 \\
\hline 9 & 13 & 277 & 3 & 6 \\
\hline 9 & 14 & 257 & 3 & 3 \\
\hline 9 & 15 & 262 & 3 & 11 \\
\hline 9 & 16 & 268 & 3 & 0 \\
\hline 9 & 17 & 264 & 3 & 4 \\
\hline 9 & 18 & 260 & 3 & 1 \\
\hline 9 & 19 & 350 & 3 & 1 \\
\hline 9 & 20 & 76 & 9 & 0 \\
\hline 9 & 21 & 60 & 3 & 0 \\
\hline 9 & 22 & 30 & 3 & 0 \\
\hline 9 & 23 & 30 & 3 & 0 \\
\hline 10 & 1 & 360 & 9 & 14 \\
\hline 10 & 2 & 276 & 9 & 0 \\
\hline 10 & 3 & 310 & 9 & 0 \\
\hline 10 & 4 & 346 & 9 & 10 \\
\hline 10 & 5 & 326 & 9 & 4 \\
\hline 10 & 6 & 30 & 9 & 0 \\
\hline 10 & 7 & 60 & 9 & 0 \\
\hline 10 & 8 & 12 & 9 & 0 \\
\hline 10 & 9 & 356 & 9 & 0 \\
\hline 10 & 10 & 248 & 9 & 0 \\
\hline 10 & 11 & 258 & 3 & 0 \\
\hline 10 & 12 & 270 & 3 & 0 \\
\hline
\end{tabular}




\begin{tabular}{|c|c|c|c|c|}
\hline Transect & Plot & Aspect & Forest Type & Possum pellets \\
& & & & \\
\hline 10 & 13 & 270 & 3 & 0 \\
\hline 10 & 14 & 266 & 9 & 0 \\
\hline 10 & 15 & 250 & 9 & 0 \\
\hline 10 & 16 & 255 & 3 & 0 \\
\hline 10 & 17 & 262 & 9 & 9 \\
\hline 10 & 18 & 257 & 9 & 5 \\
\hline 10 & 19 & 234 & 9 & 0 \\
\hline 10 & 20 & 246 & 9 & 0 \\
\hline 10 & 21 & 246 & 6 & 1 \\
\hline 10 & 22 & 257 & 6 & 15 \\
\hline
\end{tabular}




\section{Appendix B: Possum data}

\section{Morphometric measurements and collection data}

\begin{tabular}{|c|c|c|c|c|c|c|c|c|}
\hline Date & $\begin{array}{c}\text { Skull } \\
\text { number }\end{array}$ & Line & Stomach & Sex & Colour & $\begin{array}{l}\text { Body } \\
\text { length } \\
(\mathrm{cm})\end{array}$ & $\begin{array}{l}\text { Total } \\
\text { length } \\
\text { (cm) } \\
\end{array}$ & $\begin{array}{c}\text { Weight } \\
(\mathrm{kg})\end{array}$ \\
\hline $27-$ Oct-95 & & 1 & L1\1 & $\mathrm{F}$ & $\mathrm{G}$ & 48 & 79 & 2.1 \\
\hline 27-Oct-95 & & 1 & L112 & $M$ & $\mathrm{G}$ & 42 & 71 & 1.9 \\
\hline $27-$ Oct-95 & & 1 & L113 & $\mathrm{M}$ & $G$ & 40.5 & 71 & 1.85 \\
\hline 27-Oct-95 & & 1 & L114 & $M$ & $\mathrm{G}$ & 43 & 76 & 1.95 \\
\hline 27-Oct-95 & & 1 & L115 & $\mathrm{M}$ & $G$ & 47 & 79 & 3.2 \\
\hline 28-Oct-95 & & 2 & $\mathrm{~L} 2 \backslash 1$ & $\mathrm{M}$ & $\mathrm{G}$ & 51 & 83 & 2.9 \\
\hline 28-Oct-95 & & 2 & & $\mathrm{M}$ & $\mathbf{G}$ & 50 & 83 & 2.8 \\
\hline 28-Oct-95 & & 2 & L212 & $M$ & $\mathrm{~B} \backslash \mathrm{B}$ & 46 & 77 & 2.25 \\
\hline $28-$ Oct-95 & & 2 & & $\mathbf{M}$ & $\mathrm{B} \backslash \mathrm{B}$ & 44 & 76 & 2.7 \\
\hline $28-$ Oct-95 & & 2 & & FPP & $\mathrm{G}$ & 41 & 72 & 1.7 \\
\hline $28-$ Oct-95 & & 2 & & $\mathrm{M}$ & $G$ & 50 & 81 & 2.3 \\
\hline 28-Oct-95 & & 2 & & $\mathrm{M}$ & $\mathrm{G}$ & 42 & 69 & 1.6 \\
\hline 28-Oct-95 & & 2 & & $\mathrm{M}$ & $B \backslash B$ & 50 & 81 & 2.95 \\
\hline 28-Oct-95 & & 2 & & $\mathrm{~F}$ & $\mathbf{G}$ & 35 & 61 & 1 \\
\hline 28-Oct-95 & & 2 & & $\mathrm{~F}$ & $\mathrm{G}$ & 33 & 56 & 0.85 \\
\hline 28-Oct-95 & & 2 & & $M$ & $\mathrm{G}$ & 46 & 79 & 1.9 \\
\hline $28-$ Oct-95 & & 2 & & $M$ & $\mathrm{G}$ & 43.5 & 75 & 2.05 \\
\hline 28-Oct-95 & & 2 & . & $\mathrm{M}$ & $\mathrm{B} \backslash \mathrm{B}$ & 49 & 80 & 2.9 \\
\hline $28-O c t-95$ & & 2 & & FW & $\mathbf{G}$ & 43 & 71 & 1.8 \\
\hline 28-Oct-95 & & 2 & & $\mathrm{M}$ & $\mathrm{G}$ & 42 & 74 & 1.7 \\
\hline $28-O c t-95$ & & 2 & & FB & B & 48 & 80 & 2.5 \\
\hline $28-$ Oct-95 & & 2 & & $\mathbf{M}$ & $\mathrm{G}$ & 48 & 77 & 2.55 \\
\hline 28-Oct-95 & & 2 & & $\mathrm{M}$ & $\mathrm{B} \backslash \mathrm{B}$ & 49 & 70 & 1.4 \\
\hline 28-Oct-95 & & 2 & & $\mathrm{~F}$ & $\mathrm{G}$ & 41 & 75 & 1.9 \\
\hline 28-Oct-95 & & 2 & & $\mathrm{~F}$ & $\mathrm{G}$ & 36 & 60 & 1 \\
\hline 28-Oct-95 & & 2 & & FB & $G$ & 47 & 77 & 2.4 \\
\hline 31-Oct-95 & & 2 & & $\mathrm{M}$ & $\mathrm{G}$ & 49 & 81 & 3.15 \\
\hline 31-Oct-95 & & 2 & & FW & $G$ & 46 & 77 & 2.15 \\
\hline $31-$ Oct-95 & & 2 & & $\mathrm{M}$ & $\mathrm{G}^{\circ}$ & 41 & 69 & 1.8 \\
\hline 31-Oct-95 & & 3 & L3\1 & $\mathrm{F}$ & G & 39 & 67 & 1.5 \\
\hline $31-$ Oct-95 & & 3 & L312 & FB & $G$ & 50 & 81 & 2.75 \\
\hline 31-Oct-95 & & 3 & & $\mathrm{M}$ & $\mathbf{G}$ & 45 & 77 & 2.1 \\
\hline 31-Oct-95 & & 3 & & $\mathbf{M}$ & $B \backslash B$ & 50 & 82 & 2.8 \\
\hline
\end{tabular}




\begin{tabular}{|c|c|c|c|c|c|c|c|c|}
\hline Date & $\begin{array}{l}\text { Skul! } \\
\text { number }\end{array}$ & Line: & Stomach & Sex: & Colour & $\begin{array}{l}\text { Body } \\
\text { lenguh } \\
(\mathrm{cm}) \\
\end{array}$ & $\begin{array}{l}\text { Total } \\
\text { length } \\
(\mathrm{cm})\end{array}$ & $\begin{array}{c}\text { Weight } \\
(\text { (Kg) }\end{array}$ \\
\hline $31-O c t-95$ & & 3 & & $\mathrm{M}$ & $\mathrm{G}$ & 54 & 90 & 2.8 \\
\hline 31-Oct-95 & & 3 & & FB & $\mathrm{G}$ & 51 & 81 & 2.7 \\
\hline 31-Oct-95 & & 3 & & FPP & $G$ & 50 & 81 & 2.8 \\
\hline 31-Oct-95 & & 3 & & $\mathbf{M}$ & $\mathrm{G}$ & 33 & 54 & 0.6 \\
\hline 3-Nov-95 & & 4 & & FIB & $G$ & 45 & 77 & 3.15 \\
\hline 3-Nov-95 & & 4 & & $F$ & 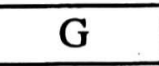 & 50 & 83 & 3.30 \\
\hline 3-Nov-95 & & 4 & & $\mathbf{M}$ & $G$ & 51 & 85 & 3.90 \\
\hline 3-Nov-95 & & 4 & & $\mathrm{~F}$ & $\mathrm{G}$ & 49 & 84 & 3.40 \\
\hline 3-Nov-95 & & 4 & & $\mathrm{~F}$ & G & 48 & 79 & 3.60 \\
\hline 3-Nov-95 & & 4 & & $\mathbf{M}$ & $G$ & 33 & 57 & 0.90 \\
\hline 3-Nov-95 & & 4 & & $\mathbf{M}$ & G & 36 & 61 & 1.30 \\
\hline 3-Nov-95 & & 4 & & $\mathrm{M}$ & $\mathrm{G}$ & 55 & 90 & 4.00 \\
\hline 3-Nov-95 & 1 & 4 & & $\mathbf{M}$ & $\mathrm{G}$ & 48 & 80 & 3.50 \\
\hline 3-Nov-95 & & 4 & taken & $F$ & $\mathbf{G}$ & 49 & 80 & 2.80 \\
\hline 3-Nov-95 & & 4 & & $\mathrm{M}$ & $G$ & 50 & 84 & 3.20 \\
\hline 3-Nov-95 & & 4 & & $\mathrm{M}$ & $G$ & 48 & 80 & 2.50 \\
\hline 3-Nov-95 & & 4 & taken & FB & $G$ & 50 & 82 & 3.40 \\
\hline 3-Nov-95 & 2 & 4 & & $\mathrm{M}$ & $G$ & 55 & 89 & 3.70 \\
\hline 3-Nov-95 & & 4 & & $M$ & $\mathrm{G}$ & 35 & 59 & 1.20 \\
\hline 3-Nov-95 & & 4 & taken & $\mathrm{F}$ & $\mathrm{B}$ & 49 & 83 & 3.60 \\
\hline 3-Nov-95 & & 4 & & $\mathrm{~F}$ & G & 43 & 72 & 2.20 \\
\hline 3-Nov-95 & 3 & 4 & & $\mathbf{M}$ & $\mathrm{G}$ & 36 & 62 & 1.30 \\
\hline 3-Nov-95 & 4 & 4 & & $\mathrm{~F}$ & $\mathrm{~B} \backslash \mathrm{B}$ & 47 & 80 & 3.10 \\
\hline 3-Nov-95 & 5 & 4 & & $\mathrm{M}$ & $\mathrm{B}$ & 35 & 61 & 1.20 \\
\hline 3-Nov-95 & & 4 & taken & $F$ & $\mathbf{G}$ & 47 & 82 & 3.20 \\
\hline 3-Nov-95 & & 4 & & $\mathbf{M}$ & $\mathrm{G}$ & 46 & 80 & 3.10 \\
\hline 3-Nov-95 & & 4 & & $\mathrm{~F}$ & $G$ & 47 & 80 & 2.60 \\
\hline 3-Nov-95 & 6 & 4 & & FP & $\mathbf{G}$ & 50 & 81 & 3.10 \\
\hline 3-Nov-95 & & 4 & taken & $\mathrm{M}$ & G\B & 53 & 84 & 3.80 \\
\hline 3-Nov-95 & & 4 & & $\mathbf{M}$ & $\mathrm{G}$ & 33 & 54 & 1.10 \\
\hline 3-Nov-95 & & 4 & & $\mathrm{M}$ & $G$ & 44 & 72 & 2.10 \\
\hline 3-Nov-95 & & 4 & taken & FP & $\mathrm{G}$ & 47 & 78 & 2.70 \\
\hline 3-Nov-95 & 7 & 4 & & $\mathrm{~F}$ & $\mathrm{G}$ & 34 & 54 & 0.90 \\
\hline 3-Nov-95 & & 4 & & FP & B. & 48 & 79 & 2.50 \\
\hline 3-Nov-95 & & 4 & & FW & $\mathrm{B} \backslash \mathrm{B}$ & 47 & 71 & 3.30 \\
\hline 3-Nov-95 & 8 & 4 & & FP & $\mathrm{B} \backslash \mathrm{B}$ & 47 & 78 & 2.95 \\
\hline 3-Nov-95 & 9 & 4 & & FIP & $\mathrm{G}$ & 46 & 79 & 3.10 \\
\hline 3-Nov-95 & & 4 & & $\mathrm{M}$ & G & 46 & 76 & 3.20 \\
\hline
\end{tabular}




\begin{tabular}{|c|c|c|c|c|c|c|c|c|}
\hline Date & $\begin{array}{l}\text { Skull } \\
\text { number }\end{array}$ & Line & Stomach & Sex & Colour & $\begin{array}{l}\text { Body } \\
\text { length } \\
(\mathrm{cm})\end{array}$ & $\begin{array}{l}\text { Total } \\
\text { length } \\
(\mathrm{cm}) \\
\end{array}$ & $\begin{array}{c}\text { Weight } \\
\text { (kg) }\end{array}$ \\
\hline 3-Nov-95 & 10 & 4 & & $\mathrm{~F}$ & $\mathbf{G}$ & 45 & 74 & 2.30 \\
\hline 3-Nov-95 & 11 & 4 & & $\mathbf{M}$ & $\mathrm{G}$ & 43 & 74 & 2.20 \\
\hline 3-Nov-95 & 12 & 4 & & $\mathrm{~F}$ & B & 41 & 75 & 2.20 \\
\hline 3-Nov-95 & 13 & 4 & & FP & $G$ & 49 & 87 & 3.30 \\
\hline 3-Nov-95 & & 4 & & $\mathrm{M}$ & $\mathrm{G}$ & 42 & 72 & 1.90 \\
\hline 3-Nov-95 & 14 & 4 & & $\mathrm{M}$ & $\mathrm{B} \backslash \mathrm{B}$ & 33 & 54 & 1.00 \\
\hline 3-Nov-95 & & 4 & & $\mathrm{M}$ & $\mathrm{G}$ & 33 & 55 & 1.00 \\
\hline 3-Nov-95 & & 4 & & $\mathrm{~F}$ & $\mathrm{~B} \backslash \mathrm{B}$ & 46 & 78 & 2.40 \\
\hline 3-Nov-95 & & 4 & & $\mathrm{~F}$ & B & 41 & 69 & 2.00 \\
\hline 3-Nov-95 & 15 & 4 & & FUP & $\mathrm{G}$ & 47 & 83 & 3.50 \\
\hline 3-Nov-95 & 16 & 4 & & $\mathbf{M}$ & $\mathrm{G}$ & 48 & 79 & 3.20 \\
\hline 3-Nov-95 & 17 & 4 & & $\mathrm{~F}$ & B\B & 42 & 73 & 2.20 \\
\hline 3-Nov-95 & 18 & 4 & & $\mathrm{~F}$ & $\mathrm{BWB}$ & 32 & 55 & 1.00 \\
\hline 3-Nov-95 & & 4 & & $\mathbf{M}$ & $\mathbf{G}$ & 48 & 80 & 2.60 \\
\hline 3-Nov-95 & 19 & 4 & & $\mathrm{~F}$ & $\mathrm{G}$ & 34 & 61.5 & 1.20 \\
\hline 3-Nov-95 & 20 & 4 & & $\mathbf{M}$ & $\mathbf{G}$ & 48 & 82 & 3.00 \\
\hline 3-Nov-95 & 21 & 4 & & $\mathrm{~F}$ & $\mathrm{~B} \backslash \mathrm{B}$ & 36 & 59.5 & 1.60 \\
\hline 3-Nov-95 & & 4 & & $\mathrm{~F}$ & $\mathrm{G}$ & 49 & 82 & 2.50 \\
\hline 3-Nov-95 & 22 & 4 & & FB & $G$ & 47 & 79 & 2.30 \\
\hline 3-Nov-95 & 23 & 4 & & FIP & $\mathrm{G}$ & 51 & 85 & 3.00 \\
\hline 3-Nov-95 & & 4 & & $\mathbf{M}$ & B & 36 & 63.5 & 1.30 \\
\hline 3-Nov-95 & & 4 & & $\mathrm{M}$ & $\mathrm{B} \backslash \mathrm{B}$ & 45 & 76 & 3.00 \\
\hline 3-Nov-95 & & 4 & & FUP & $\mathrm{G}$ & 46 & 77 & 3.10 \\
\hline 3-Nov-95 & & 4 & & $\mathrm{~F}$ & $\mathrm{G}$ & 33 & 58 & 1.00 \\
\hline 3-Nov-95 & & 4 & & $M$ & $\mathrm{G}$ & 47 & 80 & 3.20 \\
\hline 3-Nov-95 & & 4 & & $\mathrm{~F}$ & $\mathrm{G}$ & 37 & 63 & 1.20 \\
\hline 3-Nov-95 & 24 & 4 & & $\mathrm{M}$ & $\mathrm{G}$ & 29 & 52 & 0.90 \\
\hline 3-Nov-95 & 25 & 4 & & FP & $G$ & 48 & 82 & 3.00 \\
\hline 7-Nov-95 & & 5 & L5\1 & $\mathbf{M}$ & $\mathrm{G}$ & 50 & 84 & 2.80 \\
\hline 7-Nov-95 & & 5 & & $\mathrm{M}$ & $\mathrm{G}$ & 30 & 53.5 & 0.80 \\
\hline 7-Nov-95 & & 5 & L512 & $\mathbf{M}$ & $\mathrm{G}$ & 52 & 83 & 3.15 \\
\hline 7-Nov-95 & & 5 & & $\mathrm{M}$ & $\mathrm{G}$ & 36 & 60 & 1.10 \\
\hline 7-Nov-95 & 26 & 5 & $\mathrm{~L} 513$ & $\mathbf{M}$ & $\mathrm{G}$ & .49 & 78 & 2.40 \\
\hline 7-Nov-95 & & 5 & L514 & $\mathrm{F}$ & $\mathrm{G}$ & 49 & 80. & 2.50 \\
\hline 7-Nov-95 & 27 & 5 & L515 & $\mathrm{M}$ & GIB & 53 & 85 & 3.00 \\
\hline 7-Nov-95 & 28 & 6 & L611 & $\mathrm{M}$ & $\mathrm{G}$ & 47 & 75 & 2.40 \\
\hline 7-Nov-95 & & 6 & L612 & $\mathbf{M}$ & $\mathrm{G}$ & 53 & 85 & 3.55 \\
\hline 7-Nov-95 & & 6 & L613 & $\mathrm{M}$ & $\mathrm{G}$ & 41 & 68 & 1.80 \\
\hline
\end{tabular}




\begin{tabular}{|c|c|c|c|c|c|c|c|c|}
\hline Date & $\begin{array}{c}\text { Skull } \\
\text { number }\end{array}$ & Line & Stomach & Sex & Colour & $\begin{array}{l}\text { Body } \\
\text { length } \\
(\mathrm{cm}) \\
\end{array}$ & $\begin{array}{l}\text { Total } \\
\text { length } \\
(\mathrm{cm}) \\
\end{array}$ & $\begin{array}{c}\text { Weight } \\
\text { (kg) }\end{array}$ \\
\hline 7-Nov-95 & & 6 & L614 & $\mathrm{M}$ & $G$ & 47 & 80 & 2.30 \\
\hline 7-Nov-95 & & 6 & & $\mathrm{M}$ & GLB & 51 & 87 & 3.45 \\
\hline 7-Nov-95 & 29 & 7 & & $\mathrm{M}$ & $\mathrm{G}$ & 46 & 77 & 2.70 \\
\hline 7-Nov-95 & 30 & 7 & $L 7 \backslash 1$ & $F$ & $G$ & 47 & 77 & 2.10 \\
\hline 7-Nov-95 & & 7 & & FB & $G$ & 50 & 81 & 2.80 \\
\hline 7-Nov-95 & & 7 & & $\mathrm{M}$ & $G$ & 45 & 76 & 2.50 \\
\hline $7-$ Nov-95 & 31 & 7 & L7\2 & $\mathrm{F}$ & $G$ & 46 & 79 & 2.30 \\
\hline 7-Nov-95 & 32 & 7 & & $\mathrm{M}$ & B & 35 & 61 & 0.95 \\
\hline 8-Nov-95 & 33 & 5 & L516 & $M$ & $\mathrm{~B} \backslash \mathrm{B}$ & 52 & 83 & 3.30 \\
\hline 8-Nov-95 & & 5 & & $\mathrm{~F}$ & $\mathbf{G}$ & 47 & 75 & 2.20 \\
\hline 8-Nov-95 & 34 & 5 & $\mathrm{~L} 517$ & FB & B & 47 & 78 & 2.50 \\
\hline 8-Nov-95 & 35 & 5 & L518 & $\mathrm{F}$ & B & 45 & 77 & 1.90 \\
\hline 8-Nov-95 & & 5 & & $F$ & $\mathrm{G}$ & 46 & 79 & 2.40 \\
\hline 8-Nov-95 & & 5 & & $\mathrm{M}$ & $G$ & 37. & 63 & 1.05 \\
\hline 8-Nov-95 & & 5 & L519 & $\mathrm{F}$ & $\mathrm{G}$ & 50 & 82 & 2.00 \\
\hline 8-Nov-95 & 36 & 6 & L615 & FB & $G$ & 47 & 78 & 2.10 \\
\hline 8-Nov-95 & 37 & 6 & L616 & $\mathbf{M}$ & $G$ & 54 & 87 & 3.30 \\
\hline 8-Nov-95 & & 6 & L617 & $\mathrm{M}$ & $G$ & 44 & 71 & 1.90 \\
\hline 8-Nov-95 & 38 & 6 & & $\mathrm{M}$ & B & 38 & 63 & 1.10 \\
\hline 8-Nov-95 & & 6 & & $\mathbf{M}$ & B & 45 & 73 & 1.65 \\
\hline 8-Nov-95 & & 6 & L618 & $\mathbf{M}$ & $\mathrm{G}$ & 45 & 76 & 1.90 \\
\hline 8-Nov-95 & & 7 & $L 7 \backslash 3$ & $\mathrm{~F}$ & $\mathrm{G}$ & 45 & 75 & 2.40 \\
\hline 8-Nov-95 & 39 & 7 & L7\4 & $M$ & $\mathrm{G}$ & 50 & 79 & 2.80 \\
\hline 8-Nov-95 & 40 & 7 & L7\5 & $\mathrm{M}$ & $\mathrm{G}$ & 51 & 85 & 2.65 \\
\hline 8-Nov-95 & 41 & 7 & L7\6 & $F$ & $\mathrm{~B}$ & 49 & 79 & 3.00 \\
\hline 8-Nov-95 & & 7 & $\mathrm{~L} 7>7$ & $M$ & $\mathrm{G}$ & 50 & 82 & 2.90 \\
\hline 9-Nov-95 & 42 & 5 & L5\10 & $\mathrm{M}$ & $\mathrm{G}$ & 46 & 76 & 2.10 \\
\hline 9-Nov-95 & 43 & 5 & L5\11 & $\mathrm{M}$ & $\mathrm{G}$ & 48 & 78 & 2.60 \\
\hline 9-Nov-95 & & 5 & L5\12 & $\mathrm{M}$ & $\mathrm{G}$ & 50 & 78 & 2.70 \\
\hline 9-Nov-95 & & 5 & L5\13 & $\mathrm{F}$ & $\mathrm{G}$ & 47 & 81 & 2.30 \\
\hline 9-Nov-95 & 44 & 6 & L619 & $F$ & GLB & 52 & 83 & 2.60 \\
\hline 9-Nov-95 & 45 & 6 & L6\10 & $F$ & $\mathrm{G}$ & 49 & 79 & 2.00 \\
\hline 9-Nov-95 & 46 & 7 & $\mathrm{~L} 7>8$ & $\mathrm{~F}$ & $G$ & 49 & 85 & 2.80 \\
\hline 9-Nov-95 & 47 & 7 & $\mathrm{~L} 7 \mathrm{~A}$ & $\mathrm{~F}$ & $\mathrm{G}$ & 45 & 77 & $2: 40$ \\
\hline 9-Nov-95 & 48 & 7 & $L 7 \backslash 10$ & $\mathrm{M}$ & $G$ & 45 & 74 & 2.45 \\
\hline 9-Nov-95 & 49 & 7 & $\mathrm{~L} 7 \backslash 11$ & $M$ & $\mathrm{G}$ & 46 & 76 & 2.30 \\
\hline
\end{tabular}




\section{Possum ages}

\begin{tabular}{|c|c|c|c|c|c|c|c|c|c|}
\hline $\begin{array}{c}\text { Skuil } \\
\text { number }\end{array}$ & Line & Sex: & Unstained & $\begin{array}{c}\text { Stained } \\
\text { trail } 1\end{array}$ & $\begin{array}{c}\text { Stained } \\
\text { trail } 2\end{array}$ & $\begin{array}{c}\text { Stained } \\
\text { trail } 3\end{array}$ & $\begin{array}{c}\text { Stained } \\
\text { trail } 4\end{array}$ & $\begin{array}{l}\text { Final } \\
\text { Age }\end{array}$ & $\begin{array}{c}\text { Age } \\
\text { (Winter) }\end{array}$ \\
\hline 1 & 4 & $M$ & 2 & 3 & 2 & 2 & 3 & 3 & 3 \\
\hline 2 & 4 & $M$ & 2 & 5 & 5 & 3 & 3 & 4 & 4.5 \\
\hline 3 & 4 & $M$ & 1 & 1 & 1 & 1 & 1 & 1 & 1 \\
\hline 4 & 4 & $F$ & 6 & 8 & 7 & 7 & 7 & 7 & 5 \\
\hline 5 & 4 & $M$ & 1 & 1 & 1 & 1 & 1 & 1 & 1 \\
\hline 6 & 4 & FIP & 3 & 2 & 2 & 2 & 1 & 2 & 3 \\
\hline 7 & 4 & $F$ & 2 & 2 & 1 & 1 & 1 & 1 & 1.5 \\
\hline 8 & 4 & FP & 7 & 7 & 6 & 5 & 5 & 6 & 4 \\
\hline 9 & 4 & FP & 2 & 3 & 3 & 2 & 3 & 3 & 4 \\
\hline 10 & 4 & $\mathrm{~F}$ & 3 & 2 & 2 & 3 & 3 & 3 & 3.5 \\
\hline 11. & 4 & $M$ & 2 & 2 & 1 & 2 & 1 & 2 & 2 \\
\hline 12 & 4 & $F$ & 2 & 1 & 2 & 2 & 2 & 2 & 3 \\
\hline 13 & 4 & FIP & 6 & 7 & 7 & 4 & 4 & 6 & 3.5 \\
\hline 14 & 4 & $M$ & 2 & 2 & 1 & 1 & 2 & 1 & 1 \\
\hline 15 & 4 & FP & 2 & 2 & 3 & 2 & 2 & 2 & 4 \\
\hline 16 & 4 & $M$ & 2 & 2 & 2 & 2 & 2 & 2 & 4 \\
\hline 17 & 4 & $\mathrm{~F}$ & 3 & 3 & 2 & 2 & 2 & 3 & 3 \\
\hline 18 & 4 & $F$ & 1 & 1 & 1 & 1 & 1 & 1 & 4 \\
\hline 19 & 4 & $F$ & 2 & 2 & 1 & 1 & 1 & 1 & 3 \\
\hline 20 & 4 & $M$ & 4 & 3 & 3 & 2 & 3 & 3 & 3 \\
\hline 21 & 4 & $F$ & 1 & 1 & 2 & 1 & 2 & 1 & 2 \\
\hline 22 & 4 & $\mathrm{FB}$ & 2 & 3 & 3 & 3 & 2 & 3 & 3 \\
\hline 23 & 4 & $\mathrm{FP}$ & 4 & 5 & 4 & 4 & 3 & 4 & 4 \\
\hline 24 & 4 & $M$ & 1 & 2 & 1 & 1 & 1 & 1 & 2 \\
\hline 25 & 4 & FIP & 3 & 2 & 2 & 2 & 2 & 2 & 2 \\
\hline 26 & 5 & $\mathrm{M}$ & 4 & 4 & 4 & 3 & 3 & 4 & 3 \\
\hline 27 & 5 & $M$ & 4 & 7 & 7 & 4 & 7 & 7 & 4 \\
\hline 28 & 6 & $M$ & 3 & 3 & 3 & 3 & 3 & 3 & 4.5 \\
\hline 29 & 7 & $M$ & 3 & 5 & 5 & 4 & 3 & 5 & 3.5 \\
\hline 30 & 7 & $F$ & 2 & 2 & 2 & 1 & 1 & 2 & 3 \\
\hline 31 & 7 & $F$ & 1 & 2 & 1 & 2 & 2 & 2 & 1.5 \\
\hline 32 & 7 & $M$ & 1 & 1 & 1 & 2 & 1 & 1 & 1 \\
\hline 33 & 5 & $M$ & 2 & 5 & 4 & 3 & 2 & 4 & 3.5 \\
\hline 34 & 5 & $\mathrm{FIB}$ & 8 & 8 & 8 & 8 & 7 & 8 & 5 \\
\hline 35 & 5 & $F$ & 1 & 2 & 2 & 2 & 3 & 2 & . 2 \\
\hline 36 & 6 & FlB & 4 & 3 & 3 & 2 & 2 & 3 & 4 \\
\hline 37 & 6 & $\cdot M$ & 3 & 7 & 7 & 7 & 8 & 7 & 6 \\
\hline 38 & 6 & $M$ & 2 & 2 & 1 & 1 & 2 & 1 & 1 \\
\hline 39 & 7 & $M$ & 1 & 3 & 3 & 2 & 1 & 2 & 1 \\
\hline 40 & 7 & $M$ & 4 & 5 & 5 & 6 & 6 & 6 & 4 \\
\hline
\end{tabular}




\begin{tabular}{|c|c|c|c|c|c|c|c|c|c|}
\hline $\begin{array}{c}\text { Skull } \\
\text { number }\end{array}$ & Line & Sex & Unstained & $\begin{array}{c}\text { Stained } \\
\text { trail 1 }\end{array}$ & $\begin{array}{c}\text { Stained } \\
\text { trail 2 }\end{array}$ & $\begin{array}{c}\text { Stained } \\
\text { trail 3 }\end{array}$ & $\begin{array}{c}\text { Stained } \\
\text { trail 4 }\end{array}$ & $\begin{array}{c}\text { Final } \\
\text { Age }\end{array}$ & $\begin{array}{c}\text { Age } \\
\text { (Winter) }\end{array}$ \\
\hline 41 & 7 & $\mathrm{~F}$ & 1 & 5 & 4 & 4 & 4 & $\mathbf{4}$ & $\mathbf{4}$ \\
\hline 42 & 5 & $\mathrm{M}$ & 2 & 2 & 2 & 2 & 1 & $\mathbf{2}$ & $\mathbf{3}$ \\
\hline 43 & 5 & $\mathrm{M}$ & 3 & 3 & 2 & 3 & 4 & 3 & $\mathbf{4}$ \\
\hline 44 & 6 & $\mathrm{~F}$ & 2 & 3 & 4 & 3 & 4 & 3 & 3 \\
\hline 45 & 6 & $\mathrm{~F}$ & 3 & 7 & 5 & 6 & 6 & $\mathbf{6}$ & $\mathbf{5}$ \\
\hline 46 & 7 & $\mathrm{~F}$ & 2 & 3 & 4 & 4 & 3 & 3 & 5 \\
\hline 47 & 7 & $\mathrm{~F}$ & 3 & 3 & 2 & 2 & 3 & 3 & 3 \\
\hline 48 & 7 & $\mathrm{M}$ & 2 & 3 & 3 & 2 & 1 & $\mathbf{2}$ & $\mathbf{2 . 5}$ \\
\hline 49 & 7 & $\mathrm{M}$ & 3 & 3 & 3 & 2 & 2 & 3 & 4 \\
\hline
\end{tabular}




\section{Trap-catch data}

\begin{tabular}{|c|c|c|c|c|c|c|c|c|c|}
\hline Line & Trap & Aspect & $\begin{array}{c}\text { Vegetation } \\
\text { type }\end{array}$ & $\begin{array}{l}\text { Tree } \\
\text { species }\end{array}$ & $\pi 11195$ & 8117195 & 9111195 & possums & $\begin{array}{l}\text { trap } \\
\text { nights }\end{array}$ \\
\hline 5 & 1 & 36 & 9 & Mel ram & & $M$ & & 1 & 3 \\
\hline 5 & 2 & 45 & 9 & Mel ram & & & & 0 & 3 \\
\hline 5 & 3 & 112 & 3 & Mel ram & & & $M$ & 1 & 3 \\
\hline 5 & 4 & 116 & 3 & Pine & $M$ & $\mathrm{~F}$ & & 2 & 3 \\
\hline 5 & 5 & 233 & 3 & Mel ram & & FB & $M$ & 2 & 3 \\
\hline 5 & 6 & 354 & 3 & Mel ram & & & & 0 & 3 \\
\hline 5 & 7 & 356 & 3 & Mel ram & & $F$ & $M$ & 2 & 3 \\
\hline 5 & 8 & 302 & 3 & Pine & $M$ & & & 1 & 3 \\
\hline 5 & 9 & 354 & 3 & Mel ram & & & & 0 & 3 \\
\hline 5 & 10 & 61 & 3 & Pine & $M$ & & & 1 & 3 \\
\hline 5 & 11 & 350 & 3 & Pse arb & $M$ & $F$ & & 2 & 3 \\
\hline 5 & 12 & 0 & 3 & & & & & 0 & 3 \\
\hline 5 & 13 & 0 & 3 & & & $M$ & & 1 & 3 \\
\hline 5 & 14 & 340 & 3 & Pine & $M$ & & & 1 & 3 \\
\hline 5 & 15 & 20 & 3 & Pine & $F$ & $F$ & & 2 & 3 \\
\hline 5 & 16 & 318 & 3 & Mel ram & & & & 0 & 3 \\
\hline 5 & 17 & 336 & 3 & Pine & $M$ & & $F$ & 2 & 3 \\
\hline 5 & 18 & 312 & 3 & Mel ram & & & & 0 & 3 \\
\hline 6 & 1 & 318 & 3 & Pine & $M$ & $\mathrm{FB}$ & & 2 & 3 \\
\hline 6 & 2 & 342 & 3 & Pine & & & & 0 & 3 \\
\hline 6 & 3 & 350 & 3 & Pine & & $M$ & & 1 & 3 \\
\hline 6 & 4 & 80 & 9 & Ash & & & & 0 & 3 \\
\hline 6 & 5 & 0 & 9 & Pine & & & & 0 & 3 \\
\hline 6 & 6 & 0 & 9 & Mel ram & & & & 0 & 3 \\
\hline 6 & 7 & 0 & 9 & Pse arb & & & & 0 & 3 \\
\hline 6 & 8 & 270 & 9 & Pse arb & $\bar{M}$ & & & 1 & 3 \\
\hline 6 & 9 & 270 & 9 & Mel ram & & $\mathrm{M}$ & $F$ & 2 & 3 \\
\hline 6 & 10 & 270 & 9 & Mel ram & & & $S$ & 0 & 2.5 \\
\hline 6 & 11 & 320 & 9 & Mel ram & $M$ & $\bar{M}$ & & 2 & 3 \\
\hline 6 & 12 & 215 & 9 & Mel ram & & & $F$ & 1 & 3 \\
\hline 6 & 13 & 290 & 9 & Mel ram & & & & 0 & 3 \\
\hline 6 & 14 & 240 & 9 & Mel ram & & & & 0 & 3 \\
\hline 6 & 15 & 240 & 9 & Pse arb & $M$ & $M$ & & 2 & 3 \\
\hline 6 & 16 & 310 & 9 & Pine & $M$ & $M$ & & 2 & 3 \\
\hline 7 & 1 & 290 & 9 & Mel ram & & & $\mathrm{S}$ & 0 & 2.5 \\
\hline 7 & 2 & 320 & 9 & Arb uni & $M$ & $F$ & & 2 & 3 \\
\hline 7 & 3 & 260 & 9 & Mel ram & & $M$ & & 1 & 3 \\
\hline 7 & 4 & 70 & 1 & Mel ram & $F$ & & & 1 & 3 \\
\hline 7 & 5 & 330 & 1 & Fuc exc & FIB & & & 1 & 3 \\
\hline 7 & 6 & 345 & 1 & Pod tot & $M$ & & & 1 & 3 \\
\hline 7 & 7 & 300 & 1 & Hed arb & & $M$ & & 1 & 3 \\
\hline 7 & 8 & 330 & 1 & Arb uni & & & & 0 & 3 \\
\hline 7 & 9 & 320 & 1 & Fuc exc & $F$ & & & 1 & 3 \\
\hline 7 & 10 & 70 & 1 & Fuc exc & & & & 0 & 3 \\
\hline 7 & 11 & 280 & 1 & Mel ram & & & $F$ & 1 & 3 \\
\hline 7 & 12 & 280 & 1 & Pse arb & & & $F$ & 1 & 3 \\
\hline 7 & 13 & 300 & 1 & Pse arb & $M$ & $F$ & $M$ & 3 & 3 \\
\hline 7 & 14 & 275 & 9 & Pse arb & & & $\mathrm{s}$ & 0 & 2.5 \\
\hline 7 & 15 & 260 & 9 & Hed arb & & $M$ & $M$ & 2 & 3 \\
\hline total & & & & & 18 & 18 & 10 & 46 & 145.50 \\
\hline
\end{tabular}




\section{Appendix C: Stomach contents}

\begin{tabular}{|c|c|c|c|c|c|c|c|}
\hline Stomach & G11 & 1412 & Lil13. & Lill & 415 & L211 & 1,212 \\
\hline Aristotelia serrata & 1 & & & 21 & & & \\
\hline \multicolumn{8}{|l|}{ Berberis darwinii } \\
\hline Brachiglottis repanda & 2 & & & & & & \\
\hline Cytisus scoparius (broom) flowers and leaves & 25 & & & 43. & 28 & & 48 \\
\hline \multicolumn{8}{|l|}{ Carpodetus serratus } \\
\hline Coprosma robusta & & & & & 70 & & 52 \\
\hline \multicolumn{8}{|l|}{\begin{tabular}{|l|} 
Coprosma rotundifolia \\
\end{tabular}} \\
\hline Fuchsia excorticata & & & 9 & & & & \\
\hline Ulex europaeus (flowers) & 11 & & 86 & 22 & & & \\
\hline \multicolumn{8}{|l|}{ Melicytus ramiflorus } \\
\hline \multicolumn{8}{|l|}{ Podocarpus totara } \\
\hline \multicolumn{8}{|l|}{ Pseudopanax arboreus (petioles) } \\
\hline Pseudopanax arboreus (leaves) & 26 & & & 5 & & & \\
\hline \begin{tabular}{|l} 
Ripogonum scandens \\
\end{tabular} & & & & 9 & & & \\
\hline \multicolumn{8}{|l|}{ Weinmannia racemosa } \\
\hline Pine needles + particles & & & & & 2 & & \\
\hline \multicolumn{8}{|l|}{ Asplenium bulbiferum } \\
\hline \multicolumn{8}{|l|}{ Asplenium poliodon } \\
\hline Blechnum discolor & 5 & & & & & & \\
\hline \multicolumn{8}{|l|}{ Cyclosorus penniger } \\
\hline \multicolumn{8}{|l|}{ Phymatosorus diversifolius } \\
\hline Cyathea medullaris & 31 & & & & & & \\
\hline \multicolumn{8}{|l|}{ Trifolium spp. } \\
\hline \multicolumn{8}{|l|}{\begin{tabular}{|l|} 
Monocots \\
\end{tabular}} \\
\hline \multicolumn{8}{|l|}{ unid fern } \\
\hline \multicolumn{8}{|l|}{ unid flower } \\
\hline \multicolumn{8}{|l|}{\begin{tabular}{|l} 
unid fruit \\
\end{tabular}} \\
\hline unid leaves & & & 5 & & & & \\
\hline \multicolumn{8}{|l|}{ unid petiole } \\
\hline \multicolumn{8}{|l|}{ Pinus muricata pollen } \\
\hline Empty & & $\mathrm{XX}$ & & & & $\mathrm{XX}$ & \\
\hline Percent & 100 & 0 & 100 & 100 & 100 & 0 & 100 \\
\hline
\end{tabular}




\begin{tabular}{|c|c|c|c|c|c|c|c|}
\hline Stomach & 1311 & L312. & LA & L4. & L4. & 14 & LA. \\
\hline Aristotelia serrata & & & & & & & 38 \\
\hline Berberis darwinii & & & & & 3 & & \\
\hline Brachiglottis repanda & & 3 & & & & & \\
\hline Cytisus scoparius (broom) flowers and leaves & & 7 & 2 & & 95 & 79 & \\
\hline Carpodetus serratus & & & 1 & & & & \\
\hline Coprosma robusta & & & 27 & & & & \\
\hline \multicolumn{8}{|l|}{ Coprosma rotundifolia } \\
\hline Fuchsia excorticata & 81 & & 25 & 96 & & 1 & 49 \\
\hline \multicolumn{8}{|l|}{ Ulex europaeus (flowers) } \\
\hline Melicytus ramiflorus & & & 1 & & & & 2 \\
\hline Podocarpus totara & & & & & 1 & & 1 \\
\hline Pseudopanax arboreus (petioles) & & 32 & & & & & \\
\hline Pseudopanax arboreus (leaves) & & 4 & & & & & \\
\hline \multicolumn{8}{|l|}{ Ripogonum scandens } \\
\hline Weinmannia racemosa & 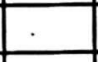 & & 2 & & & & 6 \\
\hline Pine needles + particles & & 1 & & & & 2 & \\
\hline Asplenium bulbiferum & 11 & &. & & & & . \\
\hline \multicolumn{8}{|l|}{ Asplenium poliodon } \\
\hline Blechnum discolor & & 9 & & & & & \\
\hline \multicolumn{8}{|l|}{ Cyclosorus penniger } \\
\hline Phymatosorus diversifolius & & & 39 & & & & \\
\hline Cyathea medullaris & & 41 & & & & 1 & \\
\hline \multicolumn{8}{|l|}{ Trifolium spp. } \\
\hline \multicolumn{8}{|l|}{ Monocots } \\
\hline unid fern & & 3 & & & & & 2 \\
\hline unid flower & & & & 4 & & & \\
\hline unid fruit & & & & & & 7 & \\
\hline unid leaves & 8 & & & & 1 & 10 & \\
\hline unid petiole & & & 3 & & & & 2 \\
\hline \multicolumn{8}{|l|}{ Pinus muricata pollen } \\
\hline \multicolumn{8}{|l|}{ Empty } \\
\hline Percent & 100 & 100 & 100 & 100 & 100 & 100 & 100 \\
\hline
\end{tabular}




\begin{tabular}{|c|c|c|c|c|c|c|c|}
\hline Stomach & T4 & L5T1 & 1512 & 1513 & 1.514 & L515. & 1516 \\
\hline Aristotelia serrata & 31 & & & & & & 8 \\
\hline Berberis darwinii & 1 & & & & & & \\
\hline \multicolumn{8}{|l|}{ Brachiglottis repanda } \\
\hline Cytisus scoparius (broom) flowers and leaves & 1 & & & & & & \\
\hline \multicolumn{8}{|l|}{\begin{tabular}{|l|} 
Carpodetus serratus \\
\end{tabular}} \\
\hline \multicolumn{8}{|l|}{\begin{tabular}{|l|} 
Coprosma robusta \\
\end{tabular}} \\
\hline \multicolumn{8}{|l|}{ Coprosma rotundifolia } \\
\hline Fuchsia excorticata & 61 & & & & & & \\
\hline \multicolumn{8}{|l|}{ Ulex europaeus (flowers) } \\
\hline \multicolumn{8}{|l|}{ Melicytus ramiflorus } \\
\hline \multicolumn{8}{|l|}{ Podocarpus totara } \\
\hline \multicolumn{8}{|l|}{ Pseudopanax arboreus (petioles) } \\
\hline \multicolumn{8}{|l|}{ Pseudopanax arboreus (leaves) } \\
\hline \multicolumn{8}{|l|}{ Ripogonum scandens } \\
\hline \multicolumn{8}{|l|}{ Weinmannia racemosa } \\
\hline Pine needles + particles & & & & & & & 14 \\
\hline \multicolumn{8}{|l|}{ Asplenium bulbiferum } \\
\hline \multicolumn{8}{|l|}{ Asplenium poliodon } \\
\hline \multicolumn{8}{|l|}{ Blechnum discolor } \\
\hline \multicolumn{8}{|l|}{ Cyclosorus penniger } \\
\hline Phymatosorus diversifolius & 1 & & & & & & \\
\hline Cyathea medullaris & & & & & & & 32 \\
\hline \multicolumn{8}{|l|}{ Trifolium spp. } \\
\hline Monocots & & & & & & & 7 \\
\hline \multicolumn{8}{|l|}{ unid fern } \\
\hline unid flower & 1 & & & & & & \\
\hline unid fruit & 1 & & & & & & \\
\hline unid leaves & & & & & & & 5 \\
\hline unid petiole & 3 & & & & & & 34 \\
\hline \multicolumn{8}{|l|}{ Pinus muricata pollen } \\
\hline Empty & & $\mathrm{XX}$ & $\mathrm{XX}$ & $\mathrm{XX}$ & $\mathrm{XX}$ & $\mathrm{XX}$ & \\
\hline Percent & 100 & 0 & 0 & 0 & 0 & 0 & 100 \\
\hline
\end{tabular}




\begin{tabular}{|c|c|c|c|c|c|c|c|}
\hline Stomach & $\mathrm{L} 517$ & L518: & 155 & 15110 & L5t11: & 15112 & L5Tis \\
\hline Aristotelia serrata & 58 & 38 & & & 43 & & \\
\hline Berberis darwinii & 42 & 62 & & & & & \\
\hline \multicolumn{8}{|c|}{ Brachiglottis repanda } \\
\hline \multicolumn{8}{|c|}{ Cytisus scoparius (broom) flowers and leaves } \\
\hline \multicolumn{8}{|c|}{ Carpodetus serratus } \\
\hline \multicolumn{8}{|l|}{ Coprosma robusta } \\
\hline Coprosma rotundifolia & & & & . & & & c \\
\hline \multicolumn{8}{|l|}{ Fuchsia excorticata } \\
\hline \multicolumn{8}{|l|}{ Ulex europaeus (flowers) } \\
\hline \multicolumn{8}{|l|}{ Melicytus ramiflorus } \\
\hline \multicolumn{8}{|l|}{ Podocarpus totara } \\
\hline Pseudopanax arboreus (petioles) & & & & & 18 & & 90 \\
\hline Pseudopanax arboreus (leaves) & & & & & 39 & & 3 \\
\hline \multicolumn{8}{|l|}{ Ripogonum scandens } \\
\hline \multicolumn{8}{|l|}{ Weinmannia racemosa } \\
\hline \multicolumn{8}{|l|}{ Pine needles + particles } \\
\hline \multicolumn{8}{|l|}{ Asplenium bulbiferum } \\
\hline \multicolumn{8}{|l|}{ Asplenium poliodon } \\
\hline \multicolumn{8}{|l|}{ Blechnum discolor } \\
\hline \multicolumn{8}{|l|}{ Cyclosorus penniger } \\
\hline \multicolumn{8}{|l|}{ Phymatosorus diversifolius } \\
\hline \begin{tabular}{|l|} 
Cyathea medullaris \\
\end{tabular} & & & & & & & 1 \\
\hline \multicolumn{8}{|l|}{ Trifolium spp. } \\
\hline \multicolumn{8}{|l|}{\begin{tabular}{|l|} 
Monocots \\
\end{tabular}} \\
\hline unid fern & & & & & & & 2 \\
\hline \multicolumn{8}{|l|}{ unid flower } \\
\hline \multicolumn{8}{|l|}{ unid fruit } \\
\hline unid leaves & & & & & & & 4 \\
\hline \multicolumn{8}{|l|}{ unid petiole } \\
\hline Pinus muricata pollen & & & $100 \%$ & $100 \%$ & & $100 \%$ & \\
\hline \multicolumn{8}{|l|}{ Empty } \\
\hline Percent & 100 & 100 & 0 & 0 & 100 & 0 & 100 \\
\hline
\end{tabular}




\begin{tabular}{|c|c|c|c|c|c|c|c|}
\hline Stomach & Lo11 & 16012 & Lab & 1.64 & Las & Lato & La7 \\
\hline \multicolumn{8}{|l|}{ Aristotelia serrata } \\
\hline \multicolumn{8}{|l|}{ Berberis darwinii } \\
\hline \multicolumn{8}{|l|}{ Brachiglottis repanda } \\
\hline Cytisus scoparius (broom) flowers and leaves & 50 & 48 & & 81 & & & \\
\hline \multicolumn{8}{|l|}{ Carpodetus serratus } \\
\hline \multicolumn{8}{|l|}{\begin{tabular}{|l|} 
Coprosma robusta \\
\end{tabular}} \\
\hline Coprosma rotundifolia & 4 & 3 & & 5 & & & . \\
\hline Fuchsia excorticata & 4 & & & & & & 100 \\
\hline \multicolumn{8}{|l|}{ Ulex europaeus (flowers) } \\
\hline \multicolumn{8}{|l|}{ Melicytus ramiflorus } \\
\hline \multicolumn{8}{|l|}{ Podocarpus totara } \\
\hline \multicolumn{8}{|l|}{ Pseudopanax arboreus (petioles) } \\
\hline Pseudopanax arboreus (leaves) & 1 & & & & & & \\
\hline \multicolumn{8}{|l|}{ Ripogonum scandens } \\
\hline \multicolumn{8}{|l|}{ Weinmannia racemosa } \\
\hline Pine needles + particles & & 3 & & 1 & & & \\
\hline \multicolumn{8}{|l|}{ Asplenium bulbiferum } \\
\hline Asplenium poliodon & 1 & & & & & & \\
\hline \multicolumn{8}{|l|}{ Blechnum discolor } \\
\hline \multicolumn{8}{|l|}{ Cyclosorus penniger } \\
\hline \multicolumn{8}{|l|}{ Phymatosorus diversifolius } \\
\hline Cyathea medullaris & 10 & & & & & & \\
\hline Trifolium spp. & 14 & 45 & & 13 & & & \\
\hline Monocots & & 1 & & & & & \\
\hline unid fern & 3 & & & & & & \\
\hline unid flower & 1 & & & & & & \\
\hline \multicolumn{8}{|l|}{ unid fruit } \\
\hline unid leaves & 12 & & & & & & \\
\hline \multicolumn{8}{|l|}{ unid petiole } \\
\hline Pinus muricata pollen & $75 \%$ & $20 \%$ & & $25 \%$ & $100 \%$ & $100 \%$ & \\
\hline Empty & & & $\mathrm{XX}$ & & & & \\
\hline Percent & 100 & 100 & 0 & 100 & 0 & 0 & 100 \\
\hline
\end{tabular}




\begin{tabular}{|c|c|c|c|c|c|c|c|}
\hline Stomach & 2618 & L69 & 20110 & L71 & L72 & 173 & L74 \\
\hline \multicolumn{8}{|l|}{ Aristotelia serrata } \\
\hline \multicolumn{8}{|l|}{ Berberis darwinii } \\
\hline \multicolumn{8}{|l|}{ Brachiglottis repanda } \\
\hline Cytisus scoparius (broom) flowers and leaves & & & 9 & & & & \\
\hline \multicolumn{8}{|l|}{ Carpodetus serratus } \\
\hline \multicolumn{8}{|l|}{ Coprosma robusta } \\
\hline \multicolumn{8}{|l|}{ Coprosma rotundifolia } \\
\hline Fuchsia excorticata & & & 84 & & & & 6 \\
\hline \multicolumn{8}{|l|}{ Ulex europaeus (flowers) } \\
\hline \multicolumn{8}{|l|}{ Melicytus ramiflorus } \\
\hline \multicolumn{8}{|l|}{ Podocarpus totara } \\
\hline \multicolumn{8}{|l|}{ Pseudopanax arboreus (petioles) } \\
\hline \multicolumn{8}{|l|}{ Pseudopanax arboreus (leaves) } \\
\hline Ripogonum scandens & & & & & & & 2 \\
\hline \multicolumn{8}{|l|}{ Weinmannia racemosa } \\
\hline \multicolumn{8}{|l|}{ Pine needles + particles } \\
\hline \multicolumn{8}{|l|}{ Asplenium bulbiferum } \\
\hline \multicolumn{8}{|l|}{ Asplenium poliodon } \\
\hline \multicolumn{8}{|l|}{ Blechnum discolor } \\
\hline \multicolumn{8}{|l|}{ Cyclosorus penniger } \\
\hline Phymatosorus diversifolius & & & & & & & 86 \\
\hline \multicolumn{8}{|l|}{ Cyathea medullaris } \\
\hline \multicolumn{8}{|l|}{ Trifolium spp. } \\
\hline Monocots & & & 3 & & & & \\
\hline unid fern & & & & & & & 1 \\
\hline \multicolumn{8}{|l|}{ unid flower } \\
\hline unid fruit & & & 2 & & & & \\
\hline unid leaves & & & 2 & & & & 5 \\
\hline \multicolumn{8}{|l|}{ unid petiole } \\
\hline \multicolumn{8}{|l|}{ Pinus muricata pollen } \\
\hline Empty & $\mathrm{XX}$ & $\mathrm{XX}$ & & $\mathrm{XX}$ & $\mathrm{XX}$ & $\mathrm{XX}$ & \\
\hline Percent & 0 & 0 & 100 & 0 & 0 & 0 & 100 \\
\hline
\end{tabular}




\begin{tabular}{|c|c|c|c|c|c|c|c|}
\hline Stomach & 175 & 1776 & 1777 & 1778 & L796 & 1710 & L7111 \\
\hline \multicolumn{8}{|l|}{ Aristotelia serrata } \\
\hline Berberis darwinii & & & 100 & & & & \\
\hline \multicolumn{8}{|l|}{ Brachiglottis repanda } \\
\hline Cytisus scoparius (broom) flowers and leaves & & & & & & 1 & \\
\hline \multicolumn{8}{|l|}{ Carpodetus serratus } \\
\hline Coprosma robusta & 61 & & & & & & \\
\hline Coprosma rotundifolia & 5 & & & & & & . \\
\hline Fuchsia excorticata & 8 & & & & & 49 & \\
\hline \multicolumn{8}{|l|}{ Ulex europaeus (flowers) } \\
\hline \multicolumn{8}{|l|}{ Melicytus ramiflorus } \\
\hline \multicolumn{8}{|l|}{ Podocarpus totara } \\
\hline \multicolumn{8}{|l|}{ Pseudopanax arboreus (petioles) } \\
\hline Pseudopanax arboreus (leaves) & & & & & & 10 & \\
\hline \multicolumn{8}{|l|}{ Ripogonum scandens } \\
\hline \multicolumn{8}{|l|}{ Weinmannia racemosa } \\
\hline \multicolumn{8}{|l|}{ Pine needles + particles } \\
\hline \multicolumn{8}{|l|}{ Asplenium bulbiferum } \\
\hline \multicolumn{8}{|l|}{ Asplenium poliodon } \\
\hline \multicolumn{8}{|l|}{ Blechnum discolor } \\
\hline \multicolumn{8}{|l|}{\begin{tabular}{|l|} 
Cyclosorus penniger \\
\end{tabular}} \\
\hline Phymatosorus diversifolius & & & & & & 37 & \\
\hline \multicolumn{8}{|l|}{\begin{tabular}{|l|} 
Cyathea medullaris \\
\end{tabular}} \\
\hline \multicolumn{8}{|l|}{ Trifolium spp. } \\
\hline \multicolumn{8}{|l|}{ Monocots } \\
\hline \multicolumn{8}{|l|}{ unid fern } \\
\hline \multicolumn{8}{|l|}{ unid flower } \\
\hline \multicolumn{8}{|l|}{ unid fruit } \\
\hline unid leaves & 2 & & & & & 3 & \\
\hline $\begin{array}{l}\text { unid petiole } \\
\end{array}$ & 15 & & & & & & \\
\hline Pinus muricata pollen & & $100 \%$ & & & & & \\
\hline Empty & & & & $\mathrm{XX}$ & $\mathrm{XX}$ & & $\mathrm{XX}$ \\
\hline Percent & 100 & 0 & 100 & 0 & 0 & 100 & 0 \\
\hline
\end{tabular}




\section{Appendix D: Canopy assessment surveys 1993, 1995 and 1996}

\section{1: March 1993}

\begin{tabular}{|c|c|c|c|c|c|c|c|c|c|c|c|c|c|c|c|c|c|c|c|c|}
\hline \begin{tabular}{|l|l} 
\\
0 \\
\end{tabular} & $\begin{array}{l} \\
\frac{5}{5} \\
\\
\end{array}$ & $\frac{\bar{g}}{\frac{g}{2}}$ & 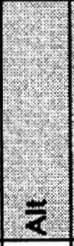 & $\begin{array}{l}\frac{2}{5} \\
\frac{2}{2} \\
\frac{2}{2}\end{array}$ & 듬 & 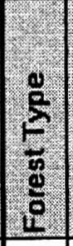 & 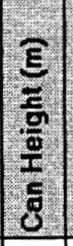 & $\begin{array}{c}\vec{j} \\
\vec{E} \\
\vec{E} \\
\vec{g} \\
\vec{f}\end{array}$ & $\begin{array}{l}\mathrm{g} \\
\frac{u}{\mathrm{~g}} \\
\mathrm{~g} \\
\mathrm{~g} \\
\mathrm{~d} \\
\mathrm{~d}\end{array}$ & \begin{tabular}{c}
$a$ \\
$\frac{a}{5}$ \\
g. \\
\multirow{2}{*}{}
\end{tabular} & 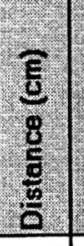 & $\begin{array}{l}\frac{2}{0} \\
\frac{5}{0} \\
\frac{a}{a} \\
\frac{0}{g} \\
\frac{0}{b} \\
\text { il } \\
\end{array}$ & 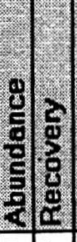 & $\begin{array}{l}\frac{E}{5} \\
\frac{T}{10} \\
口\end{array}$ & 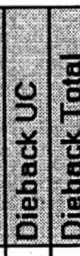 & 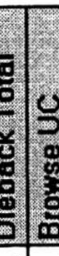 & & $\begin{array}{r}0 \\
0 \\
\\
5 \\
\\
\end{array}$ & 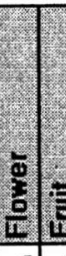 & ह5 \\
\hline 1 & & & & & & & & 1214 & Fuc exx & 0 & 0 & 50 & $E$ & & & & & 1 & 0 & $0 \mathrm{~s}$ \\
\hline & & & & & & & & 1213 & Fuc exc & s & 7 & 50 & $E$ & & 4 & 4 & 4 & 1 & 0 & 0.5 \\
\hline & & & & & & & & 1212 & Ari ser & 280 & 10 & 850 & & & & & 0 & 0 & 0 & $0 \mathrm{~s}$ \\
\hline & & & & & & & & 1211 & Ari ser & 220 & 11 & 850 & & & & & 0 & 0 & 의 & $0 \mid \mathrm{T}$ \\
\hline 2 & & & & & & & & 1210 & Ari ser & 0 & 0 & 750 & $A$ & & 0 & 1 & 0 & 0 & of & \begin{tabular}{l|l}
0 & $T$ \\
\end{tabular} \\
\hline & & & & & & & & 1209 & Fuc exc & 38 & 8 & 250 & $E$ & & 4 & 4 & 4 & 2 & 0 & os \\
\hline & & & & & & & & 1208 & Fuc exc & 38 & 8 & 350 & $E$ & & 3 & 3 & 3 & $\begin{array}{ll}3 \\
3\end{array}$ & 0 & 05 \\
\hline & & & & & & & & \begin{tabular}{l|l|}
1207 & \\
\end{tabular} & Fuc exc & 68 & 9 & \begin{tabular}{l|l|}
45 & 0 \\
\end{tabular} & $E$ & & 2 & 1 & & 0 & 0 & $0 \mid s$ \\
\hline & & & & & & & & 1206 & Fuc exx & 90 & 3 & 650 & $E$ & & 0 & 2 & 2 & 0 & 0 & $0 \mid s$ \\
\hline 3 & & & & & & & & 1205 & Pse arb & 0 & 0 & \begin{tabular}{ll|l}
65 & 0 \\
\end{tabular} & $c$ & & 2 & 1 & 0 & 2 & 0 & 25 \\
\hline & & & & & & & & 1204 & Pse arb & 250 & 10 & \begin{tabular}{ll|}
85 & 0 \\
\end{tabular} & & & & & o & 0 & 0 & \begin{tabular}{l|l}
0 & $T$ \\
\end{tabular} \\
\hline & & & & & & & & \begin{tabular}{|r|}
1203 \\
\end{tabular} & Pse arb & 38 & 5 & \begin{tabular}{l|l|l}
75 & 0 \\
\end{tabular} & & & - & & 0 & 0 & 0 & \begin{tabular}{l|l}
0 & $\mathrm{~T}$ \\
\end{tabular} \\
\hline & & & & & & & & $1208 \mathrm{ret}$ & Fuc exc & 190 & 20 & \begin{tabular}{c|c|}
55 & 0 \\
\end{tabular} & E & & 2 & 2 & & $\underline{0}$ & 1 & 15 \\
\hline & & & & & & & & 579 & Fuc exx & 262 & 20 & 650 & & & & & 1 & 1 & 0 & 25 \\
\hline & & & & & & & & 1201 & Wei rac & 130 & 15 & \begin{tabular}{l|l|l|}
75 & $R$ \\
\end{tabular} & $E$ & & 0 & 2 & 2 & 3 & 0 & $\begin{array}{l}0 \mathrm{~T} \\
\end{array}$ \\
\hline 4 & & & & & & & & 37801 & Pse arb & 0 & 0 & \begin{tabular}{c|c|}
65 & $C$ \\
\end{tabular} & $A$ & & 2 & 1 & o & 1 & 0 & $3 \mathrm{~T}$ \\
\hline & & & & & & & & 37802 & Pse arb & 305 & 3 & \begin{tabular}{l|c|}
65 & $C$ \\
\end{tabular} & $A$ & & 2 & 1 & 의 & $\underline{0}$ & 0 & 35 \\
\hline & & & & & & & & 37803 & Pse arb & 360 & 10 & \begin{tabular}{l|l|}
65 & $C$ \\
\end{tabular} & A & & 1 & 1 & 0 & 1 & 2 & $0 \mathrm{~T}$ \\
\hline & & & & & & & & 37804 & Pse arb & 305 & 5 & \begin{tabular}{l|l}
65 & $C$ \\
\end{tabular} & A & & 2 & 2 & 의 & 0 & 0 & $4 / T$ \\
\hline 5 & & & & & & & & 37805 & Wei rac & 0 & 0 & \begin{tabular}{l|l|}
75 & $\mathrm{R}$ \\
\end{tabular} & & & & & 의 & 3 & 0 & $3 \mathrm{~T}$ \\
\hline & & & & & & & & 37806 & Pse arb & 295 & 7 & 650 & A & & 2 & 1 & 0 & 2 & 0 & 15 \\
\hline 6 & & & & & & & & 1218 & Fuc exx & 0 & 0 & \begin{tabular}{l|l|}
65 & $C$ \\
\end{tabular} & $E$ & & 0 & 1 & 0 & & 0 & $0 \mid s$ \\
\hline & & & & & & & & 37807 & Fuc exc & 28 & 12 & $\begin{array}{l}65 \\
65 \\
\end{array}$ & $E$ & & 2 & 2 & 0 & & 0 & 0 s \\
\hline & & & & & & & & 37808 & Fuc exx & 66 & 18 & $65 \mid c$ & & & & & 0 & o & 0 & $0 \mathrm{~T}$ \\
\hline & & & & & & & & 37809 & Fuc exc & 98 & 18 & $65 \mid C$ & & & & & 0 & & 0 & $0 \mathrm{~T}$ \\
\hline 3 & & & & & & & & 37810 & Fuc exc & 0 & 0 & 6510 & $E$ & & 0. & 2 & 0 & 0 & 0 & 015 \\
\hline & & & & & & & & 37811 & Fuc exc & 100 & 6 & 750 & & & & & 0 & 0 & 0 & of 5 \\
\hline & & & & & & & & 37812 & Psearb & 208 & 15 & \begin{tabular}{l|l}
45 & 0 \\
\end{tabular} & & & & & 0 & & 0 & 45 \\
\hline 8 & & & & & & & & 37814 & Fuc exc & 0 & 0 & 6510 & A & & 2 & 1 & 0 & & 0 & \begin{tabular}{l|l}
0 & $T$ \\
\end{tabular} \\
\hline & & & & & & & & 37815 & Fuc exx & 360 & 8 & 6510 & & & & & 0 & 0 & 0 & 0.5 \\
\hline & & & & & & & & 37816 & Fuc exc & 340 & 16 & 650 & $E$ & & 2 & 1 & 1 & & 0 & 0,5 \\
\hline 9 & & & & & & & & 37817 & Fuc exc & 0 & 0 & 50 & $E$ & & 4 & 4 & 4 & 0 & 0 & 0.5 \\
\hline & & & & & & & & 37818 & Fuc exc & 340 & 3 & $55 \mid 0$ & $E$ & & 2 & 1 & 0 & 0 & 0 & $0 \mid \mathrm{T}$ \\
\hline & & & & & & & & 37819 & Fuc exc & 130 & 10 & 450 & $B$ & & 4 & 4 & 2 & & 0 & 0,5 \\
\hline 10 & & & & & & & & 37820 & Fuc exc & 0 & 0 & 350 & $E$ & & 3 & 3 & 2 & & 0 & $0 \mid T$ \\
\hline & & & & & & & & 37821 & Fuc exx & 195 & 10 & 4510 & $B$ & & 2 & 1 & 1 & & 0 & $0 \mid s$ \\
\hline & & & & & & & & 37822 & Fuc exc & 180 & 20 & 350 & & & & & 4 & 3 & 0 & $0 \mid s$ \\
\hline 11 & & & & & & & & 37823 & Fuc exc & 0 & 0 & 6510 & & & & & 0 & 0 & 0 & $2 / 5$ \\
\hline & & & & & & & & 37824 & Fuc exx & 205 & 14 & 2510 & $E$ & & 4 & 4 & 3. & & 0 & \begin{tabular}{l|l}
0 & $T$ \\
\end{tabular} \\
\hline & & & & & & & & 37825 & Fuc exc & 220 & 20 & 650 & A & & 2 & 1 & 0 & \begin{tabular}{l|l}
0 & 0 \\
\end{tabular} & 0 & 15 \\
\hline 12 & & & & & & & & 37826 & Fuc exc & 0 & 0 & 6510 & A & & of & 1 & 0 & & 0 & \begin{tabular}{|l|l|}
1 & $T$ \\
\end{tabular} \\
\hline & & & & & & & & 37827 & Fuc exc. & 208 & 20 & 150 & E & & 4 & 4 & 4 & & 0 & \begin{tabular}{|l|l}
0 & $T$ \\
\end{tabular} \\
\hline & & & & & & & & $\begin{array}{ll}37828 \\
\end{array}$ & Fuc exc & 190 & 20 & $5 \%$ & $E$ & & 4 & 4 & 4 & 40 & 0 & \begin{tabular}{|l|l}
0 & $T$ \\
\end{tabular} \\
\hline 13 & & & & & & & & 37829 & Fuc exc & 0 & 0 & 75 C & & & 1 & & 0 & & 0 & $0 \mid s$ \\
\hline & & & & & & & & 37830 & Fuc exc & 218 & 8 & \begin{tabular}{ll|l}
75 & $\mathrm{C}$ \\
\end{tabular} & $A$ & & 0 & 1 & 0 & $\begin{array}{ll}0 & 2 \\
\end{array}$ & 0 & \begin{tabular}{l|l}
0 & $T$ \\
\end{tabular} \\
\hline & & & & & & & & 37831 & Fuc exc & 60 & 20 & ${ }_{75} \mid \mathrm{C}$ & & & & & 0 & $\begin{array}{ll}0 & 0 \\
0 & 0\end{array}$ & 0 & $0 \mathrm{~s}$ \\
\hline & & & & & & & & 37832 & Pse arb & 70 & 10) & 8510 & & & & & 0] & \begin{tabular}{l|l}
0 & 0 \\
0
\end{tabular} & & $\begin{array}{ll}\mathrm{T} \\
\end{array}$ \\
\hline
\end{tabular}




\section{3: March 1996}

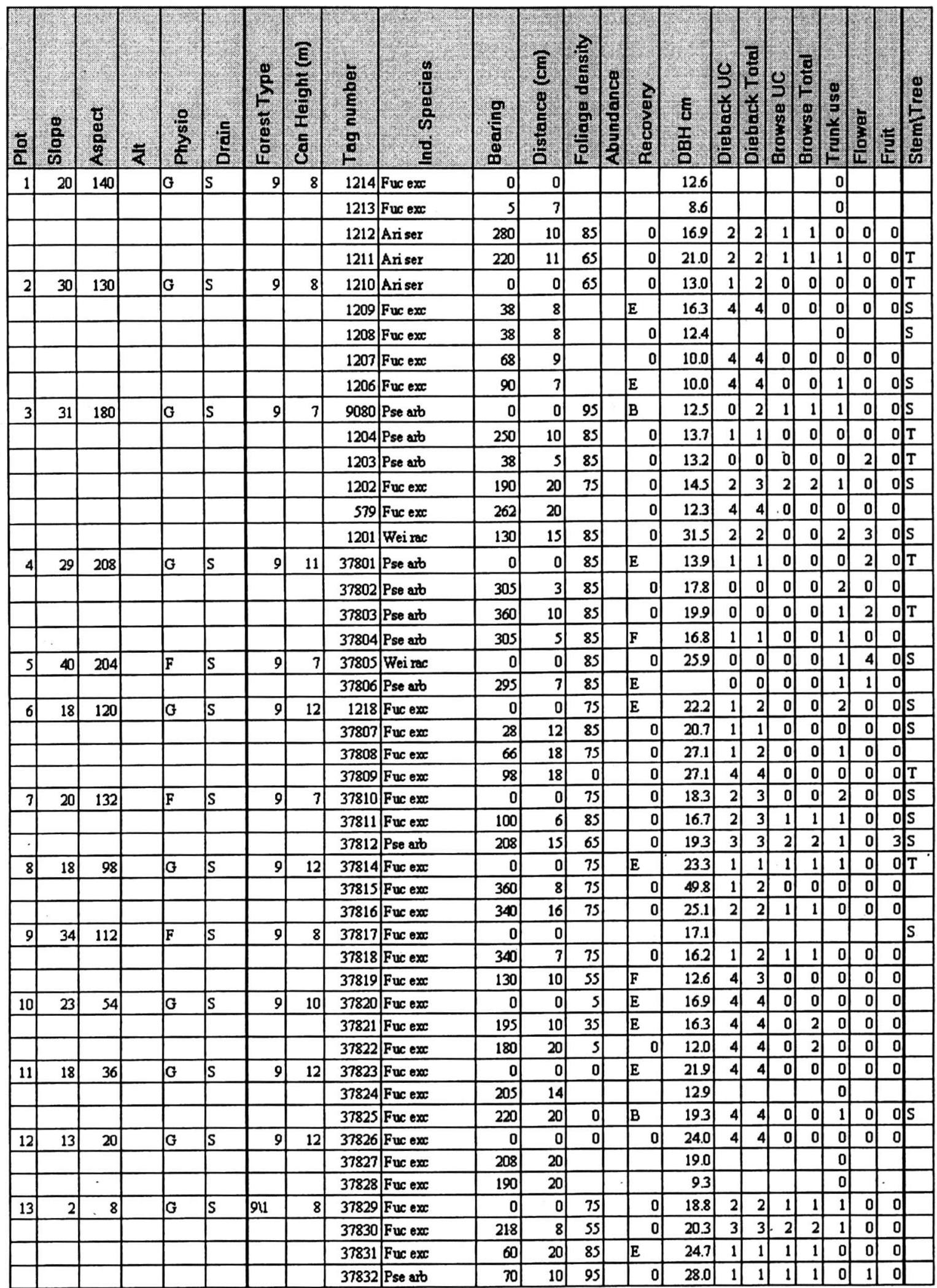




\section{References:}

Allen, H.H. 1982: Flora of New Zealand. Vol. 1. Government Printer, Wellington, New Zealand, $1085 \mathrm{pp}$.

Atkinson, I.A.E.; Campbell, D.J.; Fitzgerald, J.E.C.; Flux, M.J. and Meads, M.J. 1995: Possums and possum control; effects on lowland forest ecosystems. A literature review with specific reference to the use of 1080. Science for Conservation: 1, Department of Conservation, Wellington, New Zealand.

Atkinson, I.A.E. 1992: Effects of possums on the vegetation of Kapiti Island and changes following possum eradication. DoC Investigation No.1001, DSIR Land Resources Contract Report No.92/52.

Baddeley, C.J. 1985: Assessment of wild animal abundance. FRI Bulletin No.106. Protection Forestry Division, Forest Research Institute. P.O.Box 31-011 Christchurch, New Zealand.

Bamford, J.M. 1972: The dynamics of possum (Trichosurus vulpecula Kerr) populations controlled by aerial poisoning. Unpublished Ph.D Thesis, University of Canterbury, Christchurch, New Zealand.

Bamford, J.; Martin, J. 1971: A method for predicting success of aerial poisoning against opossums. New Zealand Journal of Science Vol.14: 313-321.

Batcheler, C.L. and Cowan P.E. 1988: Review of the status of the possum in New Zealand. Contract report for the Technical Advisory Committee (Animal Pests), Ministry of Agriculture and Fisheries, Wellington. 129p.

Batcheler, C.L. 1983: The possum and rata-kamahi dieback in New Zealand: a review. Pacific Science Vol.37: 415-426.

Batcheler, C.L. 1968: Compensatory response of artificially controlled mammal populations. Proceedings of the New Zealand Ecological Society Vol.15: 25-30.

Beauchamp, A.J. 1978: Aspects of the dendrochronology of cementum pad depositions in the teeth of the brush-tailed possum Trichosurus vulpecula Kerr. Unpubl. BSc Honours Thesis, Victoria University of Wellington.

Bell; B.D. 1981: Breeding and Condition of possums Trichosurus vulpecula in the Orongorongo Valley, near Wellington, New Zealand, 1966-1975.Pages 87-139 in Bell, B.D. (Ed.) Proceedings of the first symposium on marsupials in New Zealand

Brockie, R.E. 37 Versailles St. Karori, Wellington

Brockie, R.E. 1992: A living New Zealand forest. David Bateman Ltd. 1992. 
Brockie, R.E. 1990: European Hedgehog. Pages 99-116 in: King, C.M. (Ed.) The Handbook of New Zealand Mammals. Oxford University Press, Auckland.

Brockie, R.E. 1982: Effects of commercial hunters on the number of possums, Trichosurus vulpecula, in Orongorongo Valley, Wellington. New Zealand Journal of Ecology Vol.5: 2128.

Brockie, R.E.; Bell, B.D. and White, A.J. 1981: Age structure and mortality of possum Trichosurus vulpecula populations from New Zealand. Pages 63-85 in Bell, B.D. (Ed.) Proceedings of the first symposium on marsupials in New Zealand.

Brodie, J.w. 1986: Terawhiti and the Goldfields. publ. by the Karori Historical Society, Wright and Carman Ltd, Upper Hutt.

Brown, D. 1993: Eradication of mice from Allports and Motutapu Islands. Ecological Management Vol.1: 19-30. Department of Conservation.

Campbell, D.J. 1990: Changes in structure and composition of a New Zealand lowland forest inhabited by brushtail possums. Pacific Science Vol. 3: 277-296.

Caughley, G. 1989: New Zealand plant herbivore systems: past and present. New Zealand Journal of Ecology Vol.12: 3-10.

Chamrad, A.D. and Box, T.W. 1964: A point frame for sampling rumen contents. Journal of Wildlife Management, Vol.28, 3: 473 - 476.

Clout, M.N. and Efford, M.G. 1984: Sex differences in the dispersal and settlement of brushtail possums (Trichosurus vulpecula). Journal of Animal Ecology Vol. 53: 737-749.

Clout, N.M. 1982: Determination of age in the brushtailed possum using sections from decalcified molar teeth. New Zealand Journal of Zoology Vol. 9: 405. - 408.

Clout, M.N. 1977: The ecology of the possum (Trichosurus vulpecula Kerr) in Pinus radiata plantations. Unpublished Ph.D. thesis, University of Auckland, New Zealand.

Coleman, J.D.; Gillman, A. and Green, W.Q. 1980: Forest patterns and possum densities within podocarp/mixed hardwood forests on Mt Bryan O'Lynn, Westland. New Zealand Journal of Ecology Vol.3: 69-84.

Coleman, J.D.; Green, W.Q. and Polson, J.G. 1985: Diet of brushtail possums over a pasture-alpine gradient in Westland, New Zealand. New Zealand Journal of Ecology Vol.8: 21-35.

Cowan, P.E.; Brockie, R.E.; Ward, G.D. and Efford, M.G. 1996: Long-distance movements of juvenile possums (Trichosurus vulpecula) on farmland, Hawkes Bay, New Zealand. Wildlife Research Vol.23: 237-244. 
Cowan, P.E. 1993: Effects of intensive trapping on breeding and age structure of brushtail possums, Trichosurus vulpecula, on Kapiti Island, New Zealand. New Zealand Journal of Zoology Vol.20: 1-11.

Cowan, P.E. 1992: The eradication of introduced Australian brushtailed possums, Trichosurus vulpecula, from Kapiti Island, a New Zealand nature reserve.

Biological Conservation Vol.61: 217-226.

Cowan, P.E. 1990: Fruits, seeds and flowers in the diet of brushtail possums, Trichosurus vulpecula, in lowland podocarb/mixed hardwood forest, Orongorongo Valley, New Zealand. New Zealand Journal of Zoology, Vol.17: 549-566.

Cowan, P.E. 1990: Brushtail possum. Pages 68-98 in: King, C. M.(Ed.) The Handbook of New Zealand Mammals. Oxford University Press, Auckland.

Cowan, P.E.1989: Denning habits of common brushtailed possums, Trichosurus vulpecula, in New Zealand lowland forest. Aust. Wildl. Res. Vol.16: 63-78.

Cowan P.E. 1987: The influence of lures and relative opportunity for capture on catches of brushtailed posums, Trichosurus vulpecula. New Zealand Journal of Zoology, Vol 14: 149 161.

Cowan P.E. and Moeed A. 1987: Invertebrates in the diet of brushtail possums, Trichosurus vulpecula, in lowland podocarp/broadleaf forest, Orongorongo Valley, Wellington, New Zealand. New Zealand Journal of Zoology, Vol.14: 163-177.

Cowan, P.E. 1985: The 1983 - 85 intensive control programme on Kapiti Island, and implications for the future eradication of possums. DSIR Ecology Division Report, Lower Hutt.

Cowan, P.E. 1984: in King, C.M. Immigrant Killers-introduced predators and the conservation of birds in New Zealand. Oxford University Press. p224.

Crawley, M.C. 1973: A life-trapping study of Australian brushtailed possums Trichosurus vulpecula (Kerr), in the Orongorongo Valley, Wellington, New Zealand. Australian Journal of Zoology, Vol.21: 75-90.

Dawson, J. 1988: Forest vines to snow tussocks - The story of New Zealand plants. Victoria University Press, 264p.

Delph, L.F. and Lively, C.M. 1985: Pollinator visits to floral colour phases of Fuchsia excorticata. New Zealand Journal of Zoology Vol.12(4): 599-603.

Dugdale, J.S. 1975: The insects in relation to plants. Pp. 561 - 589 in Kuschel, G. (Ed.): Biogeography and ecology in New Zealand. Monographiae Biologicae 27.

Duncan, K.W. 1994: Susceptibility of terrestrial amphipods especially Tara taranaki, to possum control operations. Conservation Advisory Science Notes No.80. Department of Conservation, $3 \mathrm{pp}$. 
Dunnet, G.M.; Harvie, A.E. and Smit, T.J. 1973: Estimating the proportions of various leaves in the diet of the opossum Trichosurus vulpecula (Kerr), by faecal analysis. Journal of Applied Ecology Vol.10: 737-745.

Efford, M. 1995: Possum population recovery following control- Priliminary results. Possum Research News Vol.2: 7-8.

Efford, M. and Hearfield, M.E. 1992: The long term dynamics of a local population of brushtail possums (Trichosurus vulpecula) (Marsupialia: Phalangeridae). Unpublished Landcare Research report, Private Bag 1930, Dunedin, New Zealand.

Empson, R.: Department of Conservation, P.O.Box 5086, Bowen St. Wellington, New Zealand.

Fitzgerald, B.M. 1990: House cat. Pages 330-348 in: King, C. M.(Ed.) The Handbook of New Zealand Mammals. Oxford University Press, Auckland.

Fitzgerald, A.E. 1984: Diet of the possum (Trichosurus vulpecula) in three Tasmanian forest types and its relevance to the diet of possums in New Zealand forests. Pages $137-143$ in: Possums and Gliders. Smith, A. P.; Hume, I. D. et al., Australian Mammal Society, Sydney.

Fitzgerald, A.E. and Wardle, P. 1979: Food of the oppossum Trichosurus vulpecula (Kerr) in the Waiho Valley, South Westland. New Zealand Journal of Zoology Vol.6: 339345.

Fitzgerald, A.E. 1977: Number and Weight of faecal pellets produced by opossums. Proceedings of the New Zealand Ecological Society, Vol 24: 76-78.

Fitzgerald, A.E. 1976: Diet of the opossum (Trichosurus vulpecula) Kerr in the Orongorongo Valley, Wellington, New Zealand, in relation to food plant availaility. New Zealand Journal of Zoology, Vol 3: 399-419.

Flux, J.E.C. 1990: Brown hare. Pages 161-174 in: King, C. M.(Ed.) The Handbook of New Zealand Mammals. Oxford University Press, Auckland.

Frampton, C. M. and Nugent, G., 1992: Age and sex independent comparisons of morphological measurements. Growth, Development and Ageing Vol.56: 45-52.

Fraser, K. W., 1979: Dynamics and condition of possum (Trichosurus vulpecula) populations in the Copland Valley, Westland, New Zealand. Mauri Ora Vol.7: 117-137.

Fraser, K.W. and Sweetapple, P.J. 1993: Assessing the age and condition of deer from jawbones. Manaaki Whenua - Landcare Research New Zealand Ltd, Christchurch.

Freeland, W.J. and Winter, J.W. 1975: Evolutionary consequences of eating: Trichosurus vulpecula (Marsupialia) and the genus Eukalyptus. Journal of Chemical Ecology Vol.1 :439-455. 
Froude, V.A. 1980: The allelopathic potential of some abundant New Zealand forest and scrub plants. Unpublished DSIR Ecology Division Report. 18pp.

Fuller, S. and Gorman, N. 1997: Karori Wildlife Sanctuary Trust fence trials. Pages 37 43 in Proceedings of the National Predator Management Workshop 1997, held 21-24 April 1997, St Arnaud, Nelson Lakes. Published by Department of Conservation, Wellington.

Fuller, S. 1996: Draft Karori Sanctuary Development Plan. Karori Wildlife Sanctuary Trust, unpublished.

Fuller, S. 1994: Feasibility report on the Native Wildlife Sanctuary proposal for Karori Reservoir. Karori Reservoir Wildlife Sanctuary Steering Committee, unpublished.

Gabites, I. 1993: Wellingtons living cloak: a guide to the natural plant communities. Wellington Botanical Society, Victoria University Press, 120pp.

Gilmore, D.P. 1966: Studies on the biology of Trichosurus vulpecula (Kerr). Unpublished $\mathrm{PhD}$ thesis, University of Canterbury, New Zealand.

Green, W.Q. 1984: A review of ecological studies relevant to management of the common brushtailed possum. pages 483-499 in Possums and Gliders, ed. by Smith A.P. and Hume I.D. Australian Mammal Society, Sydney 1984.

Green, W.Q. and Coleman, J.D. 1984: Response of a brushtailed possum population to intensive trapping. New Zealand Journal of Zoology Vol.11:319-328.

Grue, H. and Jensen, B. 1979: Review of the formation of incremental lines in tooth cementum of terrestrial mammals. Danish Review of Game Biology Vol.11(3): 1-48.

Hickling, G.J.; Morgan, D.R. and Henderson, R.J. 1996: Management of 1080 bait aversion in repeatedly poisoned possum populations. Improving conventional control of possums. The Royal Society of New Zealand Miscellaneous Series Vol.35: 54-56

Hickling, G.J. 1995: Implications of learnt and innate behavioural resistance for singletactic control of vertebrate pests. Proceedings of the Australian Vertebrate Pest Control Conference Vol.10: 303-308.

Hickling, G.J. and Pekelharing, C.J. 1989: Intrinsic rate of increase for a brushtail possum population in rata/kamahi forest, Westland. New Zealand Journal of Ecology Vol.12: 117-120.

Hickson, R.E.; Moller, H. and Garrick, A.S. 1986: Eradicating rats on Steward Island. New Zealand Journal of Ecology Vol. 9: 12 -19.

Hocking, G.J. 1981: The population ecology of the brushtailed possum Trichosurus vulpecula (Kerr) in Tasmania. Msc Thesis, unpubl. University of Tasmania, Australia.

Honigmann, H. 1941: Studies of nutrition of mammals. Part III. Proceedings of 
Zoological Society, London Vol.111: 1-35.

How, R.A. 1981: Population parameters of two congeneric possums, Trichosurus spp., in North Eastern New South Wales. Australian Journal of Zoology Vol.29: 205-215.

How, R.A. 1979: Population strategies of four species of Australian possums. In: Montgommery, G.:.et.al., The Ecology of Arboreal Folivores: Smithsonian Institute, Washington.

Husheer, S. 1994: Demography and condition of brushtailed possums. Unpublished MSc Thesis Lincoln University.

Hutton, M. 1990: Mana: island of hope and glory. Forest \& Bird Vol.21(2): 13-17.

Innes, J. G. 1995: The impacts of possums on native fauna. Pp.11-15 in O'Donnell,C.F.J. (Ed.): Proceedings of a workshop on possums as conservation pests organised by the

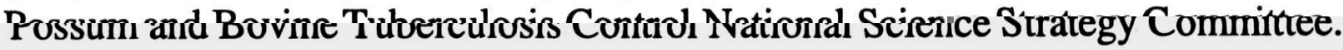
Department of Conservation, Wellington, New Zealand.

Innes, J. G. and Skipworth, J.P. 1983: Home ranges of ship rats in a small New Zealand forest as revealed by trapping and tracking. New Zealand Journal of Zoology Vol.10(1): 99110.

James, E.A. 1985: The dynamics of hunted populations of brushtailed possums (Trichosurus vulpecula) in Tasmania: a technique for population analysis.M Env. Studies Thesis, unpubl. University of Tasmania, Australia.

Jane, G.T. and Green, T.G.A. 1983: Episodic forest mortality in the Kaimai Ranges, North Island, New Zealand. New Zealand Journal of Botany Vol 21: 21-31.

Jansen, W.P. 1993: Eradication of norway rats and rabbits from Moutohora (Whale) Island, Bay of Plenty. Ecological Management Vol.1: 10-16.

Karl, B.J. and Moller, H. 1981: Spatial organization and ecology of a sparce population of house mice (Mus musculus) in a New Zealand forest. Journal of Animal Ecology Vol. 50(2): 489-518.

Kean, R. I. 1971: Selection for melanism and for low reproductive rate in Trichosurus vulpecula (Marsupialia). Proceedings of the New Zealand Ecological Society Vol.18: 42-47.

King, C.M. 1990: Stoat. Pages 288-312 in: King, C. M.(Ed.) The Handbook of New Zealand Mammals. Oxford University Press, Auckland.

King, C.M. 1990: Weasel. Pages 313-319 in: King, C. M.(Ed.) The Handbook of New Zealand Mammals. Oxford University Press, Auckland.

King, C.M. 1977: Techniques for trapping and tracking stoats (Mustela erminea): a review, and a new system. New Zealand Journal of Zoology Vol.4(2): 193-212. 
Kingsmill, E. 1962: An investigation of criteria for estimating age in the marsupials Trichosurus vulpecula (Kerr) and Perameles nasuta Geoffroy. Australian Journal of Zoology Vol.10: 597 - 616.

Kitchin, S. 1991: Natural Wellington - Conservation in the capital. Forest and Bird Magazine, Vol.22(4): 47-49.

Klevezal, G.A. and Kleinenberg, S.E. 1967: Age determination of mammals from anual layers in teeth and bones.-in Russian. Translation by Israel Programfor Scientific Translations, Jerusalem 1969. 128 pp.

Lavers, R.B. and Clapperton, B.K. 1990: Ferret. Pages 320-329 in: King, C. M.(Ed.) The Handbook of New Zealand Mammals. Oxford University Press, Auckland.

Lovegrove, T. 1987: Counts of forest birds on three transects on Kapiti Island 1982 1987. Unpublished report to the Wellington Conservancy, Department of Conservation.

Lusk, C. and Ogden, J. 1992: Age structure and dynamics of a podocarp-broadleaf forest in Tongariro National Park, New Zealand. Journal of Ecology Vol.80: 379-393.

Mac Arthur, R.H. and Wilson, E.O. 1967: The theory of island biogeography. Princeton University Press, Princeton, New Jersey.

MacLennan, D.G., 1984: The feeding behaviour and activity patterns of the brushtail possum, Trichosurus vulpecula, in an open eukalypt woodland in southeast Queensland. in: Possums and Gliders. Smith, A. P.; Hume, I. D. et al., Australian Mammal Society, Sydney.

Manion, P.D. 1981: Tree disease concepts. Prentice and Hall, Englewood Cliffs, New Jersey.

Mark, A.F.; Scott, G.A.M.; Sanderson, F.R. and James, P.W. 1964: Forest succession on landslides above Lake Thomson, Fjordland. New Zealand Journal of Botany, Vol 1(2): 60-89.

Mason, R. 1958: Foods of the Australian opossum (Trichosurus vulpecula Kerr) in New Zealand indigenous forest in the Orongorongo Valley, Wellington, New Zealand. New Zealand Journal of Science Vol.1: 590-613.

Meads, M. 1978: Opossums are killing the rata in our forests. Forest and Bird, May 1978, pages $17-20$.

Meads, M. 1976: Effects of opossum browsing on northern rata trees in the Orongorongo Valley, Wellington, New Zealand. New Zealand Journal of Zoology Val.3: 127-139.

Meenken, D. 1995: Monitoring results for the Karori Reservoir control operation. Unpublished memorandum, Wellington Regional Council. 
Moors, P.L. 1985: Eradication campaigns against Rattus norvegicus on the Noises Islands, New Zealand, using brodifacoum and 1080. International Council for Bird Preservation, Cambridge, ICBP Technical Publication Vol.3: 143-155.

Morgan, D.R. Protection Forestry Division, Forest Research Institute, P.O.Box 31-011, Christchurch, New Zealand.

Morgan, D.R. 1995: Will possums become "bait shy" in Control Programs? Possum Research News Vol. 3: 4-5.

Morgan, D.R.; Meikle, L. and Hickling, G.J. 1995: Induction, persistance and management of 1080 bait "shyness " in captive brushtail possums. Proceedings of the $10^{\text {th }}$ Australian Vertebrate Pest Conference: 328-332.

Morgan, D.R. 1982: Field acceptance of toxic and non-toxic baits by brush-tailed possum Trichosurus vulpecula (Kerr) populations. New Zealand Journal of Ecology Vol.5:36-43.

Morris, P.1972: A review of mammalian age determination methods. Mammal Review Vol.2: 69-104.

Nugent, G. 1995: Effects of possums on the native flora. Pp.5-11 in O'Donnell,C.F.J. (Ed.): Proceedings of a workshop on possums as conservation pests organised by the Possum and Bovine Tuberculosis Control National Science Strategy Committee. Department of Conservation, Wellington, New Zealand.

Nugent, G. 1990: Forage availability and the diet of fallow deer (Dama dama) in the Blue Mountains, Ortago. New Zealand Journal of Ecology. Vol.13: 83-95.

Nugent, G. 1989: Identifying the sex of fallow deer from jawbone measurements. Australian Wildlife Research Vol.16: 441-447.

Owen, H.J. and Norton, D.A. 1995: The diet of introduced brushtail possums in a lowdiversity New Zealand Nothofagus forest and possible implications for conservation management. Biological Conservation Vol.71: 339-345.

Payton, I. and Pekelharing, C.J. 1993: Monitoring possum related damage in native forests. Landcare Research interim report to Department of Conservation, unpublished, 12 pp.

Pekelharing, C.J. 1995: Assessing response in tree condition following possum control in Otari Native Botanic Garden, Wellington. The Royal Society of New Zealand, Miscellaneous Series 35, pages 4-6.

Pekelharing, C.J. 1993: Impact of possums on the vegetation in four Wellington City reserves. Landcare Research Contract Report LC9293/68 for Manager, Parks Dept, Wellington City Council.

Pekelharing, C.J. and Batcheler, C.L. 1990: The effect of control of brushtail possums (Trichosurus vulpecula) on condition of a southern rata/kamahi (Metrocideros 
umbellata/Weinmannia racemosa) forest canopy inWestland, New Zealand. New Zealand Journal of Ecology Vol.13: 73-82.

Pekelharing, C.J and Reynolds, R.N. 1983: Distribution and abundance of browsing animals in Westland National Park, and some observations on the impact on the vegetation. New Zealand Journal of Forestry Science Vol.13: 247-265.

Pekelharing, C.J. 1970: Cementum deposition as an age indicator in the brushtailed possum, Trichosurus vulpecula Kerr (Marsupialia). Australian Journal of Zoology Vol.18: 71-76.

Pracy, LC. 1973: Introduced animals: Opossums (2) NZ Nature Heritage, August 1973.

Pracy, L.T. 1974: Introduction and liberation of the opossum (Trichosurus vulpecula) into New Zealand. New Zealand Forest Service, Wellington, New Zealand.

Parrish, G.R. 1984: Wildlife and wildlife sites of the Wellington Region. Fauna Survey Unit Report No.38, New Zealand Wildlife Service.

Purchas, T.P.G. 1975: Autumn food of the brushtailed opossum, Trichosurus vulpecula Kerr in the Otari Reserve, Wellington. Proceedings of the New Zealand Ecological Society, Vol 22: 25-27.

Riney, T. 1957: The use of faeces counts in studies of several free- ranging mammals in New Zealand. NZ Journal of Science and Technology Vol.38 (6): 507 - 532.

Rose, A.B.; Pekelharing, C.J. and Platt, K.H. 1992: Magnitude of canopy dieback and implications for conservation of southern rata - kamahi (Metrocideros umbellata/ Weinmannia racemosa) forests, Central Westland, New Zealand. New Zealand Journal of Ecology Vol.16(1): 23-32.

Rose, A.B.; Pekelharing, C.J.; Platt, K.H. and Woolmore, C.B. 1993: Impact of invading brushtailed possum populations on mixed beech-broadleaved forests, South Westland, New Zealand. New Zealand Journal of Ecology Vol.17(1): 19-28.

Sherley, G.H.1992: Eradication of brushtail possums (Trichosurus vulpecula) on Kapiti Island, New Zealand: Techniques and methods. Conservation Advisory Science Notes No.64. Department of Conservation, 22pp 
Simberloff, D. 1990: Reconstructing the ambiguous: Can island ecosystems be restored? Pages 37-51 in Towns, D.R.; Daugherty, C.H. and Atkinson, I.A.E. (Eds.) 1990 Ecological restauration of New Zealand islands. Conservation Science Publication No.2. Dept. of Conservation.

Simms, E.L. and Fritz, R.S.1990: The ecology and evolution of host-plant resistance to insects. Tree Vol.5: 356-360.

Speed, H. 1986: Demography and Diet of Kiore (Rattus exulans) on Little Barrier Island. Unpublished Master of Science Thesis of Zoology, University of Auckland 1986.

Stevens, G.R. 1974: Rugged Landscape. The Geology of Central New Zealand.DSIR Information Series, ISSN $0077-9636: 169$, Wellington, New Zealand.

Taylor, R.H. and Thomas, B.W. 1993: Rats eradicated from rugged Breaksea Island (170 ha), Fjordland, New Zealand. Biological Conservation Vol.65: 191-198.

Thomas, M.D.; Hickling, G.J.; Coleman, J.D. and Pracy, L.T. 1993: Long-term trends in possum numbers at Pararaki: evidence of an irruptive fluctuation. New Zealand Journal of Ecology Vol.17(1): 29-34.

Todd, P. and Miskelly, C. 1997: Eradication of mice from Mana Island, New Zealand. Ecological Management (in press), Department of Conservation.

Triggs, S.J. 1982: Comparative ecology of the possum Trichosurus vulpecula, in three pastoral habitats. MSc Thesis, University of Auckland

Tyndale-Biscoe, C.H. 1973: Life of Marsupials. American Elsevier Publications Co. New York. 254pp.

Tyndale-Biscoe, C.H. 1955: Observations on the reproduction and ecology of the brushtailed possum, Trichosurus vulpecula Kerr (Marsupialia), in New Zealand. Austalian Journal of Zoology, Vol. 3(2): 162-185.

Usher, M.B. 1989: Ecological effects of controlling invasive terrestrial vertebrates. Pp. 463 - 489 in J.A.Drake et al. (Ed.): Biological Invasions: a Global Perspective, (C) 1989 SCOPE. John Wiley \& Sons Ltd.

Usher, M.B. 1988: Biological invasion of nature reserves: a study for generalisations: Biological Conservation Vol.44: 119-135.

Veblen, T. and Steward, G.H. 1982: The Effects of Introduced Wild Animals on New Zealand Forests. Annals of the American Geographers Vol.72(3), 1982, pp 372-397 Vol 18: 71 - 76 .

Veblen, T. and Steward, G.H. 1980: Comparison of forest structure and regeneration on Bench and Steward Islands, New Zealand. New Zealand Journal of Ecology, Vol.3: 50-84.

Warburton, B. 1996: A lethal prescription for possums. 
Possum Research News Vol. 4: 1-2.

Warburton, B. 1996: The potential effectiveness of aerially sown 1080 baits for controlling low density possum populations. Science for Conservation Vol.24: 1-11. Department of Conservation, Wellington, New Zealand.

Warburton, B. and Drew, K.W.1994: Extent and nature of cyanide shyness in some populations of Australian brushtailed possums in New Zealand.

Wildlife Research Vol. 21: 599-605.

Wardle, J. 1974: Influence of Introduced Mammals on the Forest and Shrublands of the Grey River Headwaters. New Zealand Journal of Forestry Science Vol.4 (3): 459-86.

Wardle, P. 1973: Damage by possums in the Waiho Valley. Unpublished DSIR Botany Division vegetation report BD-VR-054.

Webb, C.J.; Sykes,W.R. and Garnock-Jones, P.J. 1988: Flora of New Zealand, Vol IV. Naturalised Pteridophytes, Gymnosperms, Dicotyledons. Botant Division, D.S.I.R., Christchurch, New Zealand.

Wilkinson, L. 1990: Systat. Systat Inc, Illinois.

Williams, C.K. 1982: Nutritional properties of some fruits eaten by the possum Trichosurus vulpecula in a New Zealand broadleaf-podocarp forest. New Zealand Journal of Ecology, Vol.5: 16-19.

Winter, J.W. 1980: Tooth wear as an age index in a population of the brush tailed possum Trichosurus vulpecula (Kerr). Australian Wildlife Research Vol 7: 359 - 363.

Winter, J.W. 1976: The behaviour and social organisation of the brushtail possum (Trichosurus vulpecula Kerr). Ph.D Thesis: University of Queensland, Brisbane.

Wodzicki, K.A. 1950: Introduced mammals of New Zealand: An ecological and economic survey. DSIR Bulletin No.98. DSIR Wellington, New Zealand, 255pp.

Wright, K. 1996: Karori Wildlife Sanctuary possum control. Memorandum for Wellington Regional Council. Unpublished 4p.

Yang, R. C.; Kozak, A.; Smith, J. H. G., 1978: The potential of Weibull-type functions as flexible growth curves. Canadian Journal of Forest Research Vol.8: 424-431. 